\title{
WRITTEN FEEDBACK IN SECOND LANGUAGE WRITING: PERCEPTIONS OF VIETNAMESE TEACHERS AND STUDENTS
}

\author{
BY
}

NGUYEN PHUONG ANH

\begin{abstract}
A thesis
submitted to the Victoria University of Wellington in fulfilment of the requirements for the degree of

Master of Arts

in Applied Linguistics
\end{abstract}

2020 


\begin{abstract}
Writing can be very challenging for ESL students since they need to overcome the changes associated with academic writing styles and their mechanics in order to improve their writing skills (Hyland \& Hyland, 2006). In Vietnam, English is known as a foreign language in all public and private schools, and writing is a compulsory component. It is unavoidable that students will make errors in their writing development process, and feedback is a fundamental requirement to reduce these errors. Even if giving feedback costs a great deal of time, it can be the most significant investment of writing instructors (Ferris, 2002). In the last 20 years, many studies have examined a wide range of issues in academic writing, including the types of feedback, and stakeholders' perceptions about feedback; however, the results have been contradictory. Mahmud (2016) revealed that teachers are often forced to use their own writing experience and intuitive criteria due to the lack of information on how to give feedback. Nevertheless, researchers tend to focus on either students' or teachers' perceptions, or both teachers' and students' perceptions, about different types of feedback in writing (Atmaca, 2016). In Vietnam, there are few studies about students' and teachers' perceptions of written feedback. This study investigated the views of both Vietnamese students and teachers on peer feedback, direct feedback, indirect coded feedback, indirect un-coded feedback, and self-feedback to fulfil the gap.

Thirty-six university students in Finance and Banking and two senior English teachers participated in this study. Due to the unexpected pandemic, the researcher changed the study from in-class to online. This qualitative research employs questionnaires and interviews. The prequestionnaire in class before the outbreak of coronavirus in Vietnam, but the rest of the questionnaire surveys and interviews were collected online because the school had shut down. The students were grouped into two separate online groups on Facebook with their classmates, and they were asked to complete five surveys about five different types of feedback. The findings revealed some similarities between teachers' and students' perceptions of feedback in L2 writing. In terms of similarities, both teachers and students agreed that feedback played an important role in L2 writing learning and teaching. Teachers and students believed that feedback could affect L2 learners' cognitive engagement in writing and some types of feedback could affect learners' psychology. Moreover, training was necessary to improve peer feedback in both quality and quantity of feedback and to help students use this type of feedback more effectively. The results
\end{abstract}


from teachers' interviews and students' surveys also revealed the discrepancies between teachers' and students' perceptions of feedback in L2 writing. This study concludes that using appropriate types of teacher feedback can boost students' confidence to improve their writing skills in the long term. 


\section{TABLE OF CONTENTS}

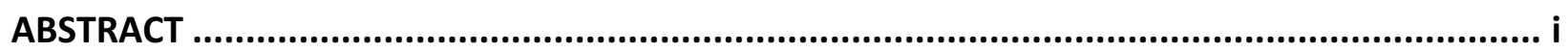

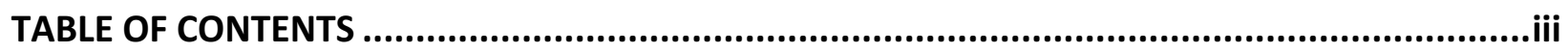

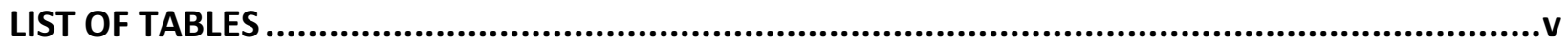

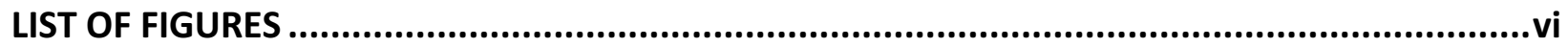

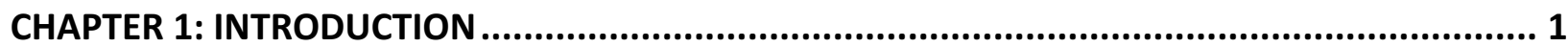

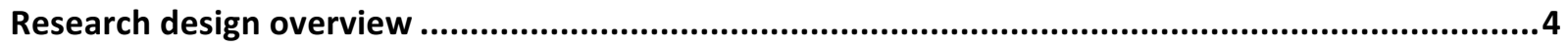

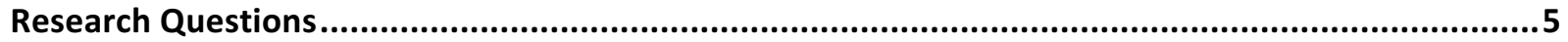

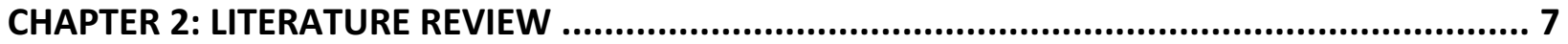

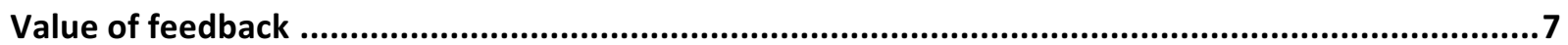

Different types of feedback in second language writing.......................................................... 10

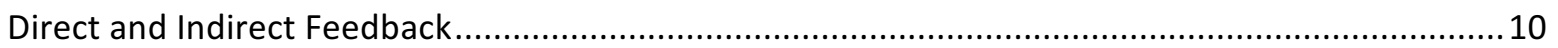

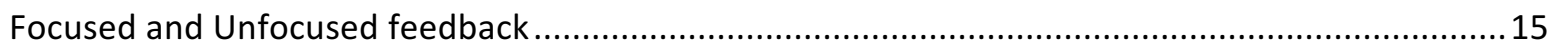

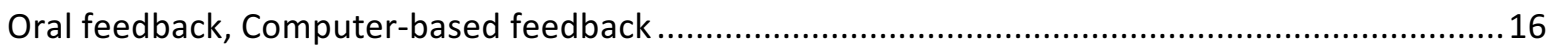

Three primary sources of Feedback: Teacher Feedback, Peer Feedback, Self Feedback....................17

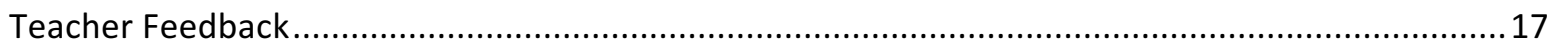

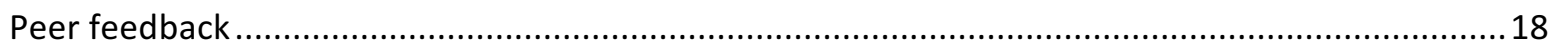

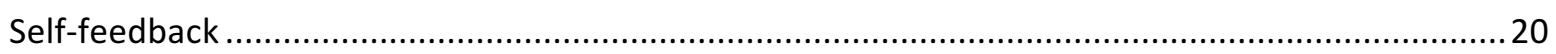

Students' and teachers' perceptions of feedback in L2 writing ...............................................21

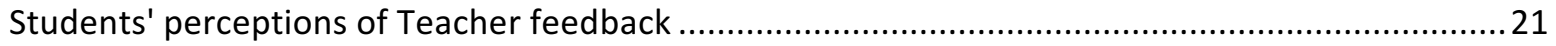

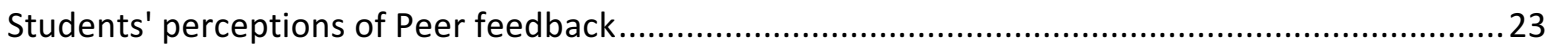

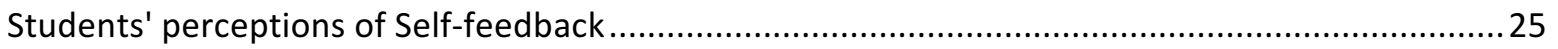

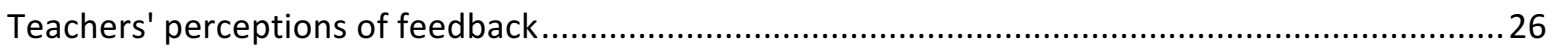

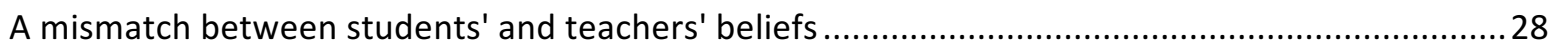

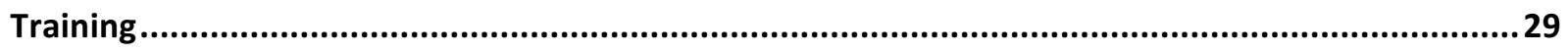

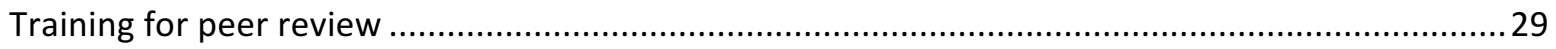

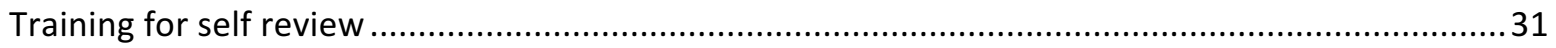

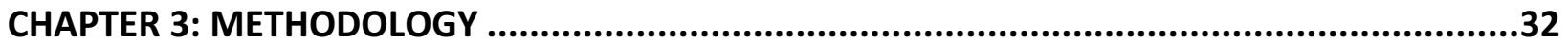

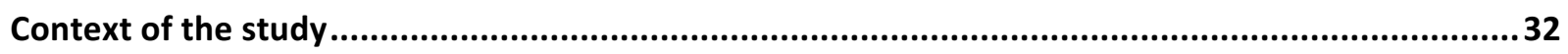

Plan A - Week 1 (in class) - The plan of this study before the outbreak of coronavirus ..................32

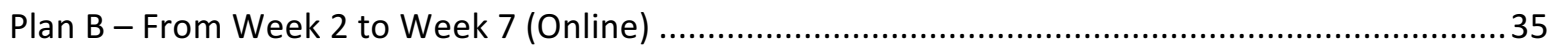

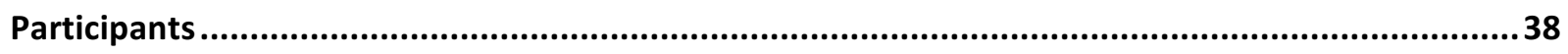

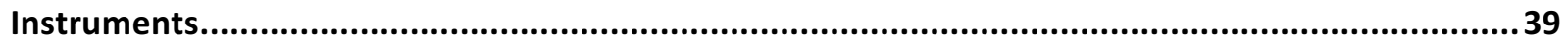

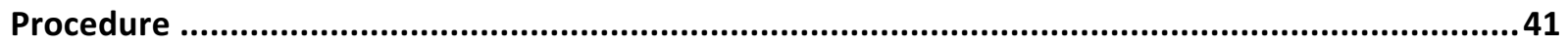

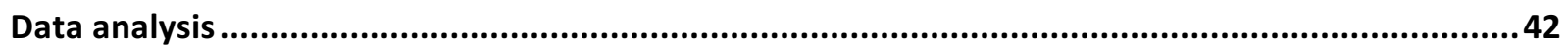

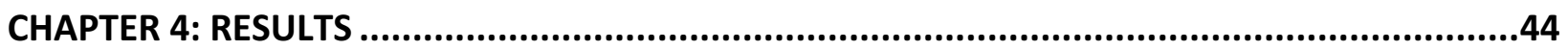

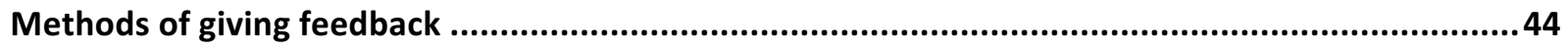

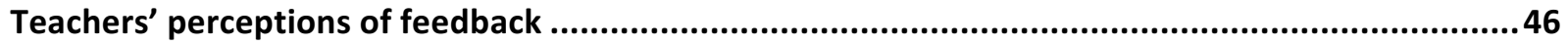

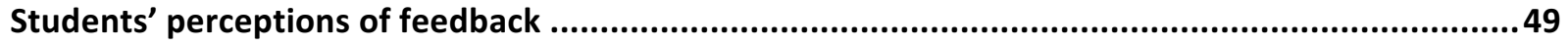

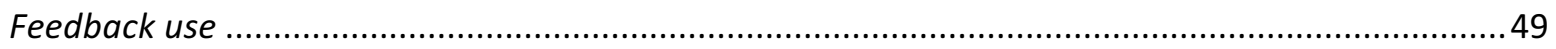

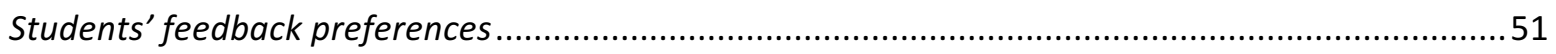

Students' expectations of teacher feedback ................................................................................ 51 
Students' perceptions of the advantages and disadvantages of self-feedback

Students' perceptions of the advantages and disadvantages of peer feedback ..............................5.

Students' perceptions of the advantages and disadvantages of direct feedback.............................55

Students' perceptions of the advantages and disadvantages of indirect coded feedback ................56

Students' perceptions of the advantages and disadvantages of indirect uncoded feedback .............57

Similarities and mismatches in students' and teachers' perceptions of feedback in L2 writing........58

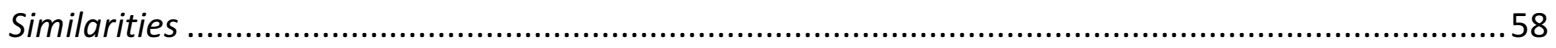

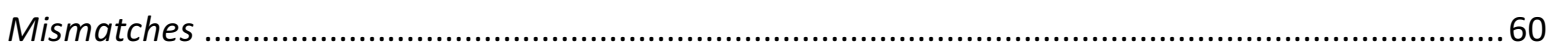

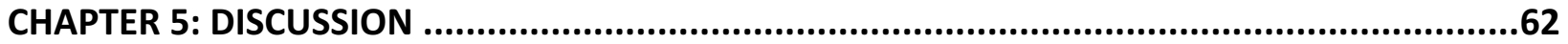

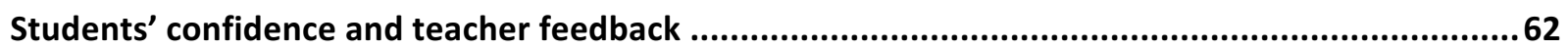

The time-consuming nature of giving and receiving feedback...................................................65

Using direct feedback for $L 2$ writing ............................................................................................68

Direct feedback and impacts on low language proficiency learners' performance. .......................68

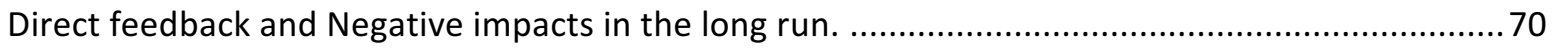

Indirect uncoded feedback ...................................................................................................................72

Indirect uncoded feedback and development of students' language ability. ................................... 72

Indirect uncoded feedback and low language proficiency students. ............................................. 74

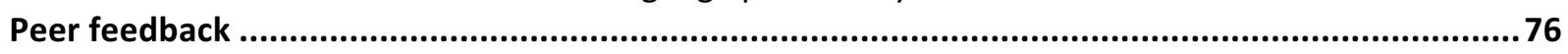

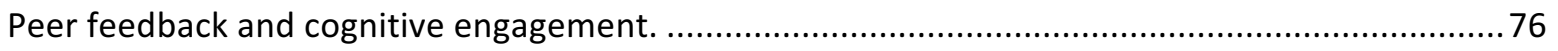

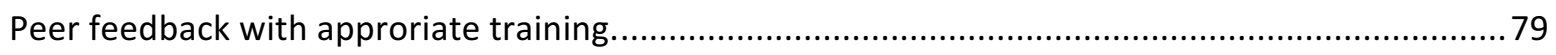

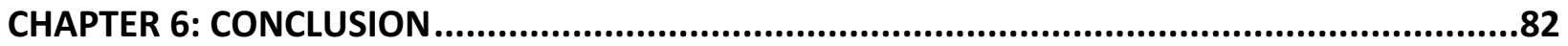

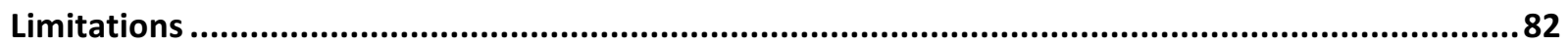

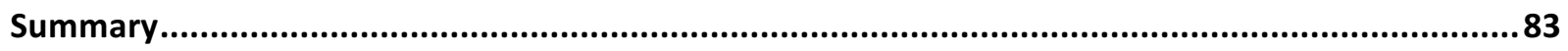

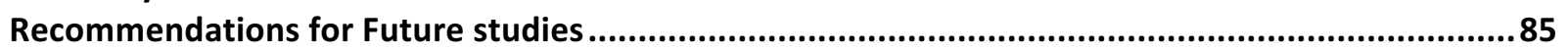

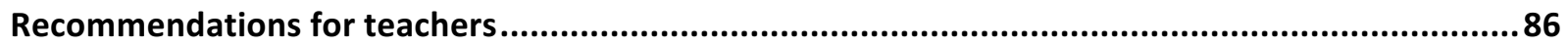

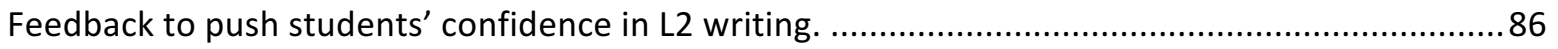

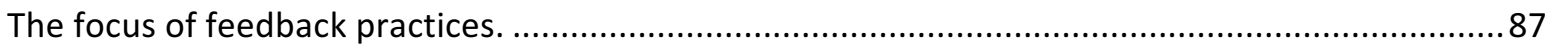

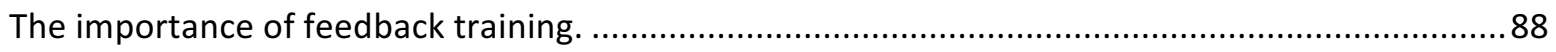

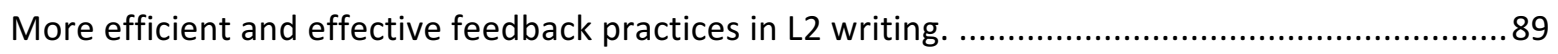

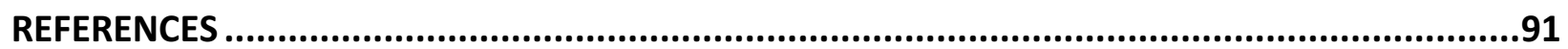

Appendix A: Human ethics application approval ..................................................................99

Appendix B: Information for participants for interviews ........................................................... 100

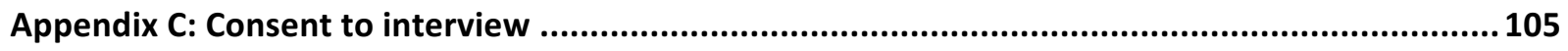

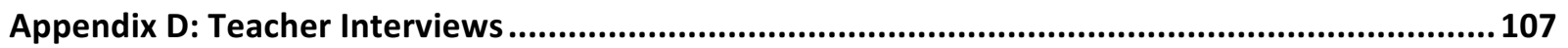

Appendix E: Information for participants for surveys.................................................................. 109

Appendix F: Consent to complete surveys ................................................................................ 111

Appendix G: Pre-treatment background questionnaire................................................................ 113

Appendix H: During-treatment questionnaire: Peer feedback........................................................117

Appendix I: During-treatment questionnaire: Direct feedback ...................................................... 120

Appendix J: During-treatment questionnaire: Indirect coded feedback ........................................122

Appendix K: During-treatment questionnaire: Indirect uncoded feedback...................................124

Appendix L: During-treatment questionnaire: Self-feedback ........................................................ 126 


\section{LIST OF TABLES}

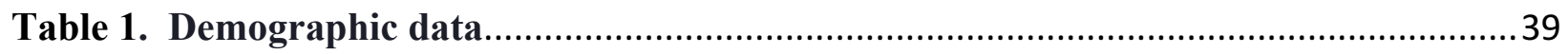

Table 2. Respondents'perceptions of feedback use ..................................................50

Table 3. Students' reactions to feedback they received ...............................................50

Table 4. Respondents' perceptions of feedback preferences ..........................................51

Table 5. Respondents'expectations on teachers'focus on feedback ....................................52

Table 6. Respondents' preferences for the focus of feedback .......................................52

Table 7. Respondents' preferences for the amount of feedback......................................52

Table 8. Respondents' expectations on teachers' comments ............................................53 


\section{LIST OF FIGURES}

Figure 1. Plan B of this study after the pandemic 35

Figure 2. The procedure and data analysis of students'surveys and teachers' interview ....42 


\section{CHAPTER 1: INTRODUCTION}

As compared to other components such as reading, listening, and speaking; many students believe that it is challenging to master writing skills. Additionally, students need to have the ability to use appropriate choices of grammatical structure, vocabulary, and paragraph organization to achieve communicative goals (Richards \& Renandya, 2002). These difficulties demand researchers and teachers to look for better ways to help learners learn writing skills successfully. In Vietnam, English is a foreign language in all public and private schools, and writing is a compulsory component. It is unavoidable that students will make errors in their L2 writing development process, and feedback is a fundamental requirement to reduce these errors (Hyland \& Hyland, 2006). As a result, many teachers have been using feedback as a fundamental requirement to reduce students' errors in L2 writing.

Even if giving feedback costs a great deal of time, it can be the most significant investment in writing instruction since this approach can bring some significant benefits to students' writing development. Many researchers have investigated the effectiveness of using feedback in L2 writing, revealing that feedback can enhance the quality of students' writing (Berger, 1990; Boggs, 2019; Chandler, 2003; Ferris \& Roberts, 2001; Karim \& Nassaji, 2015). These researchers found that students who received feedback improved their writing accuracy and made better revisions in their final drafts. Although feedback can positively affect students' writing performance, it can cause some unexpected drawbacks to L2 students. In some cases, L2 students were confused by teacher feedback since they misinterpreted the comments (Agbayahoun, 2016; Atmaca, 2016; Conrad \& Goldstein, 1999; Mahmud, 2016). In addition, students who received feedback passively depended on their teachers or peers to solve the problem, and they were under no compulsion to work with the texts (Hosseiny, 2014; Nguyen \& Rajeevnath, 2016; Westmacott, 2016). Therefore, the students' autonomy in revising their writing was significantly affected.

One particular area that has received much attention is how both teachers and students perceive feedback. Many researchers aim to identify whether any improvements could be made to teachers' current feedback practices. There are several studies mainly focused on either student's preferences in written feedback or those of the teacher. However, there were some disparities between these research findings. 
First, there is a belief that using appropriate types of teacher feedback can boost students' confidence to improve their writing skills in the long term. Sharif and Zainuddin (2017) found that students gained more confidence in writing after receiving teacher feedback. It is also in line with Nordin et al. (2010) who found that sixty-nine engineering undergraduates from Malaysia felt more confident in their writing because they were able to avoid the same mistakes and revise them more accurately. Sritrakarn (2018) showed that the feedback which could identify students' strengths and weaknesses could make students more confident in revising their work or correcting their errors in L2 writing. However, some studies point out that giving negative comments on students' writing could also affect students' confidence in L2 writing. It has been argued that the majority of students felt dissatisfied and held negative impressions of teachers' feedback. They perceived teacher feedback as discouraging, confusing, and overwhelming (Agbayahoun, 2016). Similarly, Bratkovich (2014) found that an inappropriate amount of feedback using in the classroom could cause students' anxiety instead of feeling confident in their writing.

Second, some students believe that they can improve their writing accuracy and make revisions straight away when teachers use direct feedback. Ferris (2002) argued that low language proficiency students preferred direct feedback due to their grammatical knowledge that prevented them from correcting errors by themselves. Thus, students felt more comfortable to revise and learn a second language if the correct forms were suggested in their script. In Mekala and Ponmani's (2017) study, students suggested that direct feedback enhanced not only their grammatical accuracy but also their awareness of appropriate language structures. Nguyen and Ishak (2018) stated that students' writing was improved in the short term by receiving direct feedback because they could notice their grammar and spelling mistakes easily. However, others argued that using direct feedback in L2 writing classes could have negative impacts on students because they passively depended on their teachers (Nguyen \& Rajeevnath, 2016; Westmacott, 2016). Therefore, direct feedback could affect students' learning autonomy in self-correction since they could stop their active engagement in the learning process.

Third, some students hold a belief that using indirect uncoded feedback developed their language accuracy in the long term since they felt like a part of the learning process rather than receiving correction from teachers. They preferred using indirect feedback because this type of feedback could solve their problems by giving codes or underlining key errors; thus, they could be independent with their writing skills (Ferris \& Roberts, 2001) and eventually develop their 
language skills in the long term (James, 1998). Similarly, Chandler (2003) conducted a study on undergraduate students in East Asia. The students felt that indirect uncoded feedback (underlining) helped them reduce errors consistently and learn more correct words and forms than direct correction. By contrast, Jodaie, Farrokhi, and Zoghi (2011) found that most students held a negative belief in the indirect uncoded feedback strategy because they found it hard to make accurate revisions due to their low language proficiency level. Similarly, Zaman and Azad (2012) showed that the majority of students preferred their teachers to provide the correct forms instead of underlining errors only, meaning that students felt demotivated if teachers did not give any suggestions or clarify the error forms in their writing.

Finally, students could feel disappointed with the use of peer feedback and hesitate to use it in their class. In Xiao and Lucking's (2008) study, some students were disappointed with the quality of peer feedback, and they believed that their peers' corrections were not appropriate and useful for their writing. Similarly, Chai and Nimehchisalem (2016) conducted a study that involved 107 undergraduate students about their perceptions of written feedback in Malaysia. They found that although students highly appreciated the use of peer feedback, they preferred to use teacher feedback which was more reliable. However, Ruegg (2018) stated that if students got more practice in using peer feedback, in the long term, they would reduce their embarrassment and feel more confident in their L2 writing since they realized that everyone struggled with this skill. Stanley (1992) conducted her peer feedback training in an ESL class over a long period. The findings showed that the group who experienced training provided more substantial responses and made more revisions than the control group.

There are limited studies about teachers' perceptions of feedback in L2 writing; however, they still shed light on teachers' feedback practices and expectations. Some studies found that teachers did not have a specific guideline on giving feedback, so their comments could be inadequate (Atmaca, 2016; Mahmud, 2016). Thus, the reactions of students could affect teachers' intentions or willingness to persist in new feedback practices (Hartshorn, Evans \& Tuioti, 2014). If the students did not understand the philosophy and rationale of the new feedback practices, they could avoid making revisions (Rummel \& Bitchener, 2015). Moreover, teachers might try to balance the needs of students and the feedback practices, although it could cause some burden on their teaching practices (Pearson, 2018). Although there are few studies about teachers' 
perceptions of feedback in L2 writing, these studies still shed light in understanding teachers' feedback practices and their expectations.

Although extensive research has been conducted on perceptions about written feedback, it continues to get low attention in Vietnam. Despite some studies about peer and self-feedback being investigated in other countries (Diab, 2016; Ruegg, 2015a; Wakabayashi, 2013), there is no study about these types of feedback in Vietnamese contexts. Many studies mainly investigated either teachers' or students' perceptions, and few studies focus on both teachers' and students' perceptions in using feedback in L2 writing contexts. This study also aims to fill these gaps by using questionnaires to find out students' perceptions and interviews to identify teachers' perceptions in a Vietnamese context. Five different types of feedback - peer, direct, indirect coded, indirect un-coded, and self-feedback will be investigated in five weeks in a Vietnamese public university. The findings can help teachers reflect on the advantages and disadvantages of their feedback practices using for L2 writing in order to develop subsequent pedagogical interventions and provide more effective feedback in the future.

\section{Research design overview}

This study reports on university students' and teachers' perceptions of using feedback in an English writing course in Vietnam. The participants were 63 first-year university students who majored in Finance and Banking and two senior English teachers. One of the English Writing Essay Courses in the second semester from December 2019 to May 2020 was selected for the study. The instructional languages used in this course were 60\% Vietnamese and $40 \%$ English. This course is compulsory and aims to prepare the students for writing different types of essays, general outlines and drafts, and using appropriate language for each type.

This study employs questionnaires and interviews. Due to the unexpected pandemic, the researcher had changed the study from plan A (a real EFL context) to plan B (online). The collection of writing assignments and feedback provision were cancelled while five questionnaires from students and two teachers' interviews were collected online. The pre-questionnaire at Week 1 was completed in class before the outbreak of coronavirus in Vietnam, but the rest of the questionnaire surveys could not be done in the classroom because the school shut down after Week 1.

The students were grouped into two separate online groups on Facebook with their classmates to collect the data online after the school closed. They were asked to complete the five 
surveys which were related to the five different types of feedback. The researcher contacted students through the online groups to explain about direct feedback, indirect-coded feedback and indirect-uncoded feedback before asking these students do the surveys related to each type of feedback in Week 2, 3, and 4 respectively. Students could ask the researcher anytime about the survey questionnaires by email or Facebook chat. On the other hand, the two teachers created online English writing groups on Facebook, so students uploaded their writing and experienced self-feedback and peer feedback on that tool. However, the researcher still explained these types of feedback by both email and group chat to make sure that all students understood these feedback practices. After that, the students were asked to complete the survey questionnaires about peer feedback and self-feedback in Week 5 and Week 6, respectively. The researcher aimed to know about students' perceptions of different types of feedback, expectations and suggestions after experiencing both their teacher's and researcher's feedback in Week 7; however, the school did not reopen during the experiment time due to the pandemic. Hence, the post-treatment questionnaire was cancelled. The students responded to the Likert-scale questions and expressed their own perceptions about the advantages and disadvantages of each type of feedback that they had experienced. The responses helped the researcher identify to what extent students and teachers' perceptions meet and differ from each other.

In terms of teachers' interviews, they were conducted online for 20 to 30 minutes. During the interviews, teachers shared their experiences in giving feedback; advantages and disadvantages of feedback on their teaching; and their expectations about different types of feedback. Since the teachers had not taught the students in this period, they had not experienced anything new from their students. As a result, the researcher conducted the pre-treatment interview but cancelled the post-treatment interview. The findings from the teachers' interviews could identify teachers' methods of giving feedback and their perceptions of feedback in L2 writing.

This study only focuses on students' and teachers' perspectives, so any measure on the effectiveness of the various types of feedback on the students' writing improvement is not included. This study contributes to limited studies about both students' and teachers' perceptions of the use of feedback in an L2 writing context.

\section{Research Questions}

This study addresses the following research questions: 
1. What feedback practices do teachers use? What are the reasons for the feedback practices they use?

2. What are the teachers' perceptions of using different types of feedback in L2 writing for university students?

3. What are the students' perceptions of the given feedback in L2 writing?

4. Do teachers' perceptions match their students' perceptions about feedback in L2 writing? 


\section{CHAPTER 2: LITERATURE REVIEW}

The purpose of this study is to identify teachers' and students' perceptions of different types of feedback in L2 writing in a Vietnamese EFL context. Several areas in previous studies regarding the value of feedback, different types of feedback in L2 writing; sources of feedback, and teachers' and students' perceptions of feedback in writing are presented in this chapter.

The literature review starts with a discussion of the value of feedback such as the benefits and drawbacks of using feedback on students' L2 writing. In the following part, an overview of different types of feedback, such as direct, indirect coded feedback, indirect uncoded feedback, focused feedback, unfocused feedback, metalinguistic feedback in writing contexts is reviewed. After that, a discussion focuses on three primary sources of feedback in classrooms. Finally, the perceptions of teachers and students about using feedback in L2 writing are included. Value of feedback

Since students have to switch from their first language to write and express ideas in a second language, they often face some problems in the academic writing styles, grammatical structures, and lexical knowledge. As compared to other components such as reading, listening, and speaking; many students believe that it is difficult to master their writing skills. It is undeniable that students will make mistakes in their writing process, and their teachers have been looking for a way to help them improve their work in the long term (Hyland \& Hyland, 2006). As a result, many teachers have been using feedback as a fundamental requirement to reduce students' errors in L2 writing.

In the last 20 years, several researchers have investigated the effectiveness of using feedback in L2 writing; their findings revealed that feedback could enhance the quality of students' writings. Many researchers found that students who received feedback improved their writing accuracy and made better revisions to their drafts. Although feedback can positively affect students' writing performance, the use of feedback can cause some drawbacks to students' L2 writing.

Berger (1990) investigated the effects of using peer and self-feedback on students' L2 writing. Fifty-four ESL students in the USA participated in this study. They had the same teacher and followed the same syllabus for their writing course. The data collection consisted of questionnaire surveys, the drafts of students' essays, and feedback evaluation forms. In the peer 
feedback group, students were formed in a group of three to review their peers' writing drafts. Meanwhile, students in the self-feedback group used a feedback form that was prepared by their teacher to answer questions about their drafts. Both groups had to make revisions based on the feedback and submitted their second drafts and the feedback evaluation forms to the teacher. To gain in-depth information about students' perceptions of peer feedback and self-feedback, the researcher asked the students to fill out a pre-questionnaire survey at the beginning of the course and a post-questionnaire survey at the end of the semester. The results showed that students from the peer-feedback group could make more revisions than the self-feedback group. In addition, although students only experienced peer feedback once and had little training, they still preferred using this type of feedback for their writing.

Sharif and Zainuddin (2017) conducted a case study using a qualitative method to investigate students' perceptions of the effectiveness of teacher feedback. Nineteen medical students from Malaysia who studied a 12-week English program took part in a questionnaire which comprised of open and closed-end questions to identify students' demographic information and their experiences with teacher feedback. Two students participated in interviews to clarify their writing learning experiences, challenges in writing and perceptions about teacher feedback. The finding shows that students believed teacher feedback was positive and encouraging. Similarly, Ji (2015) conducted a study on Chinese learners' perceptions of written feedback. The results showed that most students expected to receive indirect uncoded feedback and indirect coded feedback. They believed that their language proficiency could be enhanced consistently because they were aware of their errors and engaged in improving their texts after receiving teacher feedback.

Tang and Liu (2018) also found that when students appreciated their teachers' time and efforts when providing feedback, they would be willing to spend more time on revising their work. Cho and Park (2019) stated that when students countinuosly received a specific type of feedback, they could engage in their revisions. When students understand the feedback use and its effectiveness, they will appreciate teacher feedback and feel more confident to correct the errors. As a result students are likely to engage in their texts, find more information to solve their mistakes and make better revisions without passively depending on teachers.

Although feedback shows significant impacts on students' writing performance, some previous studies reveal that both teachers and students can express negative psychological aspects of feedback. Conrad and Goldstein (1999) conducted their study on the relationship between 
teacher comments and students' revisions. Three advanced language students and one teacher participated in this study. The data included teachers' comments, discussions in conferences, and copies of students' drafts before and after receiving teacher comments. The findings indicated that while students could revise some problems related to cohesion and providing examples, they were not able to make revisions on problems of logic and argument. The students misinterpreted the meaning of teachers' comments which were too broad, so they were not able to write strong statements to express their ideas.

Lee, Mak, and Burns (2016) investigated how two secondary teachers in Hong Kong provided feedback and identified some factors which influenced teacher feedback in L2 writing classrooms. These participants had significant experience (more than three years) in giving written feedback for ESL students in Hong Kong. The researchers used a qualitative method to capture the two teachers' experience and perceptions in feedback strategies. The findings from the interviews revealed that teachers faced some difficulties in an unsupportive environment. First, they had to follow the school syllabus, so they did not have enough time to give adequate feedback. They also lacked the guidance of providing feedback on L2' students writing. Finally, their students did not have time for appropriate training of giving and receiving feedback; thus, they could not apply new feedback strategies. As a result, the teachers got lost in giving sufficient feedback to meet their students' expectations and preferences.

Similarly, Mahmud (2016) aimed to determine the practice of teacher feedback in L2 writing by investigating 54 English teachers and 48 students from a variety of high-performance schools in Malaysia. The study used a mixed-methods design which used closed-ended and openended questionnaire surveys and interviews. In addition, the content analysis of 48 students' essays was included as one of the data collection. The finding shows that teachers faced time constraints when providing feedback, and thus, they easily felt stressed, exhausted, and burned out. In addition, the teachers had to make corrections without specific guidelines which led to inadequate feedback provision.

Finally, Cheng and Warren (2005) found that some students felt uncomfortable when criticizing their peers' writing, while others did not know how to use peer feedback. They also felt unsatisfied with peer correction. The main reason was that students did not receive specific guidance in giving and receiving peer assessment. Similarly, Xiao and Lucking (2008) found that 
some students were disappointed with the quality of peer feedback and believed that the correction was not appropriate and useful for their writing.

\section{Different types of feedback in second language writing}

In the following section, several types of feedback will be presented in terms of definitions, supportive and non-supportive evidence from different studies on each type. However, direct feedback, indirect coded feedback, indirect uncoded feedback, focused feedback, unfocused feedback will be discussed more in-depth than other types of feedback. These types of feedback are widely used in second language classes and received more attention from recent studies.

\section{Direct and Indirect Feedback}

In the past few decades, most studies focused mostly on two types of feedback: direct and indirect feedback. Direct feedback requires teachers to give the corrected form next to the errors, while indirect feedback is when teachers highlight students' errors with or without a code (Bitchener \& Knoch, 2009).

\section{Direct Feedback}

Direct feedback is used in correcting students' errors by giving the correct form. That means teachers can provide students with direct feedback in both writing and speaking. There are different forms of direct feedback, such as striking out incorrect words, giving correct linguistic forms above or under the wrong words, and inserting missing words. Although direct feedback has been used widely by teachers, its effectiveness is a controversial issue among researchers.

Boggs (2019) conducted a study to identify the effectiveness of direct feedback on the accuracy of ESL student's grammar in writing. Two teachers who had over eight years of teaching experience and 109 low language proficiency students in South Korea took part in this study. The researcher collected data mainly from students' writings, worksheets, and audio recordings. By analyzing students' writing by t-units and error ratios, the results revealed that students experienced a significant and durable improvement in their grammatical accuracy in L2 writing.

Sheen (2007) investigated the effect of direct feedback and direct-metalinguistic feedback on low language proficiency students' L2 writing acquisition in the United States. Ninety-one students were divided into three groups which were a control group, a direct-only feedback group, and a group with a combination of direct and metalinguistic feedback groups. The results from 
their posttests revealed that the two experiment groups performed much better than the control group who completed the tests only and did not receive any feedback.

Bitchener and Knoch (2009) investigated the effectiveness of different types of direct feedback on students' writing performance in New Zealand. Thirty-nine low intermediate ESL students were divided into three groups regarding direct feedback only; direct feedback with metalinguistic explanation in both written and oral form; and direct feedback with a written metalinguistic explanation. The study used four students' writings, which required a description of what happened in given pictures in a pre-test, immediate posttest, and two delayed posttests. The targeted feedback was two functional uses of the English article system which are referential definite "the" and referntail indefinite "a". The results from these tests showed that there were no statistically significant differences between the effectiveness of three different direct feedback types on students’ writing performance over time.

Jamalinesari et al. (2015) investigated the effectiveness of using direct feedback and indirect feedback (underlining errors or writing short comments) in two classes from a private English school in Dubai. The results showed that 20 students receiving direct feedback improved their writing accuracy, and the indirect feedback group improved their linguistic accuracy on new writing tasks better than the direct feedback group after ten sessions. However, Baker and Hansen Bricker (2010) recruited seventy-one students from different universities in the United States to participate in this study. They were both native English and non-native English speakers with scores from 630 on the TOEFL and enrolled in English writing classes. During the study, the students read their teacher comments which consisted of hedging feedback, direct feedback, and indirect feedback in two sample essays, and then responded to each teacher feedback. The main goal was to identify whether the students were able to make fast and accurate correction. The findings showed that direct feedback helped both native English and ESL learners to make faster and more accurate correction than indirect and hedged feedback.

Hosseiny (2014) identified the role of direct and indirect feedback (underlining errors) in sixty pre-intermediate students' writing in Iran by using TOEFL tests. The participants were selected into two experimental groups and one control group. The results of the study showed that the students who were provided with feedback performed differently from those who did not receive feedback. However, the students who received direct feedback passively depended on their teachers to solve the problem, and they were not willing to work with the texts. Therefore, the 
students' autonomy in revising their writing was significantly affected. Similarly, Shintani and Ellis (2015) stated that when students completely copied teacher feedback into their writing without questioning the causes of making particular errors, they could fail to engage in their future learning.

\section{Indirect Feedback}

One of the most popular types of feedback is indirect feedback. In the following section, the effectiveness of different forms of indirect feedback (indirect coded and indirect uncoded feedback) will be discussed.

\section{Indirect Coded Feedback}

Some researchers found that indirect coded feedback can enhance students' writing performance consistently and increase their cognitive engagement. Lalande (1982) examined the efficacy of feedback practices on L2 students' grammatical development. The study consisted of sixty students who enrolled in an intermediate level of German in the United States. The students were divided into two groups: a control group and an experimental group that received indirect coded feedback. The post-test data of writing essays from both groups indicated that indirect coded feedback had a significant beneficial impact on students writing development because students could reduce their grammatical errors in the long term. Similarly, Ferris (2006) examined the effect of indirect coded feedback on the students' writing drafts in an ESL university context. In her study, ninety-two participants completed three drafts on different essay topics during a semester. The teacher used indirect coded feedback on students' first draft to help them revise their second draft. The findings showed that students were able to make better revisions and successfully corrected a majority of their errors in the short term. In addition, students also reduced their errors in the third writing draft at the end of the semester, which indicated their consistent improvement in L2 writing after receiving indirect coded feedback.

Ferris and Roberts (2001) conducted their experiment on 72 university students in the United States, and their findings showed that both indirect uncoded feedback and indirect coded feedback could improve students' writing accuracy and quality in their final paper. In addition, since students engaged in their texts and were aware of making errors, they avoided making some errors in the next essays.

However, there are also some drawbacks with using indirect coded feedback which should be discussed. First of all, students do not show significant improvement in their revisions after 
receiving indirect coded feedback. For example, Robb, Ross, and Shortreed (1986) investigated the effect of four different types of feedback on Japanese students' writing quality. There were 134 low language proficiency students participated in this study during 23 classes over an academic year. Five narrative test compositions were completed by participants for the data collection. The results of the analysis of students' revisions revealed that there were no significant differences in terms of complexity, accuracy, and fluency in four experimental groups which were direct feedback, indirect coded feedback, indirect uncoded feedback, and marginal feedback.

Moreover, some teachers can not use indirect coded feedback in their class because of the school policy. Teachers felt worried about their colleagues' and students' attitudes to their new type of feedback - coded indirect feedback (Lee, Mak, \& Burns, 2016). Therefore, the teachers would only use coded feedback widely if the school leaders employed an implemented policy on the new type of feedback at school.

Finally, students can make the same or more mistakes in their revision when they misunderstand their teacher's feedback codes. For instance, Norish's (1983) findings showed that the codes followed inflexible categorization, which did not comprehend what students tried to convey in their first language. When teachers used a code on a particular word, students simply corrected that word without realizing why they made a mistake. However, while students faced difficulties in understanding and remembering codes when using indirect coded feedback, indirect uncoded feedback helped students reduce their written errors because the misconception between students and teachers about marking codes was eliminated. By contrast, Sadat et al. (2015) showed that ninety intermediate English female students in Iran performed better with indirect coded feedback than indirect uncoded feedback. Thus, if the students had appropriate training about the codes, they could be more familiar with the correct forms. Otherwise, they would continue to make the same errors.

It has been a claim that if instructors want students to appreciate written feedback and invest their time in the revisions, the feedback should meet the students' demands (Aliakbari \& Raeesi, 2014; Rummel \& Bitchener, 2015). As a result, if teachers want to use indirect coded feedback for their class, they should make sure that their students understand the codes in order to avoid any misunderstanding and improve their revisions. 


\section{Indirect Uncoded Feedback}

Several researchers have claimed that indirect feedback can have positive effects on L2 learners because teachers only highlight the errors which will be corrected by the learners. Research findings reveal that uncoded feedback helps students to improve their writing accuracy by participating in solving their writing problems. For example, Hosseiny (2014) conducted a study on twenty Iranian pre-intermediate students who were provided indirect uncoded feedback. The findings showed that the students performed better in their writing than those who did not receive feedback. They also acknowledged the given suggestions and noticed them. As a result, the students' writing accuracy with indirect uncoded feedback (underlining) was improved because they were encouraged to take part in the process of revisions.

Similarly, Ahmadi, Maftoon, and Mehrdad (2012) investigated 60 university students in Iran in a period of seven weeks to identify the effect of teacher feedback on L2 writing. They found that the indirect-uncoded feedback group performed better than the direct feedback group and a control group in their revisions. Ferris and Roberts (2001) found that 72 ESL university students in the United States could improve their writing accuracy and quality in their final paper after receiving indirect uncoded feedback. In addition, using indirect feedback enhanced students' awareness of making the same errors and developed their learning cognition in L2 writing in the long term.

Banaruee, Khatin-Zadeh, and Ruegg (2018) investigated the effectiveness of indirect uncoded feedback (recasts) and direct feedback on students writing in 20 sessions within three months in Iran. The findings by a pretest and posttest on two experimental groups indicated that the uncoded group had better performance in comparison to the group with direct feedback consistently.

Furthermore, students face difficulties in revising their errors. Dam (2018) conducted her study on the effectiveness of indirect feedback on students' L2 in a Vietnamese context. The participants of this study included 90 second-year students with a low language proficiency level (B2 CEFR) and three English teachers who were in charge of the selected course. Since the researcher collected her data in a short period, she used questionnaires to enquire students' perceptions of the benefits and drawbacks of indirect coded and uncoded feedback. In terms of teachers, interviews were employed to clarify how teachers perceived the effect of indirect coded and indirect uncoded feedback. The results from the interviews showed that indirect feedback 
enhanced students learning autonomy. However, students were not able to revise errors related to word choice and expression due to their limitations in the L2 language. They also believed that indirect feedback could influence their writing accuracy since they did not trust their own corrections. If teachers believed that their students could manage their errors, they could use indirect uncoded feedback (Ferris, 1999). As a result, teachers should take students' language ability into consideration when using this type of feedback in an L2 classroom.

\section{Focused and Unfocused feedback}

While unfocused feedback is also referred to as comprehensive feedback, focused feedback is well-known as selective feedback. In terms of comprehensive feedback, teachers locate all of the errors in students' writing. Meanwhile, teachers can select one particular error type or two or three types to give feedback.

\section{Focused Feedback}

Some studies show positive outcomes when using focused feedback to improve students' grammatical accuracy in L2 writing. Sheen, Wright, and Moldawa (2009) investigated the impacts of direct focused and direct unfocused feedback on L2 students' writing accuracy. The results showed that the focused feedback group achieved the highest scores for the accuracy in all the posttests. Thus, it was indicated that focused feedback could be useful to enhance grammatical accuracy in L2 writing. Similarly, Sheen (2007) examined the impacts of focused and unfocused feedback on students' language accuracy. Ninety-one ESL students worked with types of articles and participated in the pretests, posttests, and delayed posttests. The findings showed that the experimental groups which received direct focused feedback improved their writing accuracy better than the control group that did not receive any feedback. It was noticeable that in this study, the researcher balanced the amount of feedback received between groups, so the unfocused group received a small amount of random feedback on a random range of issues. Whereas, the focused group received the same amount feedback but focused on one error type. This study counteracted the benefit of unfocussed: unfocused feedback should involve receiving more feedback than focused group to clarify the different impacts of using them on students' writing. However, Xu (2009) suggested that although it was feasible to focus on one or two features mainly, teachers should be aware of the choice of features and structures to use for focused feedback. If teachers mainly focused on one grammatical feature, students might neglect others. 


\section{Unfocused Feedback}

Some studies indicate some impacts of using unfocused feedback on L2 students' writing in the long term. For example, Fazilatfar et al. (2014) aimed to investigate the effectiveness of unfocused feedback in students' accuracy improvement. The findings from 20 EFL advanced learners in Iran showed that unfocused feedback helped the students to remember their errors; therefore, they were aware of making the same mistakes in their writing. Hence, students could understand and remember their errors in order to avoid making them in their revisions and future writings after receiving unfocused feedback. Moreover, Ellis et al. (2008) stated that using unfocused feedback might not help students to master specific features; however, it could assist them to address a wide range of errors in their writings and improve their writing performances in the long term.

\section{Oral feedback, Computer-based feedback}

Not only written feedback, but oral feedback and computer-based feedback have been used in L2 writing classes recently. However, the efficacy of these types of feedback is controversial among researchers. In Vietnamese contexts, students and teachers may find it hard to use oral and computer-based feedback for their writing course because of the class size.

\section{Oral feedback}

According to some previous findings, cultural and social inhibition from teachers' oral feedback can affect students' motivation and self-correction in the writing process (Bruffee, 1984; Lyster \& Satio, 2010). Thus, students tend to be more assertive and confident in their writing using their teachers' suggestions. However, the effectiveness of oral feedback in students' first language texts (Bruffee, 1984), and contributions of oral feedback in the L2 context are unclear. Various studies have investigated how meanings are negotiated in writing conferences and the effects of these conferences on learners' revisions (Goldstein \& Conrad, 1990). Moreover, useful scaffolding feedback from teachers can help students work independently and enhance their language proficiency levels (Lyster \& Satio, 2010). However, it seems impossible to use oral feedback in an L2 writing class in Vietnam since there are normally 30 to 40 students studying in a 60-minute lesson. Teachers are not able to give oral feedback to every student under time constraint. 


\section{Computer-based feedback}

Since the development of technology in the educational area, the role of computer-based feedback is undeniable. Students now can read feedback online from an unseen tutor, a peer, or a computer program. There are three common types of computer-based feedback. First, students can communicate, send papers and get feedback from their teachers and peers in an online group chat. However, they have to be online at the same time (DiGiovanni \& Nagaswami, 2001). Second, both students and teachers can discuss and exchange feedback on writing by using networked sites such as Facebook page at a specific time (Warschauer \& Kern, 1999). Finally, automated feedback, using sophisticated software to scan students' texts and immediately evaluate them, is highly valued among teachers (Hyland \& Hyland, 2006) since this type of feedback assists teachers with an enormous burden of giving feedback to large-size classes. Meanwhile, students are also provided more extensive feedback in a short time. However, in Vietnam, students mainly use computer-based feedback as a supplementary tool for checking their grammatical errors in the final drafts and they still want to use teacher feedback or peer feedback for untreatable errors such as subject-verb agreement.

\section{Three primary sources of Feedback: Teacher Feedback, Peer Feedback, Self Feedback}

The sources of written feedback have been widely investigated to identify the appropriate feedback in writing types for L2 learners. In the following parts, these three primary sources of feedback will be discussed.

\section{Teacher Feedback}

According to many researchers, teacher feedback plays a significant role in students' writing ability. Teachers can improve students accuracy in writing if they use approriate feedback types. Chandler (2003) investigated the efficacy of various types of feedback for improvement of L2 students'accuracy in writing. Thirty-one ESL students were divided into a control group and an experimental group which experienced self-feedback, direct feedback, and indirect uncoded feedback (underlining) over several drafts within a 14-week period. The analysis of marking students' errors showed that students had a significant improvement in their writing accuracy after receiving teacher feedback. Similarly, Ruegg (2015) investigated the relative effects of indirect 
uncoded feedback and peer feedback on students' writing development. Fifty-three low language proficiency students in Japan participated in this study. The results from pre-test and post-test scores revealed that teacher indirect-uncoded feedback provided an advantage of writing accuracy improvement outweighed peer feedback in L2 writing.

On the other hand, some previous findings revealed that teacher feedback might cause some negative impacts on students' learning. First, giving feedback can be time-consuming for teachers. For example, Wei and Yanmei (2018) examined the changes in teacher feedback practices in a university in China and they found that the teachers perceived feedback as timeconsuming. These teachers minimized the time of offering feedback for individual students to ensure their effective teaching which strictly followed the objectives in the school curriculum. Similarly, Lee, Mak, and Burns (2016) also examined teacher feedback practices in writing classes and found that teachers had limited time within a prescribed curriculum which discouraged them from using new feedback approaches. Nevertheless, teachers had to rearrange or change their teaching schedules in order to train students for code definition before using indirect coded feedback.

In addition, teacher feedback might also overwhelm students when receiving feedback on too many errors. For instance, Sung and Tsai (2014) collected data from a feedback survey, oral interactions in class and interviews to explore the relationship between teacher feedback and learners' uptake. Two teachers and 32 ESL students in China participated in this study. The results from the survey and interviews revealed that teachers faced challenges such as time constraint and heavy workload when giving feedback and students also expressed some negative psychological aspects when receiving too much feedback on their writing.

\section{Peer feedback}

As well as teacher feedback, peer feedback may help students understand more about their weaknesses and strengths in their writing. This type of feedback encourages students to cooperate with their peers to give and receive feedback.

Some studies support the use of peer feedback in L2 writing because of following reasons. First, peer feedback can develop peer reviewers' ability to evaluate their friends' writing. For example, Yu and Lee (2016) examined peer feedback strategies by four Chinese EFL students in a 16-week class in mainland China. The results for interviews of the participants showed that peer 
feedback was mediated by a wide range of strategies. The first strategy was using first language (Mandarin Chinese) for about $90 \%$ of students' interactions such as maintaining the dialogue, pointing out errors and confirming meanings. The second strategy was using L2 writing criteria such as grammar and vocabulary for peer review. The students also adopted both explicit (reviewing) and implicit rules (maintain group harmony) to mediate their group activities. Another strategy was seeking help from teachers when students had unresolved problems in their group discussion. The fifth strategy was playing different roles which required students to participate in different activities such as reading, discussing, interpreting, and assessing. By using these five major strategies, the students felt confident in giving and receiving peer feedback in L2 writing.

Moreover, interactions with peers in pairs or groups can help students develop social supports. Wakabayashi (2013) conducted a questionnaire study with 51 students in two writing classes in a Japanese university. The lower proficiency students experienced peer feedback while the higher proficiency students employed self-feedback for their L2 writing. Although the score results of the pre-test and post-test showed that both groups improved their writing quality, most students expressed that they preferred a standard type of peer feedback (peer feedback with comment exchange) to self-feedback because they could read each other's writing and negotiate with each other. Thus, students can reduce their distance and encourage them to work more significantly.

Finally, peer feedback helps students in making better revisions. Rollinson (2005) revealed that $80 \%$ comments of high language proficiency students were regarded as valid and merely $7 \%$ were considered as detrimental. Similarly, Ruegg (2014) conducted her study about the impacts of using peer feedback on the quantity and quality of feedback given in two classes in Japan for a year. The results revealed that although there was no considerable difference in the students' feedback accuracy, the students from feedback-assessed group showed more significant improvements in quality and quantity of their points and comments than the product-assessed students. In particular, the feedback-assessed group were able to make longer comments, add more words than the product-assessed group. As a result, using peer feedback for L2 writing could improve not only students' learning autonomy but also their review ability.

Although many findings support the use of peer feedback in L2 writing classrooms, some studies show different results. First, peer feedback practice can be influenced by different factors which may cause negative results. Yu and $\mathrm{Hu}$ (2017) conducted a case study with four Chinese 
students' responses to peer feedback using in the L2 writing classroom. The results from interviews revealed that students would focus on different aspects of their peer feedback because they had different ideas about good writing. Some students would focus on sentence structures if they believed a well-written essay contained exciting ideas, while others concentrated on grammatical errors if they thought an excellent essay did not have many errors. Students' motives and goals also explained why some students wanted to provide criticisms instead of praise. They expected their negative feedback that pointed out that errors and problems could help their peers produce error-free essays. However, some students avoided giving negative comments because they wanted to keep group harmony. Since there are many factors which can influence the efficacy of peer

feedback, students should have approriate training to provide adequate and effective feedback to their peers.

Furthermore, low language proficiency learners may face difficulties in using peer feedback because they lack the language knowledge to detect and suggest corrections for their peers' errors. Leki (1990) found that students who had a lower language proficiency level were silent and frustrated in participating in the group conversation during the peer-feedback process because they were not confident in their writing ability.

Finally, peer feedback will not be effective if students lack feedback training experiences. $\mathrm{Yu}$ and Lee (2016) found that students who lacked pre-training activities might feel demotivated and less confident in their reviewability. Similarly, Ruegg (2018) found that students who did not have appropriate training would show negative psychological aspects when their peers read and gave comments on their text. Nevertheless, if students got more practice in using peer feedback, in the long term, they would reduce their embarrassment since they realized that everyone struggled with this skill. As a result, students can feel confident to cooperate with their peers and provide effective feedback on L2 writing.

\section{Self-feedback}

Compared to other types of feedback, self-feedback requires students to access their writing as a critical reader and reviewer. On the other hand, students have to identify errors and revise the text without receiving teacher or peer feedback.

Although self-feedback is a new method, some positive results of using this type of feedback have been presented. First, students may have little difficulty accepting their own 
comments. Diab (2011) used a quasi-experimental design with forty students in Lebanon to compare the effects of self-feedback to peer feedback on the students' drafts. The findings revealed that writers who experienced self-feedback could revise almost all the errors in their first drafts because they could easily understand their own comments.

Second, self-feedback encourages learners' metacognitive skills, such as distinguishing their strengths and weaknesses in their writing. For example, Diab (2016) identified the effectiveness of three feedback sources: teacher feedback, peer feedback, and self-feedback. The findings from fifty-nine students in Lebanon showed that the self-feedback group decreased their lexical errors significantly compared to the other groups. They had to spend more time on thinking, spotting the errors and reviewing. Thus, they were able to clarify their weaknesses and developed their metacognitive skills.

Students' and teachers' perceptions of feedback in L2 writing

The research on students' and teachers' perceptions on feedback is a need because it can improve the effectiveness of feedback using as well as enhance students' performance in L2 writing. Unfortunately, some studies focused on either student's preference for written feedback or those of the teacher. However, few studies which included both sides pointed out some useful findings. In the following sections, students' perceptions and teachers' perceptions of teacher feedback, peer feedback and self-feedback will be presented.

\section{Students' perceptions of Teacher feedback}

Many researchers have revealed students' positive beliefs in the use of teacher feedback in L2 writing classes. First, student feel more confident since they can understand the writing requirements. Nordin et al. (2010) aimed to find out students' perceptions of peer and teacher feedback. The participants of this study were sixty-nine engineering undergraduates from Malaysia. They were involved in the production of two texts (in a period of two months). The learners were trained to provide positive feedback for their peers' accuracy and grammatical errors of the writing. A questionnaire (6-point Likert-scale) which consisted of eight main statements about learners' perceptions on peer feedback and teacher feedback was used at the end of this experiment. The results showed that the students felt more confidence in their writing after 
receiving indirect uncoded feedback and understood the tasks' requirements. As a result, they could distinguish their own pattern of repeated errors and revise their writing more accurately.

Second, students believe that they can distinguish their strengths and weaknesses in writing to improve their performance. Sharif and Zainuddin (2017) investigated ESL medical students' perceptions of teachers' feedback on their reflective essays in Malaysia. The findings showed that the students had good experiences with teacher feedback after a 12-week period. The students also believed that the feedback was positive and helped them to identify their strengths and weaknesses in writing. On the other hand, students expressed that teacher feedback was precise and helpful in order to reflect various problems in their writing such as grammar, and structure (Zumbrunn, Marrs, \& Newborn, 2016). Tom, Morni, Metom and Joe (2013) pointed out that students valued both negative and positive comments and expected to receive them on their texts because they could identify their strengths and weaknesses. Students believed that negative comments were a challenge that pushed them to perform better in their future writing while positive comments showed students what they had done well.

Moreover, students prefer direct feedback since they can improve their writing accuracy from feedback suggestions. In Mekala and Ponmani’s (2017) study, 116 second year BA English Literature students with a low language proficiency level in India faced difficulties to use appropriate forms for basic grammatical features such as prepositions and irregular verbs in their L2 writing. The results showed that students believed that direct feedback enhanced not only their grammatical accuracy but also their awareness of appropriate language structures immediately. This was in line with Nguyen and Ishak (2018) who conducted interviews on 12 high school students in Malaysia. The findings illustrated that while six of them believed that indirect feedback was better than direct feedback, six other students believed that direct feedback was very straightforward and clear. They believed that their written work was improved in the short term by receiving direct feedback because they could notice their grammar mistakes and spelling easily. Similarly, Ferris (2002) also found that low language proficiency students faced difficulties in correcting errors by themselves due to their grammatical knowledge. However, they felt comfortable in revising their texts because their teachers suggested correct forms for the errors using direct feedback. Bitchener (2008) also found that learners could locate and use the correct forms by direct feedback with suggestions without any delay and they felt that direct feedback was straightforward and easy to understand. 
However, students believe there are some negative impacts of feedback on L2 writing. First, teacher feedback can lead to negative psychological aspects. For example, Agbayahoun (2016) used mixed-method instruments to investigate teachers' feedback on EFL students' writing in the Republic of Benin. This study involved 132 secondary students and two teachers. The findings showed that the majority of students felt dissatisfied and held negative impressions on both teachers' feedback. They considered it discouraging, confusing, useless, and overwhelming because they were not able to understand or revise their errors.

Second, students feel dissatisfied with the teacher feedback types if they do not match their preferences. Aliakbari and Raeesi (2014) examined learners' perceptions of teacher feedback on L2 writing in Iran. In this study, fifteen MA students were asked to complete a questionnaire which comprised a list of aspects of error correction. The results showed that the advanced students would not be satisfied with the same type of feedback which was used for elementary students. Therefore, teachers should consider student-centred feedback when they decide to use any feedback in L2 writing classrooms. Similarly, Chai and Nimehchisalem (2016) explored ESL students' perceptions toward feedback in Malaysian students' writing development. One hundred seven students were randomly selected to respond to a set of questionnaires which elicited information about their perceptions on the usefulness of feedback. The researchers used 30 five-point Likert scale items, three multiple-choice items, and three open-ended items for their questionnaires. The findings showed that the students were not satisfied with teacher feedback because they preferred the teacher to focus on organization and content of writing rather than grammatical accuracy.

Finally, students faced difficulties to understand teacher feedback. In Karim and Nassaji's (2015) study, students stated that indirect feedback with underline only or underline plus metalinguistic feedback was not useful. They could guess some errors, but they could not correct them due to their insufficient lexical and grammatical knowledge. Sritrakarn (2018) also stated that it was hard for students to understand their teacher's comments because the teacher's handwriting was unclear. Unfortunately, these students hesitated to express this problem to their teacher or arrange meetings with their teacher to get advice.

\section{Students' perceptions of Peer feedback}

Many studies show that students hold positive opinions towards the use of peer feedback in L2 writing classes. First, peer feedback can enhance students' confidence in interacting with 
peers to improve their writing. For instance, Ruegg (2017) interviewed twelve students to investigate their perceptions of using peer feedback on L2 writing in a Japanese university. The findings showed that the students were inclined to ask their peers for feedback explanations. Students also stated that they got fewer benefits from their teachers' feedback due to the time limitation. In a similar way, Bratkovich's (2014) study revealed that seven students from the United States felt more comfortable with peer feedback than teacher feedback and perceived their writing to have improved. The students stated that excessive amount of teacher feedback caused them anxiety instead of helping them improve their writing.

In addition, students believe that peer feedback is easy to understand because it involves peer interaction and discussion. For instance, Sritrakarn (2018) conducted a study at a Thai university with the participation of two groups of students: 22 fourth-year students who reviewed their peers' drafts, and 33 third-year students who submitted their essays for the review. The fourthyear groups were intermediate to upper-intermediate levels of English while the third-year groups were Lower Intermediate to Intermediate levels of language proficiency. This study used mixmethod strategies to collect data. Specifically, two sets of questionnaires which combined students' demographic data, five-point Likert scales, and open-ended questions were employed to investigate the perceptions of all the participants. The overall findings revealed that the students' experiences of peer feedback were positive and they perceived that peer feedback was useful and easy to understand after discussing with their peers. In contrast, Miao, Badger, and Zhen (2006) revealed that although 38 students showed improvement after they experienced peer feedback by asking questions and discussing problems with their peers, they preferred teacher feedback to peer feedback in their L2 writing.

Finally, students believe that peer feedback could enhance their cognitive engagement which supported their writing in the long term. Tai, Lin and Yang (2015) examined EFL students' perceptions of a writing course in Taiwan. Two classes with 107 first-year student from a college of nursing participated in this study. Their English language proficiency levels were lower than A2 CEFR (Common European Framework of Reference for Languages). The primary language teachers with more than eight years of experience in teaching writing were responsible for guiding these learners. Consistent with previous studies, the findings from a questionnaire (5-point Likertscale) students believed peer feedback contributed to their performance. Students considered it as a demanding task to make revisions by using comments from their peers, so they devoted more 
time to give feedback to their peers and reflecting on their own work. The results from a pretest and posttest showed that the combination of peer feedback and teacher feedback enhanced learners' writing competence significantly and effectively.

However, some studies reveal that although students appreciate the use of peer feedback on their texts, they still want to rely on teacher feedback. Students believe that peer feedback is less reliable and accurate than teacher feedback. For example, Chai and Nimehchisalem (2016) examined their study in Malaysia with 107 undergraduate students to identify their perceptions of different sources of feedback. The findings showed that although the students appreciated peer feedback, they still preferred teacher feedback because of its accuracy.

Peer feedback can be inadequate because some students want to keep the class harmony instead of giving negative feedback. Carson and Nelson (1996) found that three advanced Chinese students in the US tended to employ face-saving strategies by giving only praise comments instead of negative ones. Similarly, Yu and $\mathrm{Hu}$ (2017) conducted a case study with two university students in China. The findings showed that these students had appropriate training on how to use peer feedback at the beginning of the semester; they were encouraged to express their comments in different ways. Unlike most previous studies, these Chinese students wanted to maintain group harmony or saving face which were considered as the cultural influences in L2 classes. Therefore, it is necessary to train students how to use peer feedback to help them understand the purpose and positive outcomes of this feedback practice in order be confident in providing and receiving both positive and negative feedback in L2 writing.

\section{Students' perceptions of Self-feedback}

Although self feedback is a new method, many studies show different findings about students' perceptions on receiving self feedback in L2 writing classes. First, students feel more comfortable in critically evaluating their papers and changing their writing process to be more productive. Wakabayashi (2013) conducted a questionnaire study with 51 students in two writing classes in a Japanese university, the results found that most students preferred peer feedback to self-feedback because they could read each other's writing and exchange comments with each other.

In addition, students believe that using self-feedback can enhance their learning autonomy. For instance, Siow (2018) conducted a study in Malaysia to identify 62 ESL students' perceptions 
on the effectiveness of self feedback and peer feedback. The results showed that more than 50\% of students felt independent in critical thinking in L2 writing. Most students stated that selffeedback was extremely useful because they could build their competency as well as autonomy.

Lastly, self feedback enhances students' confidence in writing. Amelia (2020) conducted a study on 23 students in Indonesia to identify their perceptions on the use of self-feedback. The study used a questionnaire and an interview to gather students' understanding and perceptions about using self-feedback in L2 writing. The results showed that $78 \%$ of students believed that their own feedback was good and made them more confident in their ability to complete writing task requirements. Furthermore, students' preferences on teacher feedback, self-feedback, and peer feedback were $57 \%, 30 \%$, and $13 \%$ respectively.

On the other hand, some studies show that if students do not have appropriate training, they can lack confidence in their self-correction or over rate their feedback which leads to inaccurate revisions. Berger's (1990) study about the influences of peer feedback and self-feedback on students' L2 writing involved 54 ESL students. The findings showed that students from the peerfeedback group could make more revisions than the self-feedback group. Although students had little training about peer feedback, they still preferred using this type of feedback in writing. However, since the students did not receive enough training and have a chance to get used to self feedback, they felt less motivated and committed to finding appropriate words to replace the errors. They did not want to experience self-feedback again, although they had tried it only once.

Belachew, Getinet and Gashaye (2015) conducted their study on the perception and practice of 50 ESL students and 10 teachers towards self-feedback. The findings of document analysis and interviews showed that both teachers and students had positive belief in the use of self-feedback in L2 writing. However, students tended to overate their own feedback which could be inaccurate because they lacked feedback training. Therefore, L2 students in any language level should be trained to give feedback or double check their feedback with teachers or peers to ensure the accuracy.

\section{Teachers' perceptions of feedback}

Some researchers have investigated teachers' perceptions to have a more comprehensive vision about giving appropriate feedback in future writing. There are limited studies about teachers' perceptions on feedback in L2 writing. Zacharias' (2007) study showed that the amount 
of teacher feedback can affect students' feelings about their writing performance. Similarly, some scholars found that the amount of feedback in L2 writing could influence students' confidence which was one of the vital role in their developing writing performance (Agbayahoun, 2016; Bratkovich, 2014; Pearson, 2018). Therefore, excessive feedback can overwhelm students when receiving too much feedback. By contrast, Ruegg and Koyama (2010) found that students who received more teacher feedback on their assignments felt more confident in their final draft than those who got less teacher feedback.

Mahmud (2016) conducted his study in 14 Malaysian schools with the participation of 54 English teachers. The results of interviews from the participants showed that teachers believed feedback could enhance students' writing. However, they did not have a specific guideline on feedback provision, so their feedback could be inadequate. They also stated that the reactions of the students could affect their intentions or willingness to persist in new feedback practices. As a result, the teachers felt demotivated in using new feedback practices.

Hartshorn, Evans and Tuioti (2014) investigated the variables that influenced teachers' feedback choices in L2 writing. The data was collected by more than 1000 ESL/EFL writing teachers from 69 different countries using an electronic survey. The findings showed the background of teachers, teaching context, students' language proficiency level, and level of education could influence teachers' beliefs in giving feedback. However, teachers indicated that individual learner needs would be the most significant impact on their feedback practices.

Pearson (2018) explored seven teachers' feedback practices and beliefs in IELTS writing feedback in the United Arab Emirates by using semi-structured interviews. The study investigated on the textual features that the teachers focused on; the error treatment and commentary techniques; and the teacher's perceptions and motivations in feedback practices. The findings from the semi-structured interviews showed that teachers wanted to use feedback to improve students' writing and hoped to meet students' feedback preferences. They also mentioned that they tried to balance the needs of students and the amount of feedback although it could cause some burdens on their teaching practices.

In Atmaca's (2016) study, Thirty-four EFL teachers wanted to inform their students about what type of feedback would be used and expected to give appropriate feedback which could match their students' need and motivate them in writing. Although the researcher focused on both teachers 
and students, it was not enough to investigate their perceptions by using only questionnaires. This study could be further enhanced if interviews were also included.

A mismatch between students' and teachers' beliefs

The outcomes of the previous studies showed that there was not a "one-size-fits-all" style of feedback for all language learners. Therefore, teachers should consider their students' differences in the writing process.

Sharif and Zainuddin (2017) investigated ESL medical students' perceptions of teachers' feedback on their reflective essays. This case study used qualitative analysis of questionnaire and semi-structured interviews were conducted on 19 students in Malaysia. Two students were interviewed at the end of the course to direct the following issues: describing their experience of teachers' feedback on their reflective writing, expressing some challenges that they had faced in course, and their opinions about the benefits of teacher feedback. The findings showed that there was a gap between students' expectations and the teachers' feedback practices. Teachers only gave short comments and infrequent feedback while students wanted to get long and detailed comments.

Nguyen and Rajeevnath (2016) investigated four English teachers' and 50 English-major students' reactions to teacher written feedback in Vietnam. The findings demonstrated that most of the students wanted to get direct feedback, but the teachers wanted to give indirect feedback which could active students' engagement and lead to long-term benefits.

Dam (2018) used questionnaires and interviews to investigate Vietnamese teachers' and students' perceptions of the effectiveness of indirect feedback. The findings revealed that teacher believed that students' writting accuracy would be improved by using indirect feedback. Meanwhile, students stated that they did not trust their own corrections due to their limitations in the L2 language.

Jodaie, Farrokhi, and Zoghi (2011) conducted research on 30 teachers and 100 intermediate students to understand their perceptions of teacher feedback on grammatical errors. They found that most teachers wanted to use direct feedback, a combination of indirect uncoded feedback and direct feedback, and only indirect uncoded feedback in their L2 writing class. Meanwhile, seventyfive students held a negative belief in the indirect uncoded feedback strategy because they wanted to get teachers' corrections. 
Zaman and Azad (2012) investigated the feedback preferences of a group of university teachers and students in Bangladesh. The findings showed that while the majority of students preferred their teachers to provide the correct forms instead of underlining errors only, the teachers believed that indirect uncoded feedback could be suitable for students to improve in the long term.

In conclusion, although extensive studies about stakeholders' perceptions of using different types of feedback on L2 writing in other countries, there is no study about peer feedback and self-feedback in Vietnamese contexts. Moreover, the mentioned studies primarily focused on either students' or teachers' perceptions, but there are few studies about both students and teachers' beliefs. As a result, this study aims to fill these gaps by using questionnaires to find out students' perceptions and interviews to identify teachers' perceptions.

\section{Training}

Since learners do not know how to provide effective feedback, training can be used to enhance peer feedback and self-feedback practices in L2 writing. In the following parts, training for peer review and self review will be discussed briefly.

\section{Training for peer review}

Theoretically, the effectiveness of peer feedback can be enhanced by 'students' interactions through feedback exchanges, discussions, and suggestions. However, if students do not know some necessary skills to review their peers' writing, peer feedback can not benefit their learning. Therefore, some studies focus on training students to give feedback in a writing classroom to identify the importance of feedback training in the last decades. The outcomes show that students from trained groups can provide more effective and specific feedback than untrained groups.

Zhu's (1995) study investigated the impacts of training L1 peer reviewers on the quality of their feedback. In the teacher-student conference visits, the participants (both trained and untrained students) were initially trained by a video which included some basic instructions about peer feedback. However, during the study experiment, the students from the trained group experienced regular conference visits with their teachers to know how to provide better comments by oral discussions. The findings of this study revealed that the students in the trained group could provide feedback with higher quality than the untrained group. Similarly, Stanley (1992) examined the 
effects of training on feedback quality and students' improvement. The oral feedback training was conducted within seven hours. The results showed that the group who experienced the training performed more effectively in giving specific feedback than the untrained group. Rahimi (2013) also aimed to investigate if training could help students provide stronger scaffolding through peer feedback than those who did not undergo peer-feedback training. The study consisted of fifty-six EFL students enrolled in two intact advanced writing classes in Iran. One group of students was trained for writing review, and another group was not trained. The result of the study demonstrated that the trained group focused more on the global aspects than the formal ones at the end of the experiment. Moreover, the students in the trained group were able to provide more relevant and global comments in their peer feedback practices.

Husni (2017) elaborated on 32 students' perceptions towards the use of peer feedback in writing class before and after making revisions in Indonesia. Students believed that peer feedback was useful and meaningful and helped them revise and improve their writing. They also stated that their feedback validity was consistent because they were trained to use teachers' feedback guidance. As a result, the students were confident in providing and receiving effective and accurate feedback to their peers in writing classes. Similarly, Berg (1999) investigated how training shaped students' quality of revisions after received several activities in peer feedback training. The results showed that the trained group made more revisions than the untrained group, and the quality of revisions from the trained group was considerably better than the untrained group.

In Yangin Eksi's (2012) study, forty-six students in Turkey experienced feedback training in nine weeks. The findings revealed that peer feedback with appropriate training could alleviate the burden of teachers' workload on commenting on students' papers. Moreover, the students enjoyed reviewing each others' writing and belived that their autonomy of writing process was developed. They also improved their writing in both local and global issues after the feedback training.

Min's (2013) study reported a teacher's beliefs in feedback and how she gave feedback on her students' writing. The study found that the teacher changed her feedback practices on students' second and third drafts due to her realization of the importance of training students to provide quality feedback to their peers. Therefore, teachers should focus on students' intentions and having regular training to help students get used to peer feedback and use this type of feedback. 


\section{Training for self review}

Although there is little research on self-feedback, training for self review is extremely important for L2 learners who face language barriers and have a shortage of language knowledge in identify and correct their own errors. Some studies reveal positive outcomes of self-feedback training on students' performance. Kostons, van Gog, and Paas (2012) investigated the effectiveness of self-feedback training on students' writing performance in the Netherlands. The result showed that 80 students' self-regulated learning was improved after the training. Meanwhile, Xiang (2004) compared the pre-test and post-test results from an experimental group which experienced self-feedback training and a control group that did not receive self-feedback training. The study found that students could be trained to use self-feedback. This feedback was especially helpful to high language proficiency students to develop the organization of their compositions.

Overall, there is no guarantee that students automatically use peer feedback and selffeedback effectively. Therefore, students need to be trained to know how to provide sufficient and relevant feedback with good quality and quantity. 


\section{CHAPTER 3: METHODOLOGY}

This study aims to identify university students' and teachers' perceptions of feedback in an English writing course in Vietnam. The participants were first-year university students who majored in Finance and Banking and two senior teachers. The study used a qualitative research method employing questionnaires and interviews.

\section{Context of the study}

A public university in the South of Vietnam was chosen for the data collection. In this territory, the English department offered English Writing Essay Course in the second semester from December, 2019 to May, 2020. The instructional languages used in this course were 60\% Vietnamese and $40 \%$ English due to the students' language proficiency level which was preintermediate. Since this course is one of the compulsory requirements, students have to pass it to complete their degree at the university. This English Writing Course aims to prepare the students for writing different types of essays, general outlines and drafts; and using appropriate language for each type. As in many other language departments across Vietnam, the English department experiences large class sizes ranging from 40 to 50 students in one class.

At the beginning, this study aimed to conduct an experiment using different types of feedback from week 1 to week 5 of the second semester. Due to the unexpected spread of coronavirus, this study had to change from plan A to plan B. In the following part, the two plans will be outlined.

\section{Plan A - Week 1 (in class) - The plan of this study before the outbreak of coronavirus}

Based on the school syllabus, the researcher had planned to use peer-feedback, direct feedback, indirect coded feedback, indirect un-coded feedback, and self-feedback in the first week, the second week, the third week, the fourth week, and the fifth week of the course respectively. Before the class, the introduction of each type of feedback would be presented to the students in 10 minutes. All five types of feedback would be explained carefully in class. Moreover, an extra 
15 minutes would be given to the students for peer-feedback and self-feedback training week by week.

\section{a. The writing assignments}

In the first week of the semester, the two teachers and students were asked for their permission to make copies of students' essays and teachers' feedback on the students' assignments. Five different types of written feedback on students' assignments were expected to be introduced and given by the researcher in class over a period of five weeks. These types of feedback were peer feedback, direct feedback, indirect coded feedback, indirect un-coded feedback (focused mainly on Grammar), and self-feedback. In terms of peer-feedback and selffeedback, the students should have been trained to focus mainly on giving feedback on verb tenses.

The researcher had planned that after giving certain types of feedback, these assignments would be given back to the students at the end of the class in the following week. Then, students would be asked to check their assignments' feedback and answer a questionnaire to give their perceptions about these types of feedback, before they received feedback from their teacher. On the other hand, students did not need to submit another draft or revision of their work, but subsequently received their grades and feedback on their writing from their teacher. Writing essays would have been selected and given five different types of feedback by the researcher.

\section{b. Feedback Provision and Survey Completion}

On the one hand, teachers would ask students to complete their assignment and give feedback based on the school syllabus. They could give their own favorite types of feedback which they usually use in their classes. Subsequently, they would allow the researcher to make copies of their feedback on students' writing before returning these papers to the students. The whole progress would be repeated. On the other hand, the researcher would make copies of the students' writing assignments during the seven-week study. All writing assignments were given individual feedback by the researcher each week in addition to the feedback provided to all students by the teacher.

It is important that the consent forms were not shown or shared between these students so they should not know on the first day who was participating and who was not. However, in the following weeks, students could know who was participating in this project because the researcher would ask the participants to complete the surveys at the beginning of the class. These students 
would be divided into two groups (one group of participating students and one group of nonparticipating students).

At the beginning, the researcher had planned to conduct a pre-treatment questionnaire (before students experience these types of feedback) in Week 1; five during-treatment questionnaires (during five weeks of experiencing five types of feedback in this writing course) which were related to students' perceptions on peer feedback, direct feedback, indirect coded feedback, indirect un-coded feedback, and self-feedback; and a post-treatment questionnaire (after experiencing five types of feedback in this writing course) in the five following weeks. Finally, the Week 7 questionnaire (14 items) includes informational questions, and questions (including Likert scale and multiple questions). In the questionnaires, the researcher aimed to know about students' perceptions of different types of feedback, expectations and suggestions after experiencing both their teacher's and researcher's feedback; however, this questionnaire was canceled due to the outbreak of coronavirus. Seven questionnaires are included in the appendix A, $\mathrm{B}$ and $\mathrm{C}$ respectively.

The researcher aimed to investigate the changes in their attitudes toward written feedback during a short period. Since the survey was expected to take only two to three minutes to complete, it would not affect teachers or non-participating students. Non-participating students could review their lessons during that time.

\section{c. Teachers' interviews}

In terms of teachers' interviews, they were predicted to last for 20 to 30 minutes and would be recorded for data analysis later. The teachers would be comfortable with the interviews in English because of their high language level of proficiency. Actually, the researcher had multiple meetings with the two teachers separately to explain about the study before the semester started. These meetings allowed the teachers to have a deep understanding of feedback, study goals, and procedures in order to give the most accurate perceptions. During the interviews, teachers were expected to share their experiences in giving feedback; advantages and disadvantages of feedback on their teaching; and their students' expectations about different types of feedback. All the interviews would have been conducted independently and recorded. Then, they would be analysed into general themes.

\section{d. Feedback training}


In the first week, the researcher had talked to the teachers and students about the project, and they also completed the consent forms to participate in this study. Seventy-eight students from two classes took part in the experiment, and they had completed the pre-treatment questionnaire to clarify their general perceptions about feedback in L2 writing. However, the school was shut down in week 2 because of the pandemic, so plan A could not be done. Specifically, the researcher could not collect the writing assignments to provide five different types of feedback on students' work. Similarly, the teachers had to delay their teaching, and they could not provide feedback. In terms of teachers' interviews, the pre-treatment interviews were conducted, but the post-treatment interviews were cancelled because the teachers had not taught students during the data collection period. As a result, the researcher had to change to plan B to ensure the validity of the study.

\section{Plan B - From Week 2 to Week 7 (Online)}

Due to the unexpected pandemic, the researcher had changed the study from plan A to plan $\mathrm{B}$, which conducted this study online. In figure 1, the plan B of this study after the pandemic is presented.

\section{Figure 1. Plan B of this study after the pandemic}




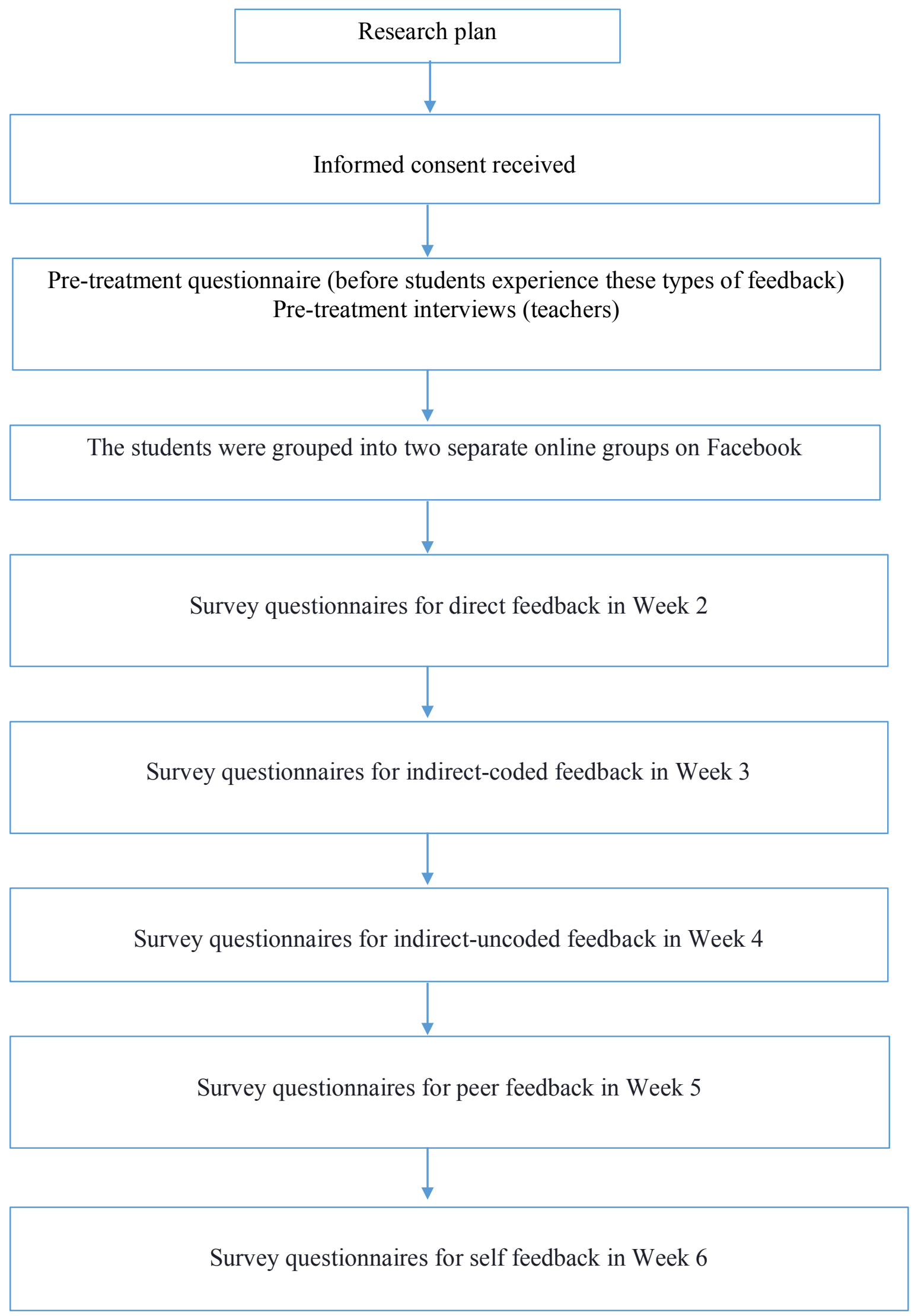




\section{a. The writing assignments and feedback provision on students' texts}

The researcher aimed to give feedback on the participants' writing assignments using different types of feedback. Seventy-eight writing assignments would be collected from 78 students every week. After five weeks, 390 writing essays were expected to be collected and used for the data collection. However, the researcher was not able to follow this methodology. She had to cancel the writing assignments and feedback provision following the school syllabus because the university was closed and the students were not writing any assignments during the data collection period.

\section{b. Questionnaire surveys}

The pre-questionnaire at Week 1 was conducted in class before the outbreak of coronavirus in Vietnam, but the rest of the questionnaire surveys could not be done in classroom because the school had shut down after Week 1.

The students were grouped into two separate online groups on Facebook with their classmates to collect the data online after the school closed. However, only 63 out of 78 students agreed to keep taking part in this study.

The researcher contacted students through online groups to explain about direct feedback, indirect-coded feedback and indirect-uncoded feedback before asking these students to complete the surveys related to each type of feedback in Week 2, 3, and 4 respectively. Students could ask the researcher anytime by email or Facebook chat. The two teachers had already created online English writing groups on Facebook so students uploaded their writing and experienced self feedback and peer feedback on that platform. However, the researcher still explained these types of feedback by both email and group chat to make sure that all students understood them. The students were asked to complete the survey questionnaires for peer feedback and self feedback in Week 5 and Week 6 respectively. They could respond to the Likert-scale questions and also express their own perceptions about advantages and disadvantages of each type of feedback

The students did not submit their writings to receive either their teacher's or researcher's feedback. Finally, the researcher aimed to know about students' perceptions of different types of feedback after experiencing both their teacher's and researcher's feedback in Week 7, but the school did not reopen during the experiment time due to the pandemic. Hence, the post-treatment questionnaire was canceled.

\section{c. Interviews}


In terms of teachers' pre-treatment interviews, one of them was conducted online and it lasted for 20 to 30 minutes in week 3 . Another teacher was not able to conduct the interview online so she typed her answers for the interview questions by herself and sent her answer back after one week. However, the researcher had to skip the post-treatment interview since the teachers had not taught the students in this period so they had not experienced anything new from their students.

Writing assignments, feedback collection, feedback provision, the post-treatment questionnaire, and the post-teacher-interviews were cancelled because all universities in Vietnam had shut down from February to April in order to stop the global pandemic. Although the researcher was in Vietnam for collecting the data, she was not able to do her experiment as originally planned.

\section{Participants}

There were around 160 students enrolled in this English writing course at the university in the second semester. All four classes and the teachers were asked for their voluntary participation in this study. Two English writing teachers (both females) and the students in their writing classes participated. All of the participants were given a consent form. They were informed that their participation in questionnaires and interviews was voluntary. The research did not affect the students' grades or the teachers' syllabus. Moreover, all of the participants' names were changed in any written report of the study. Their personal information such as email address, phone number and student number was only used to inform students about any changes in this study.

\section{a. Students}

In the first week of the semester, 78 students at the age of 18 participated in this study. They were full-time students in the Finance and Banking department with Pre-Intermediate English proficiency level. In order to pass the English Writing Course, the students had to complete writing assignments given by their teacher weekly.

The plan B was employed to get students' perceptions. First, the researcher contacted the students who agreed to take part in this study to join in an online Facebook group chat. Next, these students were informed about the changes of the experiment as well as how they could keep participating in the study online. If they found it inconvenient, they could withdraw immediately. As a result, sixty-three out of seventy-eight students agreed to keep taking part in this study 


\section{b. Teachers}

The two participating teachers in this study were invited based on their experience in giving feedback and teaching writing at the university level. Furthermore, they graduated with a masters or doctoral degree in English studies or English education. The teachers were contacted through emails. They also received consent forms and information sheets about the project. In terms of feedback collection, they were willing to allow the researcher to make copies of students' essays and their feedback on students' essays at the end of their class.

Table 1. Demographic data

\begin{tabular}{|l|c|c|}
\hline & English Teacher Class A & English Teacher Class B \\
\hline Male / Female & Female & Female \\
\hline $\begin{array}{l}\text { Teaching Writing Experience } \\
\text { (years) }\end{array}$ & $>20$ years & \\
\hline $\begin{array}{l}\text { Number of students in this } \\
\text { semesters writing course }\end{array}$ & 37 & 41 \\
\hline
\end{tabular}

Since the teachers experienced the same-unexpected situation as students, the researcher had to ask for their participation in online interviews. Moreover, their feedback on students' essays could not be included in this project. At the end, the two teachers agreed to keep participating in the study.

\section{Instruments}

\section{a. Questionnaire surveys}

Questionnaires are widely used to collect a large amount of data in a short period of time. Therefore, in this study, questionnaires were distributed to students to find out their perceptions of effectiveness and challenges in receiving different types of feedback in writing. By examining the literature (Agbayahoun, 2016; Montgomery \& Baker, 2007; Ruegg, 2017), the standard procedure of designing these questionnaires was used. The researcher had made a questionnaire at the beginning of the course, five small questionnaires for Week 2, 3, 4, 5, 6 respectively and a questionnaire at Week 7. 
The Week 1 questionnaire consisted of 12 items about informational questions and closed questions (Likert scale and 10 multiple choice questions). These questions helped the researcher find out the students' prior experiences in giving and receiving five types of feedback; and their expectations on teachers' feedback and comments. This questionnaire was used in class at the beginning of the semester after the students agreed to take part in this study. Each of the five questionnaires from Week 2 to Week 6 consisted of six open-ended questions, five Likert-scale and an open question. These five questionnaire questions were related to students' perceptions on peer feedback, direct feedback, indirect coded feedback, indirect un-coded feedback, and selffeedback respectively. The students also expressed their perceptions about the benefits and drawbacks of using each of these types of feedback.

To ensure the validity of the questionnaire content, the researcher piloted the questions with ten students from the English proficiency program. Judgment and feedback from experts who have considerable experience in teaching writing, feedback, and questionnaire design also contributed to the final questionnaires.

The questionnaires were modified to avoid any misunderstanding from the word choices such as types of feedback which may affect the findings (Montgomery \& Baker, 2007; Ruegg, 2017; Westmacott, 2016). The domain languages used in these surveys were English and Vietnamese to avoid any misunderstandings.

Based on their answers, the researcher had a general understanding of students' experiences and expectations on five types of feedback from previous learning. In terms of the during-treatment questionnaires, students completed them online after they received the feedback from the researcher on their writing in five different weeks. Their answers for these during-experiment questionnaires helped the researcher to have a deeper understanding of the expectations about each type of feedback they would like to give and receive.

However, the students had only completed the Week 1 questionnaire in class in the first week, but they had not experienced feedback training with the two teachers since the school was closed in the second week of the semester due to the coronavirus. Therefore, the students' responses in the following weeks could be related to their old experiences in L2 writing classes that did not experience appropriate training for giving and receiving feedback.

\section{b. Interviews}


The researcher used interviews to investigate two teachers' perceptions of feedback in ESL writing classroom. According to Agbayahoun (2016), interviews enable the researcher to identify participants' attitudes and perceptions. There is a list of 23 questions which were conducted based on the framework of previous studies (Agbayahoun, 2016; Mekala \& Ponmani, 2017), was made in advance. These interview questions The wording of these questions was modified for comprehensibility to be suitable and relevant. One teacher's interview which was semistructured, was conducted online and it lasted for 20 to 30 minutes in week 3. Meanwhile, another teacher was not able to conduct the interview online so she typed her answers for the interview questions by herself and sent her answer back after one week. Since this interview was structured, the researcher was not able to ask for more details.

\section{Procedure}

\section{a. Students}

The researcher had contacted all the participants to inform them of the changes as well as how they could participate in the experiment. They were also asked to complete the five surveys which are related to the five different types of feedback. However, the weekly order of feedback in the two classes had different orders to limit the possible bias to the research results.

First of all, the students were grouped into two separate online groups on Facebook with their classmates. They were asked again for consent because the researcher had to collect the data online. In addition, students could ask the researcher anytime for clarification of survey completion and types of feedback by email or Facebook chat.

In terms of self feedback and peer feedback, the two teachers had already created online English writing groups on Facebook so students uploaded their writings and experienced these two types of feedback on that social tool. However, the researcher still explained these types of feedback by both email and group chat to make sure that all students understand about them. Then, the participants were asked to complete the surveys. They could respond to the Likert-scale questions and also express their perceptions about the advantages and disadvantages of each type of feedback that they had experienced.

\section{b. Teachers}


In terms of teachers' interviews, one of them had an online interview in week 3 and lasted for 20 to 30 minutes. It was recorded for data analysis after week 7. Another teacher was not able to have an online interview so she asked the researcher for the list of interview questions in order to type the answers by herself. She then sent her answers to the interview questions back after one week. During the interviews, teachers were expected to share their experiences in giving feedback; advantages and disadvantages of feedback on their teaching; and their students' expectations about different types of feedback. The teachers' interviews were coded and transcribed into general themes.

\section{Data analysis}

\section{a. Analysis of data from the questionnaires}

Once collected from the students, the Week 1 questionnaire data were coded and then statistical analysis was conducted. Excel program was used to identify Median, Frequency, and Mode of 63 students' answers, and transfer them into tables in the results. On the other hand, the data from five-week surveys were translated into English and analyzed by NVivo. These data were synthesized and collated to make comparisons between the teachers' and students' view of different types of feedback as well as the advantages and disadvantages of using them. The responses helped the researcher identify to what extent students and teachers' perceptions meet and differ from each other. This study only focused on students' and teachers' perspectives, so any measure of the effectiveness of the various types of feedback on the students' writing improvement was not included. By analyzing the data, the researcher found out the students' preferences and expectations for feedback in L2 writing.

\section{b. Analysis of data from the interviews}

After one of the interviews was recorded and transcribed, the data from two teachers' interviews were analyzed by using NVivo software to categorize the themes. The findings from teachers' interviews showed teachers' methods of giving feedback and their perceptions of feedback in L2 writing.

Figure 2. The procedure and data analysis of students'surveys and teachers' interview 

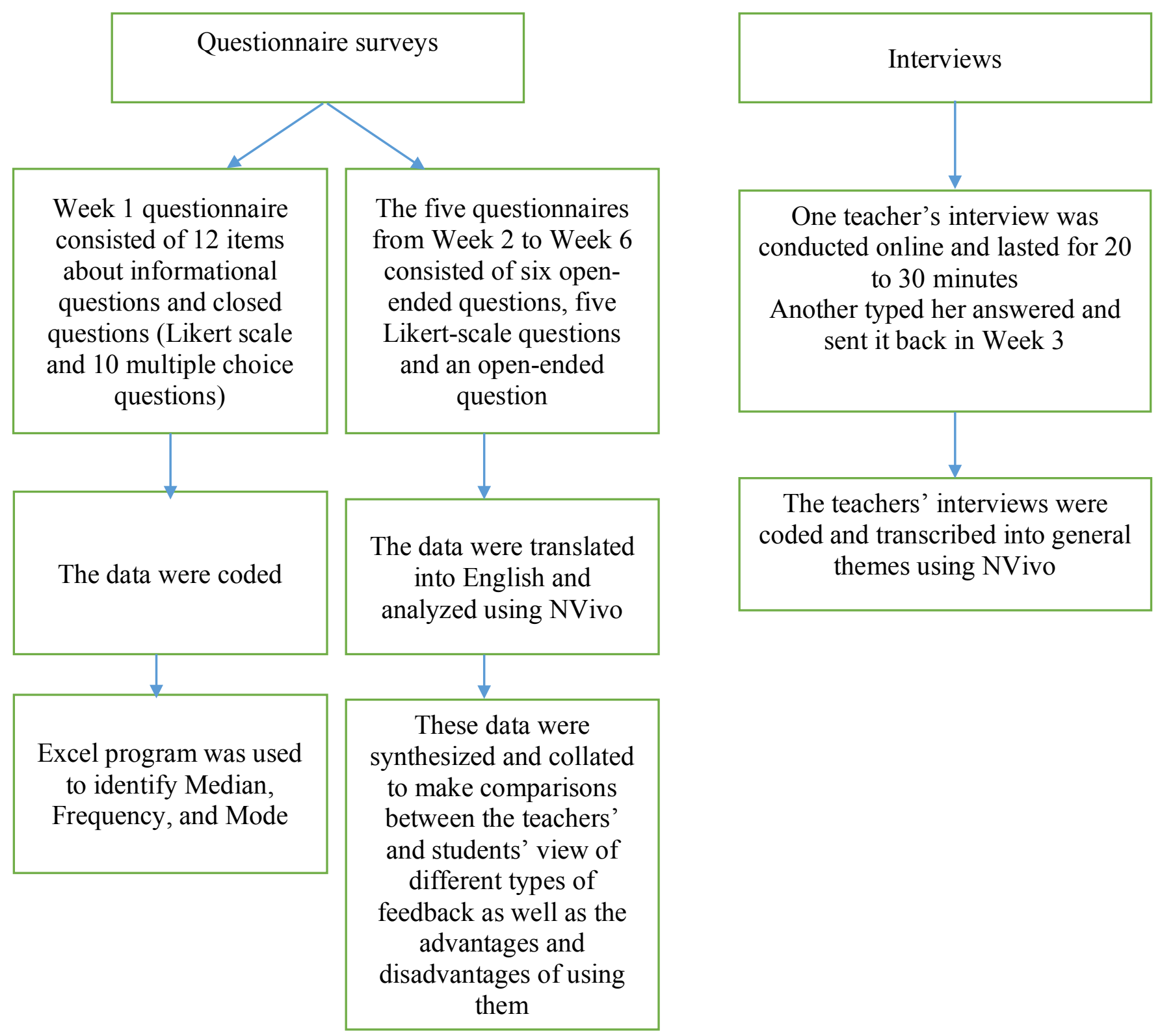

One teacher's interview was conducted online and lasted for 20

to 30 minutes

Another typed her answered and sent it back in Week 3

The teachers' interviews were coded and transcribed into general themes using NVivo 


\section{CHAPTER 4: RESULTS}

First of all, this section will discuss teachers' interviews about different methods of giving feedback in their English writing classes and the reasons why they used them. Therefore, the two teachers' interview responses will be used to answer the first research question. Secondly, the section will focus on teachers' perceptions of different types of feedback that they have employed in their classes as the findings for the second question. Following this, this section will present the non-parametric descriptive statistics from students' Week 1 questionnaire and five surveys about advantages and disadvantages of peer feedback, self-feedback, direct feedback, indirect coded feedback and indirect un-coded feedback based on students' experiences. Finally, the similarities and mismatches of students' and teachers' perceptions will be reported. Thus, all these four research questions will be answered.

\section{Methods of giving feedback}

During the interviews, the two teachers reported that they often used feedback in their writing classes. They also employed different types of feedback that were suitable for their target learners and task requirements. It is thus clear that teachers realized the importance of giving suitable types of feedback, but they had different ways of using them on their students' text.

Both of the teachers stated that using feedback for L2 writing was important. Teacher A said that she usually asked her students to revise their texts after getting their feedback to see their improvement, while teacher B reported that "I focus on the task requirements to give feedback and every type offeedback is good to some extent". When asked how they decided the type of feedback used in their class, two of them reported the same idea that "it depends on the students' language proficiency level'. Teacher A said that she would give direct feedback if her students were weak, whereas teacher B stated that she only used peer feedback if students were advanced or Englishmajors. In terms of feedback practice, they exposed different strategies. While teacher A stated that:

"I give them the indirect feedback and I ask them to read and then I inform them okay so what does the signal mean, and then I ask them to work in pairs and groups with each other to help with mistakes, then they do self-correction and write a second draft and they have to submit 
both the first draft and second draft ...but usually if they don't know how to correct the mistake by themselves, they will go and ask, I will show them".

Teacher B expressed that:

"I read through the writing for holistic assessment. Reread and highlight the points that need to be improved. Some serious mistakes are corrected right away. Some are collected to be corrected in class. My students are asked to work individually or in groups after the papers are returned to double-check their understanding of feedback while I am around to explain".

According to these responses, there are some similarities and differences in the ways that the two teachers used feedback in their classes. In terms of similarities, both of them used peer feedback and self-feedback after they read their students' texts and gave their feedback. They preferred students to work in groups to pairs after the students received their first draft because the number of students in their class was quite big. For example, teacher A said that "I created Facebook groups and asked students to give feedback for their friends there based on some criteria, and there are usually more than 30 of them in one group" while teacher B replied that "My students are asked to work in groups after the papers are returned to double check their understanding of feedback while I am around to explain". Additionally, they both agreed that students had to revise their writing and resubmit it to check their improvement. Finally, they would support their students by mistake clarifications or suggestions if any students were not able to correct the errors by themselves when the teachers used indirect feedback. However, the two teachers also used different methods of giving feedback on L2 writing texts. While teacher A employed indirect coded feedback (underline and give symbols) because most of her students were "good at English", teacher B tended to use indirect un-coded feedback by highlighting or direct feedback to correct serious errors.

The two teachers also expressed their methods that help students consider their feedback to avoid making the same mistakes. Teacher A reported that her students had to read their texts with the feedback carefully and remember their mistakes; then they would have to revise a better version of their text if they want to gain a higher mark. By contrast, teacher B required her students to revise their text if they made too many mistakes, and resubmitted the revision with its old version to clarify their uptake. 
Thus, the two teachers had their techniques to use various types of feedback to improve their students' writing. Although their way was different from each other, they mainly focused on the students' language proficiency level, class size and students' uptake.

\section{Teachers' perceptions of feedback}

Both teachers indicated that there were many advantages of using feedback on second language writing. First of all, feedback giving can positively affect students' psychological aspects. For example, teacher A stated that "feedback made students feel motivated, encourages, and more productive". Similarly, teacher B reported that "when my students can reduce the amount of errors in their revision, they feel pleased with that achievement". Secondly, feedback plays a vital role in students' writing ability in the long term. Teacher A claimed that her students had to keep working with their text to solve problems when she used indirect coded feedback. She witnessed that " $m y$ student had to work on their text again, so they could learn from their mistakes and avoid making them again". Similarly, teacher B stated that writing was a learning process and feedback helped students to identify their strengths and weaknesses in their texts. She also believed that " $m y$ students perform better after working on their papers again such as checking errors, understanding their problems, and revising a better version". Thirdly, feedback can develop students' cognitive engagement in L2 writing. Teacher A reported that students were "cooperative to discuss problems with teachers and peers when they received feedback". They also found selffeedback useful in engaging students' cognition because these students could review their text, detect their errors, and solve problems by themselves. For example, teacher B stated that "students have a chance to evaluate their knowledge before and after practice". Finally, students can enhance their writing accuracy. While teacher A reflected that her students were able to identify grammatical errors and mistake rules, teacher B said that her students could distinguish patterns of repeated errors.

Nevertheless, teachers have to cope with many drawbacks of using feedback for their L2 writing classes. One of the main problems is the class size that turns feedback into a burden. Thus, giving suitable feedback for a big class should be taken into consideration. For example, teacher A shared that: 
"Last semester I had three writing classes, one writing class consist of English major student and there is 40 of them.... it's okay for small classes but for a big class, it is very tiring because when I have a big class I have to mark and give feedback to all of them... it is very tiring and I have many other things to do other than teaching so it's quite stressful".

Secondly, teachers think that it is time-consuming to use feedback in their classes and it can affect their teaching syllabus. Since Vietnamese classes normally have more than 30 students, these teachers read, located errors, gave feedback, and asked students to revise their writing. Both teachers had to train their students to give and receive peer feedback and self-feedback, as well as distinguish symbols and codes when they wanted to use indirect coded feedback for their classes. Therefore, teachers cut their lessons shorter to give time for feedback training. Thirdly, it is difficult to say which type of feedback is more effective than the others because of different backgrounds, language proficiency levels, cognitive engagement, or autonomy levels. Teacher A stated that:

"I think that all kinds of feedback are useful in one way or another so it depends completely on the student so it can be individual. It can be the learning style, which can be the student's English level...everything that can give us the correct decision... whether what kind of feedback is useful for what type of student but it varies actually".

The two teachers also gave their perceptions of the benefits and drawbacks of using direct feedback, indirect feedback, indirect coded feedback, self-feedback, and peer feedback for second language writing. Firstly, both of them agreed that direct feedback was suitable for low language proficiency students. Teacher A mentioned that "it usually depends on the student so if these are weak student I give them direct feedback, I write directly the mistake above their errors so they can recognise their errors straight away". However, direct feedback can negatively affect students' psychological aspects. For instance, teacher B stated that students felt "demotivated" and "disappointed" when many mistakes were crossed out and corrected. They also believed that direct feedback would be time-consuming for big classes if they had to detect all errors and give a correction to every students' writing. Teacher A said that "its okay for small classes but for big class it is very tiring because when I have a big class I have to mark and give feedback to all of them". This activity can cause stress or tiredness for teachers. Teacher A indicated her view several times that "after such a long time of teaching, I don't think that direct feedback could enhance students' writing progress, but it is really time-consuming". 
Secondly, in terms of indirect coded feedback, the teachers said that this type of feedback enhanced students' writing performance because students had to work again on their texts to find some solutions for a problem to get a higher score. Although the teachers focused on different aspects while using indirect coded feedback (teacher A focused on grammar and vocabulary, teacher B focused on grammar and ideas), they both revealed that indirect feedback was suitable for high language proficiency students. For example, teacher A stated that "I am lucky to have very good students, so they make mistakes by accident not by the low level of proficiency, so indirect feedback is suitable for them". Nevertheless, teachers had to train students for code definition before using indirect coded-feedback and it would influence their teaching schedule. Teacher A said she did not have time to explain all codes so she sometimes used a checklist to clarify these codes.

Thirdly, in terms of indirect un-coded feedback, they responded that it saved their time to "highlight simple errors for a big class" and students' writing would be improved if they could "remember their correction and revisions". Teacher B stated that "students have to revise their writing many times to get the right answers for their errors". However, teacher A and teacher B shared the same idea that this type of feedback was difficult for low language students. According to their teaching experiences and observations, low language proficiency students were not able to revise their mistakes so they asked their teachers for more explanation. Teacher B said "I am around to explain the feedback for weak students who can't revise the errors".

In terms of self-feedback, they encouraged their students to use this type of feedback because it enhanced students' autonomy and reviewability. For example, teacher A mentioned in her interview that:

"I think it is a good thing for them to do because we will not be with them forever and this is the activity they will do in their normal life and daily life to improve their own writing".

Similarly, teacher B stated that:

"It's interesting for them to have a chance to evaluate their knowledge before and after the practice".

It is clear that high language proficiency students might have fewer difficulties in doing self-feedback than low language proficiency students. Moreover, this activity can take a lot of time if they have many weak students. Therefore, teachers can help less proficiency students to detect errors and check their corrections. For example, two teachers only asked their students to use self- 
feedback focusing on punctuation or word forms and they explained complicated errors such as grammatical structures.

Finally, they agreed that peer feedback could make students more active in interaction and discussion with their friends than with teachers. For instance, teacher A said that her students felt "more comfortable and more open to discussing with their peers". Similarly, teacher B believed that "peer feedback is a good way for students to learn from friends". Therefore, teachers hoped that students could improve their reviewers' ability, and then they could revise their texts. However, they have different views about which target learners benefit from peer feedback. Although teacher A recently created a Facebook group and asked her students to post their writing and practice giving and receiving peer feedback on that online tool, she stated that good students "seemed not to learn anything new from their peers". Therefore, she "consider using peer feedback in advanced classes". Similarly, teacher B preferred to use peer feedback for advanced learners and English-majors.

Overall, it seems that every type of feedback will have its advantages and disadvantages, so teachers should consider their target students, task requirements and class size as domain elements to wisely use direct feedback, indirect coded feedback, indirect un-coded feedback, selffeedback, and peer feedback in their L2 writing class.

\section{Students' perceptions of feedback}

This section presents the non-parametric statistics for three main features: students' response to feedback use, their preference, and expectations on feedback given in L2 writing from students' questionnaire in Week 1. Furthermore, students' perspectives on the advantages and disadvantages of self-feedback, peer feedback, direct feedback, indirect coded feedback, and indirect un-coded feedback will also be reported.

\section{Feedback use}

Descriptive statistics about students' perceptions of feedback use are presented in table 2. 
Table 2. Respondents'perceptions of feedback use

\begin{tabular}{|l|c|c|c|c|c|c|c|}
\hline & $\mathrm{N}$ & Median & Mode & $\begin{array}{c}\text { All of } \\
\text { it } \\
(3)\end{array}$ & $\begin{array}{c}\text { Most } \\
\text { of it } \\
(2)\end{array}$ & $\begin{array}{c}\text { Some } \\
\text { of it } \\
(1)\end{array}$ & $\begin{array}{c}\text { None } \\
\text { of it } \\
(0)\end{array}$ \\
\hline $\begin{array}{l}\text { The amount of teacher feedback that } \\
\text { students read over }\end{array}$ & 63 & 2 & 2 & $31.7 \%$ & $34.9 \%$ & $31.7 \%$ & $1.7 \%$ \\
\hline $\begin{array}{l}\text { The amount of teachers'comments } \\
\text { and corrections that students think } \\
\text { carefully about }\end{array}$ & 63 & 2 & 2 & $21.0 \%$ & $42.9 \%$ & $32.9 \%$ & $3.2 \%$ \\
\hline
\end{tabular}

The descriptive statistics of students'reactions to feedback they received in their L2 writing are reported in table 3.

Table 3. Students' reactions to feedback they received

\begin{tabular}{|l|c|c|}
\hline $\mathrm{n}=63$ & $\mathrm{~N}$ & Frequency \\
\hline Revised the writing and took into consideration teachers' feedback & 36 & $57.1 \%$ \\
\hline Read the grade and comments, and asked for clarification & 13 & $20.6 \%$ \\
\hline Read the grade and the comments, and discarded the paper & 10 & $15.9 \%$ \\
\hline Improved the writing with help of a home tutor or a peer & 4 & $6.4 \%$ \\
\hline Corrected the easy mistakes & 0 & $0.0 \%$ \\
\hline Only read the grade and discarded the paper & 0 & $0.0 \%$ \\
\hline
\end{tabular}

The descriptive statistics of the use of feedback in the L2 writing class indicated that most students read over their text when teachers returned it to them with $34.9 \%(n=22 / 63)$. Regarding teachers' comment use, nearly $42.9 \%(n=27 / 63)$ of students agreed that they always take most of the teachers' comments and corrections on their writing into serious consideration, while only $3.2 \%(2 / 63)$ completely ignored teachers' feedback. Similarly, the descriptive statistics of students , reactions to feedback they received in L2 writing showed that $57.1 \%(n=36 / 63)$ of the participants used teachers' suggestions to revise their writing; whereas, none of them only read the grade and discarded the feedback. It is clear that most students realize the importance of feedback in their L2 writing and seriously use it to make better revisions. 


\section{Students' feedback preferences}

Descriptive statistics about students' perceptions of feedback preferences are represented in table 4 .

Table 4. Respondents' perceptions of feedback preferences

\begin{tabular}{|l|c|c|c|c|c|c|c|}
\hline & N & Median & Mode & $\begin{array}{c}\text { Always } \\
(3)\end{array}$ & $\begin{array}{c}\text { More } \\
\text { than } \\
\text { twice } \\
(2)\end{array}$ & $\begin{array}{c}\text { Once } \\
\text { or } \\
\text { twice } \\
(1)\end{array}$ & $\begin{array}{c}\text { Never } \\
(0)\end{array}$ \\
\hline $\begin{array}{l}\text { How often would you like to } \\
\text { receive teacher feedback in English } \\
\text { writing course? }\end{array}$ & 63 & 3 & 3 & $69.8 \%$ & $25.4 \%$ & $3.2 \%$ & $1.6 \%$ \\
\hline $\begin{array}{l}\text { How often would you like to give } \\
\text { and receive peer feedback in } \\
\text { English writing course? }\end{array}$ & 63 & 1 & 1 & $19.0 \%$ & $28.6 \%$ & $39.7 \%$ & $12.7 \%$ \\
\hline $\begin{array}{l}\text { How often would you like to give } \\
\text { and receive self feedback in } \\
\text { English writing course? }\end{array}$ & 63 & 2 & 2 & $20.6 \%$ & $55.6 \%$ & $19.0 \%$ & $4.8 \%$ \\
\hline
\end{tabular}

Students were asked to rate on a scale of four choices (never, once or twice, more than twice, always) how they would like to give and receive peer feedback and self-feedback. The findings show that $39.7 \%(\mathrm{n}=25 / 63)$ respondents would like to get peer feedback "once or twice" in their writing course while $55.6 \%(\mathrm{n}=35 / 63)$ wanted to give and receive self-feedback "more than twice". In terms of teachers' feedback, the numbers of students chose "always" and "more than twice" for receiving feedback from their teachers at $69.8 \%(n=44 / 36)$ and $25.4 \%(n=16 / 63)$ respectively. The findings indicate that students would like to get teacher feedback, followed by self feedback and peer feedback in their L2 writing class.

\section{Students' expectations of teacher feedback}


Descriptive statistics of respondents'expectations on teachers' focus on feedback, preferences for the focus of feedback and preferences for the amount of feedback can be seen in table 5, table 6 and table 7 .

Table 5. Respondents'expectations on teachers'focus on feedback

\begin{tabular}{|l|c|c|}
\hline $\mathrm{n}=63$ & $\mathrm{~N}$ & Frequency \\
\hline Giving the mark only & 0 & $0.0 \%$ \\
\hline Suggesting error correction only & 0 & $0.0 \%$ \\
\hline Providing comments on the content only & 0 & $0.0 \%$ \\
\hline Giving a mark and providing comments on the content & 0 & $0.0 \%$ \\
\hline Suggesting error correction and providing comments on the content & 6 & $9.5 \%$ \\
\hline $\begin{array}{l}\text { Giving a mark, suggesting error correction, and providing comments } \\
\text { on the content }\end{array}$ & 57 & $90.5 \%$ \\
\hline
\end{tabular}

Table 6. Respondents' preferences for the focus of feedback

\begin{tabular}{|l|c|c|}
\hline $\mathrm{n}=63$ & Number of students & Frequency \\
\hline Grammar & 53 & $84.1 \%$ \\
\hline Vocabulary & 9 & $14.3 \%$ \\
\hline Spelling & 1 & $1.6 \%$ \\
\hline Punctuation & 0 & $0.0 \%$ \\
\hline Others & 0 & $0.0 \%$ \\
\hline
\end{tabular}

Table 7. Respondents' preferences for the amount of feedback

\begin{tabular}{|l|c|c|}
\hline $\mathrm{n}=63$ & $\mathrm{~N}$ & Frequency \\
\hline All the errors & 46 & $73.0 \%$ \\
\hline Most of the errors & 10 & $15.9 \%$ \\
\hline A few of the errors & 7 & $11.1 \%$ \\
\hline None of the errors & 0 & $0.0 \%$ \\
\hline
\end{tabular}


When asked about the aspects that teachers should focus on, 57 out of 63 students (90.5\%) responded that they hoped their teacher to not only give a mark but suggest error corrections and provide constructive comments on the content. Furthermore, although most of the students stated that they wanted teachers to focus on grammatical structures, they also believe that vocabulary and spelling (at $14.3 \%$ and $1.6 \%$ respectively) should be considered as problems that caused bad writing. In terms of numbers of errors that students would like their teachers to react to, the answers are "all the errors", "most of the errors", and "a few of the errors" with the proportions of $73.0 \%$, $15.9 \%$, and $11.1 \%$ respectively. It can be seen that most students expect their teachers to identify every error.

In the table 8 , the statistics of respondents' expectations on teachers' comments are shown.

Table 8. Respondents' expectations on teachers' comments

\begin{tabular}{|l|c|c|}
\hline $\mathrm{n}=63$ & $\mathrm{~N}$ & Frequency \\
\hline Only Negative aspects & 0 & $0.0 \%$ \\
\hline Mainly Negative aspects & 5 & $7.9 \%$ \\
\hline Both Negative and Positive aspects & 56 & $88.9 \%$ \\
\hline Mainly Positive aspects & 2 & $3.2 \%$ \\
\hline Only Positive aspects & 0 & $0.0 \%$ \\
\hline
\end{tabular}

Finally, students expect teachers to give comments and suggestions on both negative and positive aspects. The data showed that 56 students $(88.9 \%)$ would like to read both negative and positive comments, whereas only a few students expected to get mainly negative feedback or mainly positive feedback, at $7.9 \%$ and $3.2 \%$ respectively.

\section{Students' perceptions of the advantages and disadvantages of self-feedback}

According to the respondents, four main themes reflect the advantages of using selffeedback for L2 writing classes. First of all, ten students believed that self-feedback can enhance their learning autonomy. For example, two students said "it is good for self-study" or another student stated "I can not ask my friends or teachers so I have to try hard to check my writing, I think it is good for my language learning". Secondly, twelve students believed that self-feedback has positive psychological aspects. For example, they felt "comfortable", "more confident", "more private", "motivated", "productive" and "more conscious" when they checked, identified errors, 
and gave possible solutions for their problems. Thirdly, twenty-four students believed that selffeedback helps students improve their writing in a long term. The students agreed that they tried to remember the old errors to make better revisions. One student said that "if I can use self-feedback successfully, my syntactic will be improved". Finally, a few students mentioned that self-feedback could encourage students' metacognitive learning. They believed that finding their own mistakes was truly difficult so they had to engage in the texts and check them several times. Finally, selffeedback can be one of the special types of feedback that improves students' reviewing ability. Four students mentioned that they could evaluate their writing styles as well as identify their strengths and weaknesses in English writing.

On the other hand, students also mentioned some disadvantages with using self-feedback. The biggest problems of this feedback are its quality and accuracy. As most students had to work individually without teachers' or peers' assistance, they would "hesitate to give corrections". More than 40 students did not trust in their feedback and they wanted someone to check it again.

Secondly, students can find it hard to locate or revise some errors by themselves due to their low language proficiency level. One student thought that "my language proficiency is low, so I was not able to locate my errors" and another said "In some cases, although I can find out my errors, I do not know how to replace them, my English is not that good". Thirdly, struggles can negatively affect students' emotions as well as language improvement. For example, two students mentioned that if they could not revise their texts, they would feel "confused and demotivated". Another student said that "I repeated the same mistakes that I had made in the previous texts". As a result, even if students appreciate the positive outcomes of self-feedback, they still need extra support such as training or guidelines to use it more effectively.

\section{Students' perceptions of the advantages and disadvantages of peer feedback}

Many students expressed their opinions on the advantages of using peer feedback for L2 writing. Firstly, peer feedback creates a perfect platform for students to collaborate in learning. For example, twenty-four students said they could "exchange feedback with their peers", "discuss common problems inside and outside the classroom", "easily ask for explanations", "interact sufficiently with each other", " share ideas", or "improve teamwork". Second, thirty students assume that peer feedback can enhance their English writing. Two students said that they could improve their "lexical knowledge", and "grammatical rules" by asking other students who had 
more experience or higher levels of language proficiency. Peer feedback is also suitable for low language proficiency students because they are more open to asking their friends than teachers. Five students stated that they could "avoid losing face", and eleven students said they "feel comfortable" when discussing with their friends who shared the same low-language proficiency and faced with the same problems. Besides, students' critical evaluation skills can be developed by using peer feedback because the activity of giving and receiving feedback triggers their cognitive engagement. One student said that "we feel closer and more comfortable when discussing with each other. I and my friends can learn from each other and our writing will be better. We can avoid making the same mistakes in our next writing". As a result, their ability of reviewing is also upgraded.

However, some disadvantages of using peer feedback were also reported from students' opinions. The first problem of peer feedback is that some students' autonomy can be influenced negatively. Five students pointed out that they would likely "depend on their friends" for detecting or revising error forms. As a result, they are not willing to work hard on their text and wait for their peers to do their job. Similarly, one student did not feel motivated to work hard on their papers when some friends could take that "hard job". Secondly, language proficiency level could affect the quality of this type of feedback. One student stated that "We do not have enough knowledge about English writing" and another said "it will be difficult for me to discuss or work with someone who has a lower level of language proficiency". Another student said "if two low language proficiency students work together, they can not help each other to find or correct their errors". However, if the gap between students' language proficiency were big, they might have disagreements or misunderstandings. Thus, they still need teachers or peers who have high language proficiency levels to double-check their corrections. In the long term, students' writing skills will be affected if they receive unqualified feedback from peers. For example, forty-seven students indicated that they "did not trust peer feedback accuracy", and twenty-two students also mentioned that "low language proficiency students could give incorrect feedback on their texts". Finally, in terms of psychological aspects, two students felt "confused", fifteen students felt “dissatisfied" because they "can not trust my peers", or one students felt "embarrassed" because many friends could read their writing and judge them.

\section{Students' perceptions of the advantages and disadvantages of direct feedback}


Teachers commonly use direct feedback in writing classes; however, it has both benefits and drawbacks that should be taken into consideration. Firstly, students believe that their revisions are more accurate based on teacher direct feedback. Sixteen students said that they saved a lot of time for revisions because teachers helped them locate errors and suggested correct forms. Second, students think that their vocabulary and grammatical structures are improved. One student believed that direct feedback was "clear, understandable and reliable so I knew how to correct the old texts and revise them effectively" . Thirdly, direct feedback can help students to understand their task requirements and make revisions in a short time. Eight students expressed that direct feedback was "time-saving", and one said she "understand task's requirements easier" without asking teachers for explanations. Twenty students mentioned that they used direct feedback for revising their drafts and correcting grammatical errors at once. Finally, six students agreed that direct feedback was suitable for low language proficiency students regarding grammatical errors at once. One students said that "I can easily locate my errors. It helps me a lot because my language proficiency level is low".

Nevertheless, a group of students think that direct feedback can negatively affect students' learning autonomy in the long term, overwhelm them with too many errors and consume a lot of their teachers' time. First of all, five students said that they "passively depended on their teachers" because they did not feel motivated to know why they made mistakes. Thus, their learning autonomy level witnessed a dramatic decrease. Moreover, students were overwhelmed by many corrections and errors. Four students revealed that they could not remember all errors so they repeated making them several times. One student stated that "I usually correct my errors straight away after getting this feedback. Although I can revise my drafts really fast, I do not pay much attention to all of my errors. There are too many of them. I realize that I make some errors over and over again". Finally, direct feedback is time-consuming for teachers from students' perspectives. One student said that "giving direct feedback to a big class is quite stressful for my teachers" while another mentioned that "if I do not understand why I made the mistakes, I will ask my teacher again...So my teacher has to work on my text again". Hence, students agreed that teachers work hard before and after giving direct feedback.

\section{Students' perceptions of the advantages and disadvantages of indirect coded feedback}


From students' views, indirect coded feedback can have some advantages for their learning. First of all, students believe that their language ability is improved in the long term by using this type of feedback. For example, ten students said that indirect coded feedback can "enhance students' writing skills", "gain good experiences in revisions", "distinguish error forms", and "remember mistakes consistently". Moreover, students also stated that indirect coded feedback enhances their learning autonomy. Three students mentioned that they had to "understand the codes", "try to find possible solutions", and "revise their writings by themselves before checking the answer with teachers or peers". Thus, they also developed their self-study skills in learning new strategies. Finally, some students stated that indirect coded feedback is good for their cognitive engagement. Eight students stated that they revised and then met the teacher for suggestions and more explanations. As a result, they can clarify their strengths and weaknesses in writing in order to perform better in up-coming tasks.

Students also identified some disadvantages of using indirect coded feedback on L2 students' writing. Firstly, the psychological aspects of students can be affected strongly. Twentyone students answered that they felt "stressed", "depressed", "anxious", and "demotivated" when their teachers used indirect coded feedback. One student explained that she had tried to understand the feedback, but "fail to correct them based on the codes". This problem leads to discouragement in learning. Secondly, this feedback can be time-consuming for students because they need to understand the codes before using it appropriately. Six students agreed that they would have to discuss with peers or teachers to clarify the error types when they forgot the codes. Otherwise, they could misunderstand their teacher feedback and negatively affect their revisions. One of the students said that 'I can't remember all of my teachers' codes, it took me hours by hours to know the forms of errors and I usually give wrong answers for my errors". Finally, ten students believe that indirect coded feedback should be used for treatable errors which were not too advanced or difficult for them to revise. For example, one student felt that he did not "have the knowledge to correct certain errors which were too advanced". Another said "I have learnt about relative clauses for four to five years, but I still struggled with this grammatical structure. When my teacher marked " $R C$ " on my errors, I know I made errors related to relative clauses, but I could not correct them".

Students' perceptions of the advantages and disadvantages of indirect uncoded feedback 
On the one hand, indirect uncoded feedback can reduce the workload for both teachers and students in writing. In two students' opinions, while teachers only underlined errors without giving suggestions, students can identify the location of their mistakes immediately. Moreover, this type of feedback can trigger their learning autonomy. Two students felt "productive", "motivated" and "curious" when they worked on the texts several times to find the solutions. Six students believed that their language ability would be enhanced consistently because they could remember the mistakes and avoid making them in their future writings. One student said "understanding this feedback and revising my errors are really challenging, but I usually remember them and rarely make the same mistakes again". Finally, students' capacity in learning language engagement can be developed. One student mentioned "When I can correct some errors after spending several hours on them, I will be more aware of making them in the future". Hence, students would be more aware of making the same mistakes because they learned from their experiences.

On the other hand, both low language proficiency and high language proficiency students can struggle with indirect uncoded feedback. Thirteen students believed that this type of feedback was "too difficult" and "not clear" so they were not able to identify the suitable forms. Hence, students avoided making revisions. One student said "my English is not good. Sometimes, my teacher only underlined some words or some sentences. I did not know why she just underlined them, I could not revise them". Moreover, twenty-four students reported that they had to spend a lot of time to understand the feedback and fix their errors. One student said that he "wasted time for this type of feedback", but he could not revise his errors.

\section{Similarities and mismatches in students' and teachers' perceptions of feedback in L2 writing}

From students' surveys and teachers' interviews, the researcher can derive the similarities and mismatches between students' and teachers' perceptions of feedback in L2 writing.

\section{Similarities}

Regarding the general perspectives, students and teachers agree that feedback is an important element for learning and teaching second language writing. They believe that feedback will serve to enhance learners with positive outcomes in writing ability, psychological aspects, cognitive engagement. First of all, perceptions of teachers and students match in terms of the 
effectiveness of feedback in enhancing students' writing ability in the long term. In terms of indirect coded feedback, while the two teachers were in agreement that students could remember their mistakes and avoid repeating them, ten students said that this feedback can "enhance students' writing skills", and "remember mistakes consistently". Secondly, using feedback in writing can boost students' cognitive engagement. The two teachers mentioned that students were "cooperative to discuss problems with teachers and peers". They also found self-feedback useful in engaging students' cognition when they reviewed and revised their drafts. Similarly, the students mentioned that they paid more time and engaged in detecting errors and revising their texts. Eight students stated that they revised their mistakes by using indirect coded feedback and then met the teacher for suggestions and more explanations. Finally, although using feedback in a big class is time-consuming, both teachers and students believe that indirect uncoded feedback can save time. For example, teachers said that indirect uncoded feedback could reduce their workload because they only highlighted the errors and asked students to revise them. Two students stated while teachers only underlined errors without giving suggestions, students can identify the location of their mistakes immediately.

Teachers and students also agree that using feedback in their L2 writing classes can bring some drawbacks. Firstly, some students agree that teachers should consider the target learners' language proficiency level to select suitable types of feedback. They stated that not all students could use indirect coded feedback and indirect uncoded feedback effectively, and low language proficiency students faced many problems while dealing with these types of feedback. For instance, one students said that 'I can't remember all of my teachers' codes, it took me hours by hours to know the forms of errors and I usually give wrong answers for my errors". Similarly, thirteen students stated that indirect uncoded feedback was "too difficult" and "not clear" for them to find the correct forms. One student said "my English is not good. Sometimes, my teacher only underlined some words or some sentences. I did not know why she just underlined them, I could not revise them". Both teachers said that they only use indirect feedback for advanced students. For example, teacher A stated that "I am lucky to have very good students, so they make mistakes by accident not by the low level of proficiency, so indirect feedback is suitable for them". However, teacher A and teacher B shared the same idea that this type of feedback was difficult for low language proficiency students. According to their teaching experiences and observations, low language proficiency students were not able to revise their mistakes and they would contact their 
teachers for more explanation. Teacher B said "I am around to explain the feedback for weak students who can not revise the errors". They believed that supervision and appropriate suggestions were necessary for learners with low proficiency levels. Furthermore, using direct feedback in L2 writing classes can be time-consuming for a big class and negatively affect both students' and teachers' psychology. Teachers believed that giving direct feedback consumed their time and caused stress. Meanwhile, five students felt "passively depend on their teachers" if teachers only used direct feedback.

\section{Mismatches}

Although students and teachers share some agreement in certain areas, their opinions about some types of feedback are somehow different from each other. In terms of direct feedback, while teachers think that direct feedback could not help improve students' writing performance, most students preferred their teachers to use direct feedback because they were able to understand errors and revise their texts. For instance, one student said that "direct feedback was clear, understandable and reliable so I knew how to correct my old texts and revise them effectively".

Unlike teacher feedback, peer feedback is used frequently among students to improve their writing ability through peer interactions. For example, two teachers believed that students could improve their review ability, and then they could learn from each other to make better revisions. However, many students indicated that they did not trust their feedback accuracy and their writing skill could be affected if they receive inaccurate feedback from peers in a long term. For example, forty-seven students indicated that they "did not trust peer feedback accuracy", and twenty-two students also mentioned that "low language proficiency students could give incorrect feedback on their texts". As a result, they hesitated to revise or learn from the revisions which might negatively affect their writing in the long term, this is a mismatch between students' and teachers' perspectives.

When the researcher asked two teachers about feedback, they both agreed that "training students for self-feedback and peer feedback was important in their class". In addition, teachers stated that the peer feedback and self-feedback would only be successful in students' L2 writing development if teachers spent extra time to support their students. However, the students who participated in this study had not experienced feedback training with the two teachers due to the 
coronavirus. Therefore, the students' responses could be related to their old experiences in L2 writing classes that did not provide appropriate training for giving and receiving feedback. 


\section{CHAPTER 5: DISCUSSION}

The primary aim of this study was to investigate the students' and teachers' perceptions about using feedback in second language writing. In the following sections, the main outcomes with regards to the research questions will be briefly discussed.

\section{Students' confidence and teacher feedback}

As expected, the results of this study showed that both teachers and students agreed teacher feedback for L2 writing was an important element to enhance learners with positive outcomes in psychological aspects. For example, both teachers and students believed that using different types of feedback could help students perform better in second language writing. Similarly, students spent extra time on their papers because they appreciated their teacher feedback and felt "motivated". Thus, they believed that using appropriate types of teacher feedback could boost students' confidence to improve their writing skills in the long term.

In this study, the findings show that there are three main reasons to explain the gain of students' confidence by using teacher feedback. First of all, students felt confident because they could distinguish their strengths and weaknesses in their writing. Agbayahoun (2016) argued that the majority of students feel dissatisfied and hold negative impressions on teachers' feedback because they feel discouraged, confused, and overwhelmed by excessive feedback.

However, the findings in this study support Sharif and Zainuddin's (2017) study that students were more confident about the revision because they could identify their strengths and weaknesses in writing. For example, ten students in the study said that indirect coded feedback helped them "enhance writing skills", "distinguish error forms", and "remember mistakes consistently". Besides, the two teachers mentioned that students were "cooperative to discuss problems with teachers". It is also in line with Nordin et al. (2010) that sixty-nine engineering undergraduates from Malaysia could understand the task's requirements after receiving teacher feedback (indirect uncoded feedback). They felt more confident in their writing because they were able to avoid the same mistakes and revise them more accurately. Similarly, Ruegg (2018) found that students would reduce their embarrassment and feel more confident in their writing if they got more practice in using peer feedback in the long term. 
It is clear that drawing students' attention to specific strengths and weaknesses can potentially boost their confidence and improve their future performance. Hence, teachers should focus on supporting students' strengths through positive comments and suggesting appropriate methods to help students improve their weak points in writing. Similarly, other studies showed that the feedback which could identify students' strengths and weaknesses could positively enhance their confidence in revising their work or correcting their errors in L2 writing (Nordin et al., 2010; Sharif \& Zainuddin, 2017; Sritrakarn, 2018). It can be beneficial for students to write a short self-reflection essay for their first draft which can highlight their strong and weak points in writing by themselves. This suggested way can also save time for teachers who have to give feedback for a big class as well as encourage students to view their weaknesses as an inevitable element to learn a new language. Furthermore, if any students are not able to improve their weaknesses, teachers can ask them to make online or offline appointments with a school tutor for deeper clarification.

Secondly, both positive and negative aspects should be considered to enhance students' self-confidence in future writing. This study found that 56 students $(88.9 \%)$ would like to read both negative and positive comments, whereas only a few students expected to get mainly negative feedback or mainly positive feedback, at $7.9 \%$ and $3.2 \%$ respectively. Thus, the combination of positive and negative aspects of teacher feedback is recommended. This finding supports Tom et al. (2013) that students valued both negative and positive comments and expected to receive them on their texts. Students believed that negative comments were a challenge that pushed them to perform better in their future writing while positive comments showed students what they had done well.

However, some studies revealed that students' confidence in L2 writing would be affected by teachers' negative comments. Zumbrunn, Marrs, and Newborn (2016) stated that feedback could link to positive emotional reactions as pride, motivation, or happiness. Similarly, students seemed to read positive feedback that could make them feel good about themselves or pointing out their strengths. Unlikely, students might dislike negative aspects if they thought that teacher feedback was too critical (Caffarella \& Barnet, 2000). This belief is in line with Zumbrunn, Marrs and Newborn (2016) that teacher feedback is associated with negative psychologies such as unhappiness, embarrassment, and anxiety. 
Caffarella and Barnet (2000) stated that students felt more confident if they received ongoing feedback. In reality, giving feedback focusing on negative aspects to help students improve their writing is necessary. However, teachers should be careful about the tone of their feedback by using critical comments after using positive ones, and find a gentle approach to give serious mistakes. Teachers should understand that some students are not able to control their emotions towards critical feedback and they also require additional supports. Hence, teachers can train students to give and receive feedback over a period of time to help them improve their selfconfidence when they get negative feedback. It is suggested that teachers can give critical comments with suggestions on how to fix mistakes such as metalinguistic feedback.

Thirdly, the amount of teacher feedback can also affect students' confidence. Zacharias (2007) showed that the amount of teacher feedback can affect students' feelings about their writing performance. In this study, most students $(n=22 / 36)$ read their teacher feedback and took it into consideration for better revisions. Moreover, $69.8 \%$ and $25.4 \%$ of students expected to receive "always" and "more than twice" teacher feedback in their writing respectively.

Moreover, students believed that they could make better revisions if they got more teacher feedback which was described as "clear", "understandable" and "reliable". These findings indicated students preferred teacher feedback and they also felt more confident about their writing on which they receive more amount of teacher feedback. It was in the same line with Ruegg and Koyama (2010) that students who received more teacher feedback on their assignments felt more confident in their final draft than those who got less teacher feedback. Similarly, some scholars found that the amount of teacher feedback in students' L2 writing could influence students' confidence which was one of the vital elements in their developing writing performance (Agbayahoun, 2016; Bratkovich, 2014; Pearson, 2018).

However, teachers should be careful to not give excessive feedback which can overwhelm students. It is suggested that teachers should mainly focus on certain aspects that match students' expectations instead of covering everything (Aliakbari \& Raeesi, 2014). Teachers should keep in mind that if students can understand the feedback they get, they do not view teacher feedback as a burden. Then, they can ask students to work in a small group to give and receive feedback for a better understanding. Moreover, teachers should try to avoid giving too short comments which can make students confused (Sharif \& Zainuddin, 2017). This study did not focus on teachers' and students' perceptions of the amount of feedback giving in L2 writing. Thus, further studies can 
consider investigating this issue to help teachers provide an appropriate amount of feedback on students' writing.

Students' confidence in making writing progress will be boosted if they recognize the value of teacher feedback on their papers. It may be useful if teachers can ask students to write short self-reflection essays to identify their strengths and weaknesses, following by teachers' feedback and suggestions. Besides, teachers should be aware that individual students can react to negative feedback differently (Caffarella \& Barnet, 2000; Sharif \& Zainuddin, 2017). Therefore, teachers should give positive comments before critical ones. They also should give students enough time to understand that negative feedback is a good way to learn another language.

Finally, if students feel more confident about their writing ability, they be willing to revise their texts and appreciate their teachers' feedback. Meanwhile, students' cognitive engagement and autonomy are also developed, which is necessary for their writing improvement (Tai, Lin \& Yang, 2015). In fact, there are many different aspects that can affect students' confidence in L2 writing; thus, future studies can consider focusing on these elements to enhance students' confidence as well as their writing ability.

\section{The time-consuming nature of giving and receiving feedback}

The study found out that both teachers and students experienced negative psychological aspects after spending too much time on feedback in L2 writing classes. For example, one of the teachers stated that Vietnamese classes normally had more than 30 students, and these teachers had to read, locate errors, give feedback, and ask students to revise their writing. As a result, feedback turned into their burdens and affected their teaching syllabus due to the time limit.

On the other hand, students who participated in this study said that they felt stressed, demotivated, depressed, or anxious when they had to understand the feedback; and failed to locate or revise their texts after spending a great amount of time on their feedback. It has been argued that giving excessive feedback made a burden on teachers' workload (Atmaca, 2016; Hartshorn, Evan, \& Tuioti, 2014; Mahmud, 2016; Pearson, 2018); furthermore, an inappropriate amount of teacher feedback in the classroom could cause students' anxiety (Agbayahoun, 2016; Bratkovich, 2014). Thus, identifying benefits and drawbacks of different feedback types can help teachers reduce their heavy workload and help students improve their L2 writing. 
In this study, teachers believed that spending too much time on giving feedback for many students in a short time led to their excessive workload. One teacher stated that "there are 40 of them, it's okay for small classes but for a big class, it is very tiring... because when I have a big class I have to mark and give feedback to all of them... it is very tiring and quite stressful". In addition, two teachers stated that using feedback for a big class affected their teaching syllabus because they took the time to train students to distinguish symbols using indirect coded feedback.

These findings support Mahmud's (2016) study and also suggest that giving suitable feedback for a big class should be taken into consideration. Lee, Mak, and Burns (2016) also examined teachers' beliefs towards giving feedback in writing classes. Two teachers who were native speakers of Cantonese took part in this research and expressed that they had faced many challenges in applying new types of feedback (indirect coded feedback and focused feedback) in their classes. They had limited time within a prescribed curriculum which discouraged them from using new feedback approaches. Nevertheless, teachers had to train students about code definition before using indirect coded-feedback and it influenced their teaching schedule. Similarly, Wei and Yanmei (2018) examined the changes in teacher feedback practices in a university in China and they found that the teachers perceived feedback as time-consuming. These interviewees had to minimize the time offering feedback for individual students to maintain effective teaching which strictly followed the objectives in the school curriculum.

It is clear that giving teacher written feedback for a big class with too many students is truly time-consuming; therefore, teacher written feedback approaches need to be changed. In terms of high language proficiency students, this study suggests that teachers should consider using a checklist to clarify codes and task requirements if they want to use indirect coded feedback, selffeedback, and peer feedback in their limited timeframe. This study also recommends teachers to use direct feedback to short pieces of written work such as paragraphs or short essays to help low language proficiency students detect errors and improve their writing accuracy.

In this study, eight students expressed that direct feedback was "time-saving" since they did not need to spend much time on locating and correcting their errors, and one responded that direct feedback helped her "understand the task's requirements easier" without asking teachers for explanations. Unfortunately, direct feedback can be time-consuming for teachers who have to mark, locate, and give correct error forms. Therefore, teachers can consider using peer feedback for their students' first drafts, followed by teachers' direct feedback in the final drafts. By using 
this approach, teachers can reduce their workload and make feedback more interactive and timely. Since this study only focuses on perceptions, future studies can investigate the effectiveness of using teacher feedback and peer feedback in Vietnamese writing contexts.

Although students expected to receive teacher feedback on their papers, they also expressed negative psychological aspects due to spending a great amount of time on feedback. In this study, nearly half of students agreed that they took most of the teachers' comments and corrections on their writing into serious consideration. However, twenty-one students felt "stressed", "anxious", and "depressed" when they spent too much time on indirect coded feedback. They explained that they had tried to understand the feedback, but they "fail to correct them based on the codes". For example, one of the students said that 'I can't remember all of my teachers' codes, it took me hours by hours to know the forms of errors and I usually give wrong answers for my errors". Meanwhile, twenty-four students reported that they had to spend a lot of time to understand the indirect uncoded feedback and fix their errors. One student stated that he "wasted time for this type of feedback", but he could not revise the errors. This negative belief can lead to discouragement in students' learning.

It has been argued that if instructors want students to appreciate written feedback and invest their time in the revisions, the feedback should meet the students' demands (Aliakbari \& Raeesi, 2014; Rummel \& Bitchener, 2015). In this study, 90.5\% of students responded that they hoped their teacher to not only give a mark but provide error corrections and constructive comments on the content. The results support Sharif and Zainuddin's (2017) study in which ESL medical students preferred more feedback comments on different aspects than short comments and infrequent feedback.

Furthermore, most of the students in this recent study stated that they wanted teachers to focus on grammatical structures, they also believed that vocabulary and spelling (at $14.3 \%$ and $1.6 \%$ respectively) should be considered to improve their writing performance. These findings contradict Truscott's (1996) argument that all grammar correction should not be used in second language writing classes. It is important to guide students on how to revise their work which could be based on feedback (Ferris, 2002) and grammatical errors are commonly made by students in this study. Although giving the correct forms of grammatical structures and useful comments can save students time for making revisions, excessive feedback can overwhelm students as well as increase teachers' workload. 
It is suggested that teachers can ask students to use self-feedback and peer feedback to correct simple grammatical errors. As a result, students can increase their autonomy and interaction which are important for their learning progress (Diab, 2015). In addition, teachers should train students to be more familiar with some types of feedback which require students' cognitive engagement and self-review, such as peer feedback and self-feedback (Cho \& Park, 2019; Ellis, 2009). As a result, students' learning autonomy and confidence will be developed.

Moreover, teachers should ask their students about which language features they would like their teachers to focus on. For example, in this study, most students wanted their teachers to focus on grammar instead of vocabulary. Using focused feedback can both save time for teachers, avoid overwhelming students with excessive corrections and enhance students' grammatical accuracy in L2 writing (Sheen, Wright \& Moldawa, 2009). Moreover, low language proficiency students may find indirect coded and indirect uncoded feedback difficult to understand. Thus, teachers should carefully explain or train students about these types of feedback. In some cases, teachers can consider using indirect coded and indirect uncoded feedback for treatable errors such as tenses and articles in students' writing so students have a chance to do self-correction in L2 writing.

Giving feedback is time-consuming, but it can be the most significant investment of writing instructors. Tang and Liu (2018) found that students appreciated their teachers' time and efforts when providing feedback, so they were willing to spend more time on revising their work in order to improve their performances. It is unavoidable that students will make errors in their writing development process, and feedback is a fundamental requirement to reduce these errors.

\section{Using direct feedback for $\mathbf{L} 2$ writing}

The study indicates that most of the learners preferred direct feedback to enhance their grammatical accuracy in writing the target language forms. However, they also believed that this type of feedback could negatively affect their language learning progress in the long term. In terms of teachers' perceptions, although direct feedback was time-consuming, they still wanted to use it for students with low language proficiency levels.

\section{Direct feedback and impacts on low language proficiency learners' performance.}


The study's findings showed that many students preferred using direct feedback for their revisions and it helped them correct grammatical errors immediately. Sixteen students agreed that they saved a lot of time for revisions because teachers helped them locate errors and suggested correct forms. One student believed that direct feedback was "clear, understandable and reliable so I knew how to correct the old texts and revise them effectively". Therefore, they believed that their vocabulary and grammatical structures were improved significantly. Twenty students mentioned that they used direct feedback for revising their drafts and correcting grammatical errors at once. For example, one student said that "direct feedback was clear, understandable and reliable so I knew how to correct my old texts and revise them effectively".

Furthermore, in this study, two teachers and many students agreed that direct feedback was suitable for low language proficiency students. For instance, eight students expressed that direct feedback was "time-saving", and one said she could "understand the task's requirements easier" after receiving direct feedback. On the other hand, two teachers in this study believed that direct feedback was suitable for low language proficiency students because they could detect their errors immediately. Teacher A mentioned that using direct feedback could help weak students recognize their errors immediately. Six students agreed that direct feedback was suitable for low language proficiency students regarding grammatical errors at once. One students said that "I can easily locate my errors. It helps me a lot because my language proficiency level is low".

The findings support other studies that investigated students' perceptions of direct feedback as well as the positive effects of this feedback on students' writing accuracy in a short period (Baker \& Hansen Bricker, 2010; Boggs, 2019; Sheen, 2007). First of all, Ferris (2002) argued that low language proficiency students preferred direct feedback because their language proficiency of limited grammatical knowledge prevented them to self-correct their errors. Thus, students felt more comfortable to revise their writing if the correct forms were written in their script. In Mekala and Ponmani's (2017) study, 116 second year students with a low language proficiency level in India faced difficulties to use appropriate forms for basic grammatical features such as prepositions and irregular verbs in their L2 writing. The students suggested that direct feedback enhanced not only their grammatical accuracy but also their awareness of appropriate language structures immediately. Interestingly, all teachers in this study also preferred using direct feedback for low language proficiency learners' writings because they could help their students to learn specific grammatical structures. They agreed that direct feedback was time-consuming but they still wanted 
to use it because they believed that low language proficiency students were not able to correct the errors by themselves.

Moreover, Nguyen and Ishak (2018) interviewed 12 high school students in Malaysia and while six of them believed that indirect feedback was better than direct feedback, six other students said that direct feedback was very straightforward and clear. They believed that their written work was improved in the short term by receiving direct feedback because they could notice their grammar mistakes and spelling easily. These findings were in line with Bitchener (2008) who found that learners could locate and use the correct forms by teachers' feedback suggestions immediately without any delay and they felt that direct feedback was straightforward and easy to understand.

Some studies about the effectiveness of direct feedback on students' L2 writing revealed positive outcomes in students' writing accuracy. Sheen (2007) found that direct feedback helped students understand certain grammatical forms in learning L2 writing. Baker and Hansen Bricker (2010) recruited seventy-one students from different universities in the United States to participate in this study. The findings showed that direct feedback helped both native English and ESL learners to make faster and more accurate correction than indirect and hedged feedback. Boggs (2019) conducted a study to identify the effectiveness of direct feedback on the accuracy of ESL student's grammar in writing in South Korea. The results revealed that students experienced a significant and durable improvement in their grammatical accuracy in L2 writing.

\section{Direct feedback and Negative impacts in the long run.}

Although direct feedback can help students locate and make corrections straight away, it can also increase teachers' workloads and negatively affect students' psychological aspects in a long term. In this study, five students believed that they passively depended on their teachers because they can copy their teachers' corrections into their revisions. One student stated that " $I$ usually correct my errors straight away after getting this feedback. Although I can revise my drafts really fast, I do not pay much attention to all of my errors. There are too many of them. I realize that I make some errors over and over again". Thus, their learning autonomy level and the longterm learning process witnessed a dramatic decrease. Additionally, direct feedback was timeconsuming for teachers from both teachers' and students' perspectives. One of these students said that "giving direct feedback to a big class is quite stressful for my teachers" while another 
mentioned that "if I do not understand why I made the mistakes, I will ask my teacher to work on my text again". Hence, students agreed that teachers work hard before and after giving direct feedback. Similarly, teachers also believed that direct feedback was time-consuming and had negative impacts on students' long-term performance. For instance, teacher B stated that students felt "demotivated" and "disappointed" when many mistakes were crossed out and corrected. They also believed that direct feedback would be time-consuming for big classes if they had to detect all errors and give a correction to every students' writing. Teacher A said that "its okay for small classes but for big class it is very tiring because when I have a big class I have to mark and give feedback to all of them". This activity caused stress and tiredness for teachers. Teacher A had indicated her view several times that "after such a long time of teaching, I don't think that direct feedback could enhance students ' writing progress, but it is really time-consuming".

These findings were in line with other studies about the negative beliefs in using direct feedback on students and teachers in L2 writing classes. Nguyen and Rajeevnath (2016) investigated four English teachers' and 50 English-major students' reactions to teacher written feedback in Vietnam. The findings demonstrated that although most of the students wanted to receive direct feedback, the teachers believed that providing corrections all the time was not a good option. Therefore, these teachers wanted to give indirect feedback instead of direct feedback to active their students' engagement and improvement in the long term.

Similarly, Atmaca (2016) interviewed students and teachers in an advanced writing class in Turkey. The findings showed that direct feedback could be considered as "spoon feeding"and some intermadiate to advanced students did not want their teachers to correct all errors because it could stop their active engagement in the learning process. In Westmacott's (2016) study, four out of six students with high language proficiency level agreed that direct feedback made their learning passive and less meaningful, which affected their learning autonomy. It is clear that those who are willing to work on their texts to improve their languge proficiency will read and use direct feedback for their revisions. Meanwhile, those who are unlikely to invest their time on learning anything from the feedback may simply ignore the teachers' efforts. Therefore, teachers may be wasting their time for students who are not willing to learn from direct feedback.

There are three main aspects that teachers should take into consideration when they want to apply direct feedback into their writing class. Firstly, students who lack grammatical knowledge can locate and revise all of the errors in their writing immediately when receiving direct feedback 
(Baker \& Hansen Bricker, 2010). However, students who are willing to learn new things can find direct feedback demotivated; thus, teachers can use indirect uncoded feedback (underlining minor errors) instead of correcting everything in their writing (Jamalinesari et al., 2015; Nordin et al., 2010). Secondly, students who received direct feedback can show temporary improvements, but their full understanding and acquisition of the target language can be negatively affected. In fact, students prefer direct feedback because they can passively depend on their teachers (Westmacott, 2016) or merely copy the error corrections into their work. Shintani and Ellis (2015) stated that if students completely copied teacher feedback into their writing without questioning the causes of making particular errors, they would fail to engage in their future learning. Therefore, in the long term, teachers should slowly change their feedback practice from direct feedback to indirect feedback in order to help students independently work with their own errors.

Furthermore, teachers should focus on specific grammatical features instead of covering all errors to decrease their workloads. If teachers corrected more than one item at once, they could be tiring because of their heavy work and their students might also be overwhelmed because of too many errors (Bitcherner \& Knoch, 2009; Sung \& Tsai, 2014). Indeed, in the long term, using focused correction as well as correcting specific errors can enhance students' awareness of making the same mistakes in their writing (Ellis, 2009). Finally, teachers can use direct feedback for short pieces of written work such as paragraphs or short essays if they still want to cover all errors in students' papers. These short writings help teachers to complete their tasks and avoid spending too much time on locating errors and giving corrections for big classes.

Indirect uncoded feedback

According to the results, both teachers and students believed that using indirect uncoded feedback could increase learners' grammatical and lexical ability consistently because students could be involved in their learning process instead of depending on teachers' correction. However, they also held a belief that indirect uncoded feedback was not suitable for low language students who struggled to make revisions.

\section{Indirect uncoded feedback and development of students' language ability.}


The study revealed that the participants including teachers and students expected that indirect uncoded feedback could develop learners' language accuracy in the long term because of the following reasons. First of all, indirect uncoded feedback boosts students' cognitive engagement. For example, one student stated that he would be more aware of making the same mistakes that he had learned from his experiences. Secondly, students could be more involved in their learning process because they had to improve their revisions. Teacher B stated that "students have to revise their writing many times to get the right answers for their errors". Two students felt more "productive", "motivated" and "curious" when they worked on the texts several times to find the solutions. Thus, students believed that their language ability would be enhanced consistently because they could remember the correct word forms or grammar structures for their future writings.

These findings are in line with some researchers who preferred using indirect feedback because students could be independent on their writing skills (Lalande, 1982; Ferris, 2002) and develop their long-term language skills (James, 1998). Similarly, Chandler (2003) conducted a study on undergraduate students in East Asia. The findings showed that students felt that indirect uncoded feedback (underlining) helped them learn more correct words and forms. They also felt like a part of the learning process rather than passively receiving correction from teachers. Ji (2015) conducted a study on Chinese learners' perceptions of written feedback. The results showed that most students expected to receive indirect uncoded feedback and indirect coded feedback at $12.9 \%$ and $66.3 \%$ respectively. They believed that they could improve their language proficiency consistently because they were aware of their errors and engaged in improving their texts.

The results of this study also support other studies finding that indirect uncoded feedback in L2 writing can positively affect students' writing progress in the long term. Indirect uncoded feedback requires students to devote their time to critical reflection and try to find appropriate ways to revise their errors. Ahmadi, Maftoon, and Mehrdad (2012) investigated 60 university students in Iran in a period of seven weeks to identify the effect of teacher feedback on L2 writing. They found that an indirect uncoded feedback group performed better than a direct feedback group and a control group. It was in line with Ferris and Roberts (2001) who conducted their experiment on 72 university students in the United States and their findings showed that both indirect uncoded feedback and indirect coded feedback could improve students' writing accuracy and quality in their final paper. Norish's (1983) findings showed that while students faced difficulties in 
understanding and remembering codes when using indirect coded feedback, indirect uncoded feedback helped students reduce their written errors because the misconception between students and teachers about marking codes was eliminated. As a result, indirect uncoded feedback could increase students' language ability, especially grammatical and lexical accuracy.

Despite some positive aspects of learners' consistent language improvement, most students did not prefer using only indirect uncoded feedback in their writing. Ferris (1999) stated that if teachers believed that their students could manage their errors, they could use indirect uncoded feedback. Therefore, teachers should take students' language ability into consideration when using this type of feedback in an L2 classroom.

\section{Indirect uncoded feedback and low language proficiency students.}

This study revealed that not only students but also teachers believed that indirect feedback uncoded feedback could be not suitable for low language proficiency students because they feel unfamiliar to a wide range of grammatical rules due to their limited knowledge. For instance, teacher A and teacher B shared the idea that indirect uncoded feedback was difficult for low language proficiency students. According to their teaching experiences and observations, low language proficiency students were not able to revise their mistakes and they asked their teachers for more explanation. Likewise, thirteen students believed that this type of feedback was "too difficult" and "not clear" so they were not able to identify the suitable forms. In addition, twentyfour students reported that they had to spend a lot of time to understand the feedback and fix their errors. One students said he "wasted time for this type of feedback", but he could not revise the errors. As a result, L2 students felt that using indirect uncoded feedback without appropriate suggestions or explanations could not show a significant impact on their writing.

Similarly, Jodaie, Farrokhi, and Zoghi (2011) conducted research on 30 teachers and 100 intermediate students to understand their perceptions of teacher feedback on grammatical errors. They found that most teachers preferred to use direct feedback, $20 \%$ of them favored a combination

of indirect uncoded feedback and direct feedback, and only 6\% wanted to use only indirect uncoded feedback in their L2 writing class. Meanwhile, seventy-five students held a negative belief in the indirect uncoded feedback strategy because they wanted to get teachers' corrections. Zaman and Azad (2012) also investigated the feedback preferences of a group of university 
teachers and students in Bangladesh. The findings showed that the majority of students preferred their teachers to provide the correct forms instead of underlining errors only.

It is clear that low language proficiency students may hold a negative belief that indirect uncoded feedback can affect their revisions. They will feel difficult to revise their texts if they do not understand advanced or unfamiliar grammatical rules (Dam, 2018). Therefore, they need extra suggestions and explanation from teachers or peers to help them correct the errors instead of underlining only. However, students should be responsible for finding more information, figuring out what is wrong with their writing and trying different ways to correct their errors rather than depending on their teachers. By using indirect uncoded feedback, their cognitive learning will be enhanced considerably in the long term (Ferris \& Roberts, 2001). Thus, a combination of direct and indirect feedback in L2 writing classrooms can be beneficial for students instead of using indirect uncoded feedback only. For example, teachers should use direct feedback for untreatable errors which are difficult for students to work by themselves and indirect uncoded feedback for treatable errors such as singular and plural words, verb tense errors, and subject-verb agreement.

However, teacher indirect uncoded feedback will be beneficial for students without negatively affecting their psychological aspects if teachers know how to use it on L2 writing effectively. First of all, teachers should make sure that students know about the focused grammatical rules that teachers want to point out in their texts by using indirect uncoded feedback. As Ferris (1999) said teachers could use indirect uncoded feedback when they believed that learners could manage the errors. Otherwise, students would be demotivated and hesitate to make revisions. Secondly, the study suggests that teachers should not merely underline or circle errors, but they should clarify information or give guidance to help students make better revisions. Moreover, teachers should consider a combination of direct and indirect feedback in a suitable order to encourage students in revising. Diab (2015) suggested that teachers should give indirect feedback to motivate students' learning process in the first or second draft, but in the final draft for submission, teachers should use direct feedback. In some Asian coutries, students seem to avoid asking or expressing their misunderstanding to save face. Thus, teachers should encourage their students to ask or indicate their problems when using indirect uncoded feedback. This can help students improve their revisons and perform better in their final paper. Finally, low language proficiency students may be unfamiliar with indirect uncoded feedback so teachers should introduce and train their students how to work on this type of feedback. Cho and Park (2019) stated 
that when students countinuosly received a specific type of feedback, they were confident and willing to make revisions. When students understood the feedback and its effectiveness, they appreciated teacher feedback and felt more confident to correct the errors. Even if students made imperfect revisions, they would have learned from their mistakes in order to improve their learning process in the long term.

\section{Peer feedback}

Using peer feedback in the L2 writing classroom is a controversial topic that has been discussed in recent years. In this study, the findings from both students and teachers showed that peer feedback was considered as an important element for students' language improvement. In fact, using peer feedback could develop students' cognitive engagement in collaborative activities, boost their confidence in making revisions as a writer, and also learning from their review as a reader. However, like many other types of feedback, peer feedback would be less successful if teachers did not provide sufficient training to their students.

\section{Peer feedback and cognitive engagement.}

The study found that both students and teachers believed that peer feedback made them more confident in interaction and discussion. For instance, teacher A said that her students felt "more comfortable and more open to discussing with their peers". Similarly, teacher B believed that "peer feedback is a good way for students to learn from friends". In addition, teachers believed that students gain more opportunities to develop their reviewability and learn from friends. Unlike teacher feedback, peer feedback was used frequently among students to improve their writing ability through peer interactions. Likewise, twenty-four students came up with advantages of peer feedback as a platform for student collaboration. For example, the students said they could "discuss common problems inside and outside the classroom", "easily ask for explanations", "interact sufficiently with each other" or "improve teamwork". Five students stated that they could "avoid losing face", and "feel comfortable" when asked their friends who shared the same language proficiency and faced the same problems; thus, they felt confident in their L2 writing. Lastly, students' critical evaluation could be developed by using peer feedback because it triggered their cognitive engagement. One student said that "we feel closer and more comfortable when 
discussing with each other. I and my friends can learn from each other and our writing will be better. We can avoid making the same mistakes in our next writing”. By interacting with peers, students can feel confident in their writing because they understand that everyone struggles with this skill. Therefore, they can accept their weaknesses and try to improve them instead of being demotivated.

These findings were in line with some previous studies which investigated students' perceptions of peer corrections in L2 writing. Miao, Badger, and Zhen (2006) revealed that students preferred teacher feedback to peer feedback in writing. They also found that 38 students showed significant improvement after they experienced peer feedback by asking questions and discussing problems related to their writing with their peers. Meanwhile, Husni (2017) elaborated on 32 students' perceptions towards the use of peer feedback in writing class before and after making revisions in Indonesia. Students believed that peer feedback was useful and helped them revise and improve their writing. They considered it as a demanding task to make revisions using comments from their peers; meanwhile, their cognition was developed by devoting more time to give feedback to their peers and reflecting on their own work (Tai, Lin \& Yang, 2015). As a result, students were more confident in providing and receiving peer feedback in writing classes.

Some studies have pointed out that peers could provide useful feedback in L2 writing. Rollinson (2005) revealed that $80 \%$ comments of high language proficiency students were regarded as valid and merely 7\% were considered as detrimental. Similarly, Ruegg (2014) conducted her study about the effectiveness of assessment of peer feedback on the quantity and quality of feedback given in two classes in Japan for a year. The results revealed that although there was no considerable difference in the students' feedback accuracy, the students from feedback-assessed group showed more significant improvements in quality and quantity of their points and comments than the product-assessed students. In particular, the feedback-assessed group were able to make longer comments, add more words than the product-assessed group. In addition, using peer feedback for L2 writing could improve not only students' learning autonomy but also their review ability.

Although in recent years using peer feedback has been supported by many studies, doubts about its validity and quality among teachers and students are still common. Teachers may not know how much time should be spent for this activity while students may feel uncertain about its advantages because they believe that only a qualified writer such as their teacher or a native 
English speaker can judge their work. This perception can be one of the main reasons negatively influencing the outcomes of using peer feedback in L2 writing classes.

The findings of this study showed that students held a belief that peer correction could be incorrect due to the lack of knowledge and they preferred to get more teacher feedback. Many students indicated that they did not trust their feedback accuracy and their writing skill could be affected if they used inaccurate feedback. For example, forty-seven students indicated that they "did not trust peer feedback accuracy" and they "kept repeating the same errors because my friends could not locate or correct them for me". Twenty-two students also mentioned that "low language proficiency students could give incorrect feedback on their texts". However, these students believed that when evaluating their peers' feedback and deciding whether the feedback was appropriate for their texts or not, they could develop their cognitive engagement in language learning. As a result, their engagement in learning would be decreased in the long term. In addition, students also felt "confused", "dissatisfied", or "embarrassed" because many friends could read their writing and judge them. It was clear that students who did not have appropriate training would show negative psychological aspects when their peers read and gave comments on their text. Nevertheless, if students got more practice in using peer feedback, in the long term, they would reduce their embarrassment and feel more confident in their writing since they realized that everyone could face the same problem (Ruegg, 2018). Lastly, the students who participated in this study had not started their writing class in the second semester and had not experienced feedback training with the two teachers due to the coronavirus. Therefore, the students' responses could be related to their old experiences in L2 writing classes that did not provide appropriate training for giving and receiving feedback.

These findings support Cheng and Warren's (2005) study that some students felt uncomfortable when criticizing their peers' writing while others did not know how to use peer feedback. The main reason was that students did not receive specific guidance in giving and receiving peer assessment. In Xiao and Lucking's (2008) study, some students were disappointed with the quality of peer feedback and they believed that the correction was not appropriate and useful for their writing. Similarly, Chai and Nimehchisalem (2016) conducted a study involved 107 undergraduate students about their perceptions towards written feedback in Malaysia. They found that although students highly valued the use of peer feedback, they preferred to use teacher feedback in their writing class. 
Since students are unfamiliar with the idea that their friends can critique their work, they are less likely to appreciate peer feedback. Meanwhile, they usually feel uncomfortable with giving critical comments on their peers' writing because they want class harmony (Cheng \& Warren, 2005). Carson and Nelson (1996) pointed out that students who came from Asian countries with a collectivist culture generally tried to maintain face-saving and group harmony. In addition, students can feel embarrassed or less confident in their writing since they do not have appropriate peer-feedback training or practices. Leki (1990) found that students having little experience with peer feedback were silent and frustrated in participating in the group conversation because they were not confident in their writing ability. Without appropriate training, students may give inappropriate responses such as being over-generous or uncritical to their peers' papers (Ruegg, 2018). Therefore, teachers should implement peer feedback for more extended periods so students can get used to this activity and be confident in giving and receiving this type of feedback effectively.

\section{Peer feedback with approriate training.}

The peer response process is time-consuming because students need to read their peers' drafts and write comments. In addition, pre-training is a necessary activity and it requires the investment of time for learning basic procedures and the purpose of peer feedback. Yu and Lee (2016) examined peer feedback strategies by four Chinese EFL students in a 16-week period and found that peer feedback was mediated by a wide range of strategies, such as using the first language, including second language writing criteria, developing group activity rules, seeking help from teachers, and playing various roles. This study found that students who lacked pre-training activities might feel demotivated and less confident in their review. For example, they believed that two students who had low language proficiency levels could not find the mistakes for each other. One student stated that "it will be difficult for me to discuss or work with someone who has a lower level of language proficiency". Thus, they wanted their teachers to double-check their corrections. Some studies found that a lack of training could lead to a false perception among students that the accuracy of peer feedback was low and unreliable (Husni, 2017; Min, 2013; Yu $\& \mathrm{Hu}, 2017)$. Thus, appropriate training is important for student to improve their reviewability and confidence in writing. 
Peer feedback involves a high level of interaction between writer and reader and it creates a collaborative conversation when two parties give and receive feedback. Their interactions include explanation, clarification, justification, and even argument, which can help both writers and readers gain a deeper understanding about their text. Although the writers who receive feedback from peers may potentially reject comments and persistently stick with their texts, they also learn from peer feedback.

However, this study also found that students showed negative psychological aspects when their peers criticize their papers. For example, some students felt "confused", "dissatisfied", or "embarrassed" because many friends could read their writing and judge them. These findings support other studies that cultural backgrounds could affect students' narratives (Carson \& Nelson, 1996; Yu \& Hu, 2017). These students were more disposed to initiate harmony than to criticize someone's work by pointing out the errors. These findings were in line with Carson and Nelson (1996) who found that three advanced Chinese students in the US tended to employ face-saving by giving only praise comments instead of negative ones. Yu and $\mathrm{Hu}$ (2017) also aimed to clarify how contextual factors and individual differences influence peer feedback activities, so they conducted a case study with two university students in China. The findings showed that these students had appropriate training on how to use peer feedback at the beginning of the semester; they were encouraged to express their comments in different ways. Unlike most previous studies, these Chinese students were willing to provide negative comments on their peer's work. They had different opinions about maintaining group harmony or saving face which was considered as the cultural belief in L2 classes. It is clear that peer feedback can be more successful if students are willing to give negative feedback or criticize others (Cheng \& Warren, 2005). However, if teachers want to use peer corrections effectively, they will need to train their students.

Many researchers had investigated the effect of feedback training on students' performance. Stanley (1992) conducted training for giving and receiving peer feedback in an ESL class over a long period. The findings showed that the group who experienced training provided more substantial responses and made more revisions than the control group. In Zhu's (1995) study, university students were trained to use peer feedback by watching a video that introduced basic concepts of this activity. The study found that trained students could make longer comments and more corrections than the untrained students. Berg (1999) aimed to identify how training shaped students' quality of revisions. In this study, the experimental group received several activities in 
peer feedback training which ranged from five to forty-five minutes for each. The results showed that the trained group made more revisions than the untrained group, and the quality of revisions from the trained group was considerably better than the untrained group.

Having an appropriate method to train students can be considered as a great contribution to the success of peer feedback. Firstly, teachers should provide clear guidance throughout the course. For example, Rollinson (2005) suggested that teachers should consider the size of groups, number of drafts, and ways of evaluation and informed these aspects clearly at the beginning of the course. Particularly, a group should consist of three to four students to have enough face-toface interaction. Teachers should let students know the numbers of drafts they need to do for peer evaluation, and inform the way they expect their students to evaluate the writing in individual or group decisions. Secondly, having specific guidance through videos, conferences, or meetings. Teachers should make sure that their students can understand and know how to apply the guidance into practice. Clear and informative guidance could be an effective way to make students more actively engage in their learning (Berger, 1990; Chai \& Nimehchisalem, 2016). Moreover, teachers should inform students that peer feedback is an essential technique to review and learn from each other's work. Therefore, students should be encouraged to give both praise and critical comments. The teacher should also support students in questioning and try to give comments which may satisfy both readers and writes. It is clear that teachers play an important role in the quality of students' collaboration in using peer feedback. Finally, teachers can help students deal with specific error forms or word choices; or suggest flexible techniques for improving the revision when students have any doubts about it.

Therefore, identifying students' perceptions of the types of feedback that match their needs and language proficiencies is necessary because it can help teachers avoid giving excessive feedback on their students' writing (Min, 2013; Ruegg, 2015; Ruegg 2017; Yangin Eksi, 2012). Moreover, feedback can be a helping tool for teaching and learning instead of a burden in L2 writing. 


\section{CHAPTER 6: CONCLUSION}

In this final chapter, limitations of this study are presented first, followed by a summary of the study which covers the research goal and both students' and teachers' perceptions based on the research questions. In the following part, the implications of the study are addressed. To conclude the chapter, suggestions for future studies are included.

\section{Limitations}

Although this study contributes to the limited studies about both students' and teachers' perceptions of the use of feedback in an L2 writing context, there are some limitations that should be discussed. First and foremost, the students who participated in this study did not experience feedback training with the two teachers due to the coronavirus. Therefore, the students' responses could be related to their old experiences in L2 writing classes that did not provide appropriate training for giving and receiving feedback. Second, this study was conducted in a Vietnamese university, so the findings did not generalize to other university contexts. In addition, the students majored in Finance and Banking so they could respond differently from English majors.

Moreover, due to the coronavirus, all data was collected online, which could lead to misunderstanding and misconceptions among the students. The researcher had planned that after giving certain types of feedback, these assignments would be given back to the students at the end of the class in the following week. They would be asked to check their assignments' feedback given by the researcher and answer a questionnaire to express their perceptions about each type of feedback before they received feedback from their teacher. However, writing assignments, feedback collection, and feedback provision were cancelled because all universities in Vietnam had been shut down from February to April in order to stop the global pandemic. In addition, the researcher also had to conduct the surveys online instead of in class.

In terms of interviews, the researcher had to skip the post-treatment interview since the teachers had not taught the students in this period, so they had not experienced anything new from their students. In the pre-treatment interview, one of the teachers wrote her answers and sent them through email instead of having verbal communication with the researcher. Therefore, the researcher could not ask her for more details to understand clearly about her feedback practices. 
Since this study mainly investigated students' and teachers' perceptions of feedback, the efficacy of using feedback in L2 writing was not considered. This study did not focus on the effectiveness of using feedback in L2 writing in Vietnamese contexts.

It is clear that feedback is an essential element in raising students' awareness of making mistakes, so it is beneficial for teachers to identify students' feedback preferences and expectations on what types of feedback works better for them. Despite difficulties in terms of time constraints and data collection during the pandemic of coronavirus, this study has gained some positive findings. This study may help teachers develop subsequent pedagogical interventions and give more effective feedback practices in the future. They can also avoid spending too much time on giving excessive feedback that students may not read. As a result, feedback can be a helpful tool for teaching and learning L2 writing instead of a burden on both teachers and students.

\section{Summary}

In the last 20 years, many studies have examined a wide range of issues in academic writing, including the types of feedback, and stakeholders' perceptions about feedback; however, the results have been contradictory. In Vietnam, there are few studies about students' and teachers' perceptions of written feedback. This study investigated the views of both Vietnamese students and teachers on peer feedback, direct feedback, indirect coded feedback, indirect un-coded feedback, and self-feedback to fulfil the gap.

Thirty-six university students who majored in Finance and Banking and two senior English teachers participated in this study. Due to the unexpected pandemic, the researcher changed the study from in-class to online. This qualitative research employs questionnaires and interviews. The pre-questionnaire at Week 1 had been completed in class before the outbreak of coronavirus in Vietnam, but the rest of the questionnaire surveys were collected online because the school had shut down after Week 1. The students were grouped into two separate online groups on Facebook with their classmates, and they were asked to complete five surveys about five different types of feedback. They could respond to the Likert-scale questions and also express their own perceptions about the advantages and disadvantages of each type of feedback that they experienced. The researcher also aimed to know about students' perceptions of different types of feedback after experiencing both their teacher's and researcher's feedback, but the school could not be reopened 
during the experiment time due to the pandemic. Therefore, the post-treatment questionnaire was cancelled.

During the interviews, teachers shared their experiences in giving feedback; advantages and disadvantages of feedback on their teaching; and their expectations about different types of feedback. The teachers had not taught the students in this period, so they had not experienced anything new from their students. Thus, the researcher cancelled the post-treatment interview and only conducted the pre-treatment interview.

The findings revealed some similarities between teachers' and students' perceptions of feedback in L2 writing. In terms of similarities, both teachers and students agreed that feedback played an important role in L2 writing learning and teaching. First of all, teachers and students believed that feedback could affect L2 learners' cognitive engagement in writing. For example, some students believed that they paid more time to engage in their texts when they experienced peer feedback, indirect coded feedback, and indirect uncoded feedback. Meanwhile, others felt "bored", "discouraged", and "demotivated" to engage in their writing when receiving direct feedback. Secondly, both students and teachers believed that some types of feedback could affect learners' psychology. Some students felt confident in their writing ability after receiving peer feedback while others faced many problems and felt "depressed" or "demotivated" when dealing with these types of feedback.

The results from teachers' interviews and students' surveys also revealed the discrepancies between teachers' and students' perceptions of feedback in L2 writing. In terms of direct feedback, while teachers think that direct feedback did not help to improve students' writing performance, most students preferred their teachers to use direct feedback because they felt that they were able to understand errors and revise their texts. Although teachers believed that students could improve their reviewability by giving and receiving peer feedback, students responded that they did not trust their peers and their corrections due to lack of knowledge. Therefore, training was necessary to improve peer feedback in both quality and quantity of feedback and to help students use this type of feedback more effectively.

When students have to switch from their first language to write and express ideas in a second language, they will make mistakes in their writing process. Therefore, teachers have been looking for a way to help them improve their work in the long term (Hyland \& Hyland, 2006). Using feedback is considered as a fundamental requirement to reduce students' errors in L2 
writing. This study revealed that using appropriate types of teacher feedback could boost students' confidence to improve their writing skills in the long term. Students' confidence in making writing progress will be boosted if they recognize the value of teacher feedback on their papers.

\section{Recommendations for Future studies}

The problem is that teachers are not aware of their options in giving feedback, so they spend too much time on identifying and correcting all of the errors in students' writing. However, the students may be overwhelmed by the excessive feedback and ignore using it in their revisions. Therefore, many researchers have investigated how both teachers' and students' perceive feedback to solve this current issue.

Although there are many studies about perceptions, they mainly either investigated teachers or students' perceptions of feedback in L2 writing, few studies focus on both teachers' and students' perceptions. In terms of students' preferences, many studies found out that students gained more confidence in writing after receiving teacher feedback (Nordin et al., 2010; Ruegg, 2018; Sharif \& Zainuddin, 2017); developed their language accuracy in the long term (James, 1998; Lalande, 1982). Others pointed out that teacher feedback made students passively depend on their teachers (Nguyen \& Rajeevnath, 2016; Westmacott; 2016), and feel discouraged, dissatisfied and overwhelmed (Agbayahoun, 2016; Jodaie, Farrokhi, \& Zoghi, 2011; Mahmud, 2016). In terms of teachers' perceptions, giving feedback for a big class created a burden on teachers' teaching practices since they do not have a specific feedback option (Atmaca, 2016; Hartshorn, Evan, \& Tuioti, 2014; Pearson, 2018). Since the results have been contradictory, future studies should continue to investigate in students' and teachers' perceptions on feedback in L2 writing to identify the advantages and disadvantages of feedback practices; therefore, students can improve their writing effectively.

In particular, there is no study about both teachers and students' perceptions of different types of feedback in L2 writing in Vietnam. This study recommends future researchers to continue focusing on both students' and teachers' perceptions to provide insight into feedback practices at a university level. It is also beneficial if they find any differences and similarities in their findings compared to this study. Moreover, this study did not focus on the efficacy of using feedback in L2 writing due to the time constraints, so future studies are suggested to cover both perceptions and 
effectiveness of using feedback in L2 writing to clarify whether the preferred feedback can positively affect Vietnamese students' writing outcomes. As a result, they can contribute to the limited literature review in students' and teachers' perceptions as well as the efficacy of feedback in L2 writing classes.

Since this study had to collect the data online due to the coronavirus, the findings could be different from the real ESL writing context where students received and responded to the feedback practices with the researcher and their teachers. In this study, one of the teachers had completed her interview by email, which limits the researcher to ask more questions about her feedback practices. Therefore, future researchers are recommended to conduct the study in class in order to observe how students work and complete their surveys. Similarly, interviews should be conducted in class to help researchers have a deeper understanding of feedback practices in L2 writing.

\section{Recommendations for teachers}

In the following parts, some pedagogical implications in using feedback to push students' confidence in L2 writing and how to improve feedback practices with adequate training will be presented.

\section{Feedback to push students' confidence in L2 writing.}

Students in this study felt confident because they could distinguish their strengths and weaknesses in their writing. For example, students were able to avoid the same mistakes and make better revisions if they could avoid making the same errors. It is clear that drawing students' attention to specific strengths and weaknesses can potentially boost their confidence and improve their future performance. This finding suggests that teachers should ask their students to write a short self-reflection essay for their first draft, which can highlight their strengths and weaknesses in second language writing by themselves. This suggested way can also save time for teachers who have to give feedback for a big class as well as encourage students to view their weaknesses as an inevitable element to learn a new language. Furthermore, if any students are not able to improve their weaknesses, teachers can ask them to make online or offline appointments with a school tutor for more in-depth clarification. 
The study also found that students considered negative comments as a challenge that pushed them to perform better in their future writing, while positive comments showed students what they had done well. Thus, this study suggests the combination of positive and negative aspects of teacher feedback instead of using only praise or too critical comments which could negatively influence students' work and psychology. In reality, giving feedback focusing on negative aspects to help students improve their writing is necessary (Caffarella \& Barnet, 2000). However, teachers should be careful about the tone of their feedback by using critical comments after using positive ones and find a gentle approach when pointing out serious mistakes. They should understand that some students are not able to control their emotions towards critical feedback and always require additional support. Hence, teachers can train students to give and receive feedback over a period of time to help them improve their self-confidence when they get negative feedback. It is suggested that teachers can give critical comments with suggestions on how to fix mistakes such as metalinguistic feedback.

Finally, in some Asian countries, students seem to save face, so they avoid asking or expressing their misunderstanding. Thus, teachers should encourage their students to ask or indicate their problems when using indirect uncoded feedback. If students have any questions, they can contact the teacher by email for clarification. This can help students improve their revisions and perform better in their final paper. As a result, students are likely to engage in their texts, find more information to solve their mistakes and make better revisions without passively depending on teachers.

\section{The focus of feedback practices.}

This study indicated that students preferred teacher feedback, and they also felt more confident about their writing on which they received more teacher feedback. However, increasing the amount of feedback can overwhelm students (Agbayahoun, 2016; Bratkovich, 2014; Pearson, 2018). Thus, teachers should keep in mind that if students can understand the feedback they get, they will not view teacher feedback as a burden. It is suggested that teachers should mainly focus on specific aspects that match students' expectations, such as grammar instead of covering everything. This study suggests that teachers ask their students about which language features they would like their teachers to focus on. For example, in this study, most students wanted their 
teachers to focus on Grammar instead of Vocabulary. Using focused feedback can both save time for teachers and avoid overwhelming students with excessive corrections.

Moreover, students with a low level of language proficiency can face difficulties when they self-correct after receiving indirect feedback because they were not able to clarify the errors types or find suitable forms to replace their mistakes. If most students are not able to detect and correct their errors, teachers should use direct feedback to assist them. However, teachers also need to slowly change students' attitudes towards the use of other types of feedback (Cho \& Park, 2019). Students should be responsible for finding more information, figuring out what is wrong with their writing, and trying different ways to correct their errors rather than depending on their teachers.

Students may be unfamiliar with indirect uncoded feedback so teachers should introduce and train their students on how to work on this type of feedback. Cho and Park (2019) stated that when students continuously receive a specific type of feedback, they will be cooperative with it in their revisions. When students understand the feedback and its effectiveness, they will appreciate teacher feedback and feel more confident to correct the errors. Thus, if teachers want to use indirect uncoded feedback instead of familiar feedback forms like direct feedback, their students should receive appropriate feedback training. In the long term, students can be more independent in locating and revising their errors.

\section{The importance of feedback training.}

Since some students can be unfamiliar with the idea that their friends critique their work, they are less likely to appreciate peer feedback. Meanwhile, many students normally feel uncomfortable with giving critical comments on their peers' writing because they want class harmony. Carson and Nelson (1996) pointed out that students who came from Asian countries with a collectivist culture generally tried to maintain face-saving and group harmony. Ruegg (2018) found that without appropriate training, students could give inappropriate responses such as overgenerous or uncritical comments to their peers' papers.

Peer feedback involves a high level of interaction between writer and reader, and it creates a collaborative conversation when two parties give and receive feedback. Their interactions include explanation, clarification, justification, and even argument, which help both writers and readers gain a deeper understanding of their text (Wakabayashi, 2013). Although the writers who receive feedback from peers may potentially reject comments and persistently stick with their 
texts, they also learn from peer feedback. These students can develop their critical thinking and review ability to determine whether they should use their peers' comments on their text or not.

An appropriate method to train students could be considered as a significant contribution to the success of peer feedback. Firstly, teachers should provide clear guidance throughout the course in class. For big classes, a group should consist of three to four students to have enough face-to-face interaction (Rollinson, 2005). Teachers are recommended to let students know the numbers of drafts they need to do and how to evaluate their writing. Similarly, specific guidance through videos or online meetings can be introduced at the beginning of the class to make sure that students can know how to work with peer feedback if the course has to run online.

Moreover, teachers should inform students that peer feedback is an essential technique to

review and learn from each other's work, so both praise and critical comments can be beneficial for both reviewers and writers (Yu \& Hu, 2017). Finally, teachers can select and focus on one or two common errors that students usually make in their revisions after having peer review to discuss in class and recommend reliable learning sources for self-study.

\section{More efficient and effective feedback practices in L2 writing.}

This study found that both teachers and students experienced negative psychological aspects after spending too much time on feedback in L2 writing classes. In some cases, low language proficiency students may find indirect feedback difficult and consider direct feedback as to their preferred types. However, giving direct feedback for a big class is time-consuming for teachers because they have to have to mark, locate, and give correct error forms. In addition, teachers can be tired when correcting many errors at once and their students may also be overwhelming because of too many errors (Bitcherner \& Knoch, 2009; Sung \& Tsai, 2014). Therefore, teacher-written feedback approaches need to be changed. This study suggests some implications to help teachers give more efficient and effective feedback practices in L2 writing.

First of all, teachers should only use direct feedback for short pieces of written work such as paragraphs or short essays when they want to cover all errors in students' work. These short writings help teachers to complete their tasks and avoid spending too much time on locating errors and giving corrections for the big class. If students have to write long essays, teachers can use focused correction to help students identify the specific problems such as subject-verb agreement and verb tenses and save their time. 
In a limited timeframe, teachers can use direct feedback for untreatable errors which are difficult for students to correct by themselves and indirect feedback for treatable errors such as singular and plural words, word choices, and subject-verb agreement. This approach helps teachers have enough time to give feedback to the whole class and encourage students to be more independent and engage in their revisions. They can also consider using peer feedback or selffeedback for their students' first drafts, followed by teacher direct feedback on the final drafts. Self-feedback and peer feedback can be used effectively by correcting simple grammatical errors. It can be beneficial for students to increase their autonomy and interaction, which are inevitable for their learning progress. However, teachers should train students to be more familiar with peer feedback and self-feedback to enhance the quality of peer and self-review (Koston, van Gog, \& Paas, 2012; Zhu, 1995). By using these approaches, teachers can reduce their workload and students can still receive useful feedback for their revisions.

This current study will be useful for Vietnamese teachers to have a better understanding of students' preferences and expectations in using written feedback in L2 writing to use different types of feedback more effectively. Meanwhile, they can employ peer feedback and self-feedback, which are two uncommon types of feedback in institutional contexts. The study also indicates the importance of using feedback for students' writing development based on both students' and teachers' perspectives. Moreover, identifying the similarities and mismatches in perceptions of both sides can help the stakeholders to come to an agreement of which types of feedback or feedback practices work best for them. On a broader scale, this study contributes to the limited number of research studies that investigate not only students' but also teachers' perceptions of feedback using in L2 writing in a university context. 


\section{REFERENCES}

Agbayahoun, J. (2016). Teacher written feedback on student writing: Teachers' and learners' perspectives. Theory and Practice in Language Studies, 6(10), 1895-1904. https://doi.org/10.17507/tpls.0610.01

Ahmadi, D., Maftoon, P., \& Mehrdad, A. (2012). Investigating the Effects of Two Types of Feedback on EFL Students' Writing. Procedia - Social and Behavioral Sciences, 46, 25902595. https://doi.org/10.1016/j.sbspro.2012.05.529

Aliakbari, M., \& Raeesi, H. (2014). Teacher's feedback and student's preferences in an Advanced Writing Course: A Case Study. Advances in Language and Literary Studies, 5(1), 62-64. https://doaj.org/article/9b96708b6e184b59a40a85d7d653cf14

Amelia, R. (2020). Students' perception on employing self-directed feedback in writing. Journal of Applied Linguistics and Literature, 5(1), 60-70.

Atmaca, Ç. (2016). Contrasting Perceptions of Students and Teachers: Written Corrective Feedback. Journal of Language and Linguistic Studies, 12, 166-182.

Baker, W., \& Hansen Bricker, R. (2010). The effects of direct and indirect speech acts on native English and ESL speakers' perception of teacher written feedback. System, 38(1), 75-84. https://doi.org/10.1016/j.system.2009.12.007

Banaruee, H., Khatin-Zadeh, O., \& Ruegg, R. (2018). Recasts vs. direct corrective feedback on writing performance of high school EFL learners. Cogent Education, 5(1), 1-23.

Belachew, M., Getinet, M., \& Gashaye, A. (2015). Perception and practice of self-assessment in EFL writing classrooms. Academic Journals, 6(1), 1-8.

Berg, C. E. (1999). The effects of trained peer response on ESL students' revision types and writing quality. Journal of Second Language Writing, 8(3), 215-241.

Berger, V. (1990) The Effects of Peer and Self-Feedback. The CATESOL Journal, 3, 21-35.

Bitchener, J. (2008). Evidence in support of written corrective feedback. Journal of Second Language Writing. 17, 102-118.

Bitchener, J., \& Knoch, U. (2009). The relative effectiveness of different types of direct written corrective feedback. System, 37(2), 322-329. https://doi.org/10.1016/ j.system.2008.12.006. 
Boggs, J. (2019). Effects of teacher-scaffolded and self-scaffolded corrective feedback compared to direct corrective feedback on grammatical accuracy in English L2 writing. Journal of Second Language Writing, 46, 1-13. doi:10.1016/j.jslw.2019.100671

Bratkovich, M. O. (2014). Assessment and Feedback: Examining the Relationship Between Selfassessment and Blind Peer-and Teacher-assessment in TOEFL Writing. Studies in Applied Linguistics and TESOL, 14(2), 100-127.

Bruffee, K. A. (1984). Collaborative learning and the conversation of mankind. College English, $46(7), 635-52$.

Caffarella, R., \& Barnett, B. (2000). Teaching Doctoral Students to Become Scholarly Writers: The importance of giving and receiving critiques. Studies in Higher Education, 25(1), 3952. https://doi.org/10.1080/030750700116000

Carson, J. G., \& Nelson, G. L. (1996). Chinese students' perceptions of ESL peer feedback group interaction. Journal of Second Language Writing, 5(1), 1-19.

Chai, H., \& Nimehchisalem, V. (2016). Malaysian Tertiary Level ESL Students' Perceptions toward Teacher Feedback, Peer Feedback and Self-assessment in their Writing. International Journal of Applied Linguistics \& English Literature, 5(5), 158-170. https://doi.org/10.7575/aiac.ijalel.v.5n.5p.158

Chandler, J. (2003). The efficacy of various kinds of error correction for improvement of the accuracy and fluency of L2 student writing. Journal of Second Language Writing, 12(3), 267-296.

Cheng, W., \& Warren, M. (2005). Peer assessment of language proficiency. Language Testing, 22(1), 93-121.

Cho, S., \& Park, C. (2019). Students' responses to tutor feedback: Focusing on their writing and perceptions. GEMA Online Journal of Language Studies, 19(3), 75-87. https://doi.org/10.17576/gema-2019-1903-05

Conrad, S., \& Goldstein, L. (1999). ESL student revision after teacher written comments: Texts, contexts and individuals. Journal of Second Language Learning, 8, 147-180.

Dam, M. L. (2018). The Effectiveness of Indirect Written Corrective Feedback as Perceived by Teachers and Students of a Public University in Vietnam. International Journal of Education \& Literacy Studies, 6(4), 152-162. 
Diab, N. M. (2011). Assessing the relationship between different types of student feedback and the quality of revised writing. Assessing writing, 16(4), 274-292.

Diab, N. M. (2015). Effectiveness of written corrective feedback: Does type of error and type of correction matter?. Assessing Writing, 24, 16-34.

Diab, N. M. (2016). A comparison of peer, teacher and self-feedback on the reduction of language errors in student essays. System, 57, 55-65.

DiGiovanni, E., \& Nagaswami, G. (2001). Online peer review: an alternative to face-to-face? ELT Journal, 55(3), 263-272. https://doi.org/10.1093/elt/55.3.263

Ellis, R. (2009). A typology of written corrective feedback types. ELT Journal, 2(2), 97-107.

Ellis, R., Sheen, Y., Murakami, M., \& Takashima, H. (2008). The effects of focused and unfocused written corrective feedback in an English as a foreign language context. System: International Journal of Educational Technol- ogy and Applied Linguistics, 36(3), 353371. Retrieved from https://doi.org/10.1016/j.system.2008.02.001 doi:10.1093/elt/ccn023

Fazilatfar, A., Fallah, N., Hamavandi, M., \& Rostamian, M. (2014). The Effect of Unfocused Written Corrective Feedback on Syntactic and Lexical Complexity of L2 Writing. Procedia - Social and Behavioral Sciences, 98, 482-488. https://doi.org/10.1016/j.sbspro.2014.03.443

Ferris, D. (2002). Treatment of error in second language student writing. Ann Arbor, MI: The University of Michigan Press.

Ferris, D., \& Roberts, B. (2001). Error feedback in L2 writing classes: How explicit does it need to be?. Journal of Second Language Writing, 10(3), 161-184. https://doi.org/10.1016/S1060-3743(01)00039-X

Ferris, D. R. (1999). The case for grammar correction in L2 writing classes: A response to Truscott (1996). Journal of Second Language Writing, 8, 1-10.

Ferris, D. R. (2006). Does error feedback help student writers? New evidence on the short- and long-term effects of written error correction. In K. Hyland \& F. Hyland (Eds.), Feedback in second language writing, 81-104. Cambridge, UK: Cambridge University Press.

Goldstein, L., \& Conrad, S. (1990). Student input and negotiation of meaning in ESL conferences. TESOL Quarterly, 24(3), 443-460. 
Hartshorn, K., Evans, N., \& Tuioti, E. (2014). Influences on Teachers' Corrective Feedback Choices in Second Language Writing. Writing \& Pedagogy, 6(2), 251-282. https://doi.org/10.1558/wap.v6i2.251

Hosseiny, M. (2014). The Role of Direct and Indirect Written Corrective Feedback in Improving Iranian EFL Students’ Writing Skill. Procedia - Social and Behavioral Sciences, 98, 668674. https://doi.org/10.1016/j.sbspro.2014.03.466

Husni, M. (2017). Students' Perception toward the Implementation of Peer-Assessment in Writing; Before and After Revision. A journal of Culture, English Language, Teaching and Literature, 17(1), 13-26. https://doi.org/10.24167/celt.v17i1.1136

Hyland, K., \& Hyland, F. (2006). Interpersonal Aspects of Response: Constructing and Interpreting Teacher Written Feedback, in K Hyland and F Hyland (Eds.). Feedback in Second Language Writing: Contexts and Issues, 206-224. Cambridge, UK: Cambridge University Press.

Jamalinesari, A., Rahimi, F., Gowhary, H., \& Azizifar, A. (2015). The Effects of Teacher-Written Direct vs. Indirect Feedback on Students' Writing. Procedia - Social and Behavioral Sciences, 192,116-123.

James, C. (1998). Errors in language learning and use: Exploring error analysis. London: Longman.

Ji, X. (2015). Error correction in college EFL writing instruction: Students' expectations and correction effects 1. Journal of Asia TEFL, 12(1), 117-140.

Jodaie, M., Farrokhi, F., \& Zoghi, M. (2011). A Comparative Study of EFL Teachers' and Intermediate High School Students' Perceptions of Written Corrective Feedback on Grammatical Errors. English Language Teaching, 4(40), 36-48.

Karim, K., \& Nassaji, H. (2015). ESL Students' perceptions of written corrective feedback: What types of feedback do they prefer and why?. The European Journal of Applied Linguistics and TEFL, 4(5), 5-25.

Kostons, D., van Gog, T., \& Paas, F. (2012). Training self-assessment and task-selection skills: A cognitive approach to improving self-regulated learning. Learning and Instruction, 22(2), 121-132. https://doi.org/10.1016/j.learninstruc.2011.08.004

Lalande, J.F. (1982). Reducing composition errors: an experiment. Modern Language Journal, 66 (2), 140-149. 
Lee, I., Mak, P., \& Burns, A. (2016). EFL teachers' attempts at feedback innovation in the writing classroom. Language Teaching Research, 20(2), 248-269. https://doi.org/10.1177/1362168815581007

Leki, I. (1990). Potential problems with peer responding in ESL writing classes. CATESOL Journal, 3, 5-17.

Lyster, R., \& Satio, K. (2010). Oral feedback in classroom in SLA: A meta-Analysis. Studies in Second Language Acquisition, 32, 265 - 302.

Mahmud, N. (2016). Investigating the Practice of Providing Written Corrective Feedback Types by ESL Teachers at the Upper Secondary Level in High Performance Schools. Malaysian Online Journal of Educational Sciences, 4(4), 48-60. http://search.proquest.com/docview/1871574887/

Mekala, S., \& Ponmani, M. (2017). The Impact of Direct Written Corrective Feedback on Low Proficiency ESL Learners' Writing Ability. IUP Journal of Soft Skills, 11(4), 23-54. http://search.proquest.com/docview/1989499872/

Miao, Y., Badger, R., \& Zhen, Y. (2006). A comparative study of peer and teacher feedback in a Chinese EFL writing class. Journal of Second Language Writing, 15(3), 179-200.

Min, H. (2013). A case study of an EFL writing teacher's belief and practice about written feedback. System, 41(3), 625-638. https://doi.org/10.1016/j.system.2013.07.018

Montgomery, J., \& Baker, W. (2007). Teacher-written feedback: Student perceptions, teacher selfassessment, and actual teacher performance. Journal of Second Language Writing, 16(2), 82-99. https://doi.org/10.1016/j.jslw.2007.04.002

Nguyen, H. D., \& Rajeevnath, R. (2016). Students' reactions to teacher written feedback in their compositions at An Giang University, Vietnam. The New English Teacher, 10(1), 42-54.

Nguyen, L. L., \& Ishak, S.A. (2018). Instructor's Direct and Indirect Feedback: How do they Impact Learners' Written Performance?. The Southeast Asian Journal of English Language Studies, 24(3), 95-110.

Nordin, S., Halib, M., Ghazali, Z., \& Ali, R. (2010). Error correction and students' perception on teachers' written feedback: An exploratory study on L2 learners in a Malaysian University. International Journal of Learning, 17(2), 55-64.

Norish, J. (1983). Language learners and their errors: Essential language teaching series. London. Macmillan Press. 
Pearson, W. S. (2018). Written corrective feedback in IELTS writing Task 2: Teachers' priorities, practices, and beliefs. The Electronic Journal for English as a Second Language, 21(4), 132.

Rahimi, M. (2013). Is training student reviewers worth its while? A study of how training influences the quality of students' feedback and writing. Language Teaching Research, 17(1), 67-89. https://doi.org/10.1177/1362168812459151

Richards, J., \& Renandya, W. (2002). Methodology in language teaching. Cambridge: Cambridge University Press.

Robb, T., Ross, S., \& Shortreed, I. (1986). Salience of Feedback on Error and Its Effect on EFL Writing Quality. TESOL Quarterly, 20(1), 83-95. https://doi.org/10.2307/3586390

Rollinson, P. (2005). Using peer feedback in the ESL writing class. ELT Journal, 59(1), 23-30. https://doi.org/10.1093/elt/cci003

Ruegg, R. (2014). The effect of assessment of peer feedback on the quantity and quality of feedback given. Papers in Language Testing and Assessment, 3(1), 24-43

Ruegg, R. (2015). The relative effects of peer and teacher feedback on improvement in EFL students' writing ability. Linguistics and Education, 29, 73-82. https://doi.org/10.1016/j.linged.2014.12.001

Ruegg, R. (2017). Learner revision practices and perceptions of peer and teacher feedback. Writing \& Pedagogy, 9(2), 275-300. http://search.proquest.com/docview/2138605540/

Ruegg, R. (2018). The effect of peer and teacher feedback on changes in EFL students' writing self-efficacy. The Language Learning Journal, 46(2), 87-102. https://doi.org/10.1080/09571736.2014.958190

Ruegg, R., \& Koyama, D. (2010). Confidence in writing: the effect of feedback. Studies in Linguistics and Language Teaching, 21, 123-135.

Rummel, S., \& Bitchener, J. (2015). The Effectiveness of Written Corrective Feedback and the Impact Lao Learners' Beliefs Have on Uptake. Australian Review of Applied Linguistics, 38(1), 66-84. https://doi.org/10.1075/aral.38.1.04rum

Sadat, T., Zarifi, A., Sadat, A., \& Malekzadeh, J. (2015). Effectiveness of direct and indirect corrective feedback on Iranian EFL learners' accuracy and retention of conditional sentences types I, II \& III. Theory and Practice in Language Studies, 5(10), 2023-2028. https://doi.org/10.17507/tpls.0510.07 
Sharif, A., \& Zainuddin, S. (2017). Students' perceptions of their reflective essay writing experience and teacher feedback comments. Indonesian Journal of Applied Linguistics, 6(2), 204-212. https://doi.org/10.17509/ijal.v6i2.4845

Sheen, Y. (2007). The effect of focused written corrective feedback and language aptitude on ESL learners' acquisition of articles. TESOL Quarterly, 41(2), 255-283. https://doi.org/10.2307/40264353.

Sheen, Y., Wright, D., \& Moldawa, A. (2009). Differential effects of focused and unfocused written correction on the accurate use of grammatical forms by adult ESL learners. System, 37(4), 556-569. https://doi.org/10.1016/j.system.2009.09.002

Shintani, N., \& Ellis, R. (2015). Does language analytical ability mediate the effect of written feedback on grammatical accuracy in second language writing? System, 49, 110-119. https://doi.org/10.1016/j.system.2015.01.006.

Siow, L. (2015). Students' Perceptions on Self- and Peer-Assessment in Enhancing Learning Experience. Malaysian Online Journal of Educational Sciences, 3(2), 21-35.

Sritrakarn, N. (2018). A comparison of teacher's and senior students' feedback: Student attitudes and their writing improvement. Journal of Asia TEFL, 15(2), 329-348. https://doi.org/10.18823/asiatefl.2018.15.2.1.329

Stanley, J. (1992). Coaching student writers to be effective peer evaluators. Journal of Second Language Writing, 1, 217-233.

Sung, K., \& Tsai, H. (2014). Exploring student errors, teachers' corrective feedback, learner uptake and repair, and learners' preferences of corrective feedback. The Journal of Language Teaching and Learning, 4(1), 37-54.

Tai, H., Lin, W., \& Yang, S. (2015). Exploring the Effects of Peer Review and Teachers' Corrective Feedback on EFL Students' Online Writing Performance. Journal of Educational Computing Research, 53(2), 284-309. https://doi.org/10.1177/0735633115597490

Tang, C., \& Liu, Y. (2018). Effects of indirect coded corrective feedback with and without short affective teacher comments on L2 writing performance, learner uptake and motivation. Assessing Writing, 35, 26-40. https://doi.org/10.1016/j.asw.2017.12.002 
Tom, A., Morni, A., Metom, L., \& Joe, S. (2013). Students' perception and preferences of written feedback in academic writing. Mediterranean Journal of Social Sciences, 4(11), 72-80. https://doi.org/10.5901/mjss.2013.v4n11p72

Truscott, J. (1996). The case against grammar correction in L2 writing classes. Language Learning, 46(2), 327-369.

Wakabayashi, R. (2013). The Effects of the Peer Feedback Process on Reviewers' Own Writing. English Language Teaching, 6(9), 177-192.

Warschauer, M., \& Kern, R. (1999). Network-based language teaching: Concepts and practice. Cambridge: Cambridge University Press.

Wei, W., \& Yanmei, X. (2018). University teachers' reflections on the reasons behind their changing feedback practice. Assessment \& Evaluation in Higher Education, 43(6), 867879. https://doi.org/10.1080/02602938.2017.1414146

Westmacott, A. (2016). Direct vs. Indirect Written Corrective Feedback: Student Perceptions. Íkala, 22(1), 17-32. https://doi.org/10.17533/udea.ikala.v22n01a02

Xiang, W. (2004). Encouraging self-monitoring in writing by Chinese students. ELT Journal, 58(3), 238-246.

Xiao, Y., \& Lucking, R. (2008). The impact of two types of peer assessment on students' performance and satisfaction within a Wiki environment. The Internet and Higher Education, 11(3), 186-193.

$\mathrm{Xu}, \mathrm{C}$. (2009). Overgeneralisation from a narrow focus: A response to Ellis et al. (2008) and Bitchener (2008). Journal of Second Language Writing, 18, 270-175.

Yangin Eksi, G. (2012). Peer review versus teacher feedback in process writing: how effective? International Journal of Applied Educational Studies, 13(1), 33-48.

Yu, S., \& Hu, G. (2017). Can higher-proficiency L2 learners benefit from working with lowerproficiency partners in peer feedback?. Teaching in Higher Education, 22, 178-192.

Yu, S., \& Lee, I. (2016). Exploring Chinese students' strategy use in a cooperative peer feedback writing group. System, 58, 1-11. https://doi.org/10.1016/j.system.2016.02.005

Zacharias, N. (2007). Teacher and Student Attitudes toward Teacher Feedback. RELC Journal, 38(1), 38-52. https://doi.org/10.1177/0033688206076157

Zaman, M. M., \& Azad, M. A. K. (2012). Feedback in EFL writing at tertiary level: 
Teachers' and learners' perceptions. ASA University Review, 6(1), 139-156

Zhu, W. (1995). Effects of training for peer response on students' comments and interaction. Written Communication, 12(4), 492-528.

Zumbrunn, S., Marrs, S., \& Mewborn, C. (2016). Toward a better understanding of student perceptions of writing feedback: a mixed methods study. Reading and Writing, 29(2), 349370. https://doi.org/10.1007/s11145-015-9599-3

Appendix A: Human ethics application approval 
Dear Phuong Anh,

Thank you for your application for ethical approval (Written feedback in Second Language Writing: Perceptions of Vietnamese Teachers and Students, reference 0000028136), which has been considered by the Standing Committee of the Human Ethics Committee.

Your application is approved as of today. Your approval apples for their years from the date of this email.

If you would like to receive a formal letter please contact the HEC Administrator (ethicsadmin@vuw.ac.nz).

Best wishes with research.

Human Ethics Committee

Appendix B: Information for participants for interviews 


\section{Written feedback in Second Language Writing: \\ Perceptions of Vietnamese Teachers and Students}

\section{INFORMATION SHEET FOR PARTICIPANTS FOR INTERVIEWS}

You are invited to take part in this research. Please read this information before deciding whether or not to take part. If you decide to participate, thank you. If you decide not to participate, thank you for considering this request.

Who am I?

My name is Nguyen Phuong Anh and I am a Masters student in Applied Linguistics at Victoria University of Wellington. This research project is work towards my thesis.

What is the aim of the project?

In Vietnam, there are few studies about students' and teachers' perceptions of written feedback. This study aims to fill this gap by investigating the views of both students and teachers on different kinds of feedback. This research has been approved by the Victoria University of Wellington Human Ethics Committee 0000028136.

How can you help?

You have been invited to participate because you have a secure experience in giving feedback and teaching writing at the university level. If you agree to take part in, I will interview you in your classroom. There will be two primary semi-structured interviews (a pre interview and a post interview). I will ask your opinions providing feedback. The interview will take 20 to 30 minutes. I will audio record the interview with your permission and write it up later. You can choose to not answer any question or stop the interview at any time, without giving a reason.

Morerover, I will collect the copies of your students' written assignments after you have provided your feedback on them during seven-week process. You can withdraw from the study by contacting me at any time before $20^{\text {th }}$ of January. If you withdraw, the information you provided will be destroyed. 
What will happen to the information you give?

This research is confidential. This means that the researcher named below will be aware of your identity but the research data will be combined and your identity will not be revealed in any reports, presentations, or public documentation.

Only my supervisor-Rachael Ruegg and I will read the notes or transcript of the interview. The interview transcripts, summaries and any recordings will be kept securely and destroyed on $30^{\text {th }}$ of July, 2023.

What will the project produce?

The information from my research will be used in my Masters thesis and academic publications.

If you accept this invitation, what are your rights as a research participant?

You do not have to accept this invitation if you don't want to. If you do decide to participate, you have the right to:

- choose not to answer any question;

- ask for the recorder to be turned off at any time during the interview;

- withdraw from the study before $20^{\text {th }}$ of January;

- ask any questions about the study at any time;

- receive a copy of your interview recording;

- receive a copy of your interview transcript;

- be able to read any reports of this research by emailing the researcher to request a copy. 


\section{Phản hồi dưới dạng viết trong bài viết ngôn ngữ thứ hai: \\ Nhận thức của giáo viên và sinh viên Việt Nam}

\section{BẢNG THÔNG TIN DÀNH CHO ĐÓI TƯợ̂ THAM GIA PHỎNG VẢN NGHIÊN CỨU}

Bạn được mời tham gia vào nghiên cứu nảy. Vui lòng đọc thông tin này trước khi quyết định có tham gia hay không. Nếu bạn quyết định tham gia, cảm ơn bạn. Nếu bạn quyết định không tham gia, cảm ơn bạn đã xem xét yêu cầu nảy.

Tôi là ai?

Tôi tên là Nguyễn Phương Anh và tôi là sinh viên thạc sĩ ngành Ngôn ngữ học ứng dụng tại Đại học Victoria tọa lạc tại Wellington. Dự án nghiên cứu này là hướng tới luận án của tôi.

\section{Mục đích của nghiên cứu này là gì?}

Ở Việt Nam, có rất ít nghiên cứu về nhận thức của giáo viên và sinh viên về phản hồi đưới đạng viết. Nghiên cứu này nhằm lấp đầy khoảng trống này bằng cách khảo sát quan điểm của cả sỉnh viên và giáo viên về các đạng phản hồi khác nhau. Nghiên cứu này đã được phê duyệt bởi Ửy ban đạo đức con người của Đại học Victoria tại Wellington.

\section{Bạn có thể giúp gì?}

Bạn được mời tham gia vì bạn có kinh nghiệm đảm bảo việc đưa ra phản hồi và giảng dạy kỹ năng viết ở bậc đại học. Nếu bạn đồng ý tham gia, tôi sẽ phỏng vấn bạn tại lớp. Sẽ có hai bài phóng vấn bán cấu trúc (bao gồm một bài phỏng vấn trước thực nghiệm và một bài phỏng vấn sau thực nghiệm). Tôi sẽ hơi ý kiến của bạn về việc đưa ra phản hồi (đánh giá). Bài phỏng vấn sẽ̃ kéo đài khoảng 20 đến 30 phút. Tôi sẽ ghi âm buổi phỏng vẩn khi bạn cho phép và hoàn chỉnh sau đó. Bạn có thể chọn không trả lời bất kỳ câu hỏi hoặc dừng buổi phỏng vấn bất kỳ lúc nào, mà không cần phải nêu lý do.

Thêm vào đó, tôi sẽ thu thập các bài viết từ sinh viên của bạn đã bao gồm phản hồi của bạn trên các bài viết đó trong 7 tuần. Bạn có thể rút khỏi nghiên cứu này khi liên lạc với tôi bất kỳ lúc nào trước ngày 20 tháng 01 . Nếu bạn rút khỏi nghiên cứu, thông tin mà bạn cung cấp sẽ bị hủy bỏ hoặc hoàn lại cho bạn.

\section{Điều gì sẽ̃ xảy ra đối với các thông tin mà bạn cung cấp?}

Nghiên cứu này được báo mật. Điều nảy có nghĩa là nghiên cứu viên có tên dưới đây sẽ biết về danh tính của bạn nhưng số liệu nghiên cứu sẽ được tổng hợp và danh tính của bạn sẽ được bảo mật trong báo cáo, bài thuyết trình hoặc tài liệu công khai. 
Chi có Người hướng dẫn của tôi - Rachael Ruegg vả tôi sẽ đọc các ghi chú hoặc bảng ghi chép của cuộc phỏng vấn. Bảng ghi chép phỏng vấn, tóm tất và bất kỷ bản ghi âm sẽ được giữ an toàn và hủy vào ngày 30 tháng 7 năm 2023.

\section{Sản phẩm của dự án nghiên cứu là gì?}

Thông tin từ nghiên cứu của tôi sẽ được sử dụng trong văn bằng thạc sĩ và các ấn phẩm học thuật và hội thảo.

Nếu bạn chấp nhận lời mời này, quyền của bạn với tư cách là người tham gia nghiên cứu là gì?

Bạn không cần phải chấp nhận lời mời này nếu bạn không muốn. Nếu bạn quyết định tham gia, bạn có quyền:

- chọn không trả lởi bất kỳ câu hơi nào;

- yêu cầu tắt máy ghi âm bất kỳ lúc nào trong buổi phỏng vấn;

- rút khỏi nghiên cứu trước ngày 20 tháng 01 ;

- có bất kỳ câu hỏi nào về nghiên cứu này mọi lúc;

- nhận bản sao bản ghi âm phỏng vấn của bạn;

- nhân bản sao bản ghi chép phóng vấn của bạn;

- có thể đọc bất kỳ báo cáo của nghiên cứu này bằng cách gửi email cho nghiên cứu viên để yêu cầu một bản sao. 
Appendix C: Consent to interview

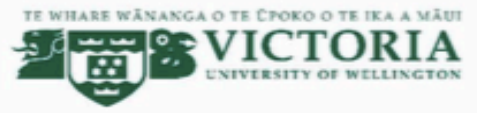

\section{Written feedback in Second Language Writing:}

\section{Perceptions of Vietnamese Teachers and Students}

\section{CONSENT TO INTERVIEW}

This consent form will be held for one year.

Researcher: Nguyen Phuong Anh, Master Thesis of Applied Linguistics, Victoria University of Wellington.

- I have read the Information Sheet and the project has been explained to me. My questions have been answered to my satisfaction. I understand that I can ask further questions at any time.

- I agree to take part in audio recorded interviews and allow the researcher to collect copies of my students' written assignments after I have provided my feedback on them during seven-week process.

I understand that:

- I may withdraw from this study at any point before $20^{\text {th }}$ of January and any information that I have provided will be returned to me or destroyed.

- The identifiable information I have provided will be destroyed on $30^{\text {th }}$ of July, 2023 .

- Any information I provide will be kept confidential to the researcher and the supervisor Rachael Ruegg.

- I understand that the findings may be used for a Masters thesis and academic publications and presented to conferences].

- I understand that the recordings will be kept confidential to the researcher and the supervisor Rachael Ruegg.

- I would like a copy of the recording of my interview:

$\begin{array}{ll}\text { Yes } & \text { No } \square \\ \square & \\ \text { Yes } & \text { No } \square \\ \square & \\ \text { Yes } & \text { No } \square\end{array}$

- I would like a copy of the transcript of my interview: address below.

Signature of participant:

Name of participant:

Date:

Contact details: 


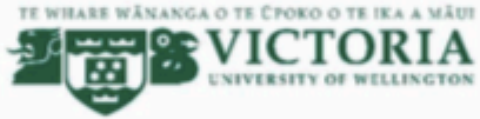

\section{Phản hồi dưới dạng viết trong bài viết ngôn ngữ thứ hai:}

\section{Nhận thức của giáo viên và sinh viên Việt Nam}

\section{CHÁP THUẬN PHỎNG VÁN}

Mẫu chấp thuận này sẽ̃ được giữ trong một năm.

Nghiên cứu viên: Nguyễn Phương Anh, Luận văn thạc sĩ ngành Ngôn ngữ học ứng dụng, Đại học Victoria tạ Wellington.

- Tôi đã đọc Bảng thông tin và được giải thích về dự án. Các câu trả lời thắc mắc cũng đáp ứng sự hài lòng của tôi. Tôi hiểu rẳng tôi có thể hỏi thêm bất cứ lúc nào.

- Tôi đồng ý tham gia vào nghiên cứu này để thu thập phản hồi và cho phép nghiên cứu sinh nhận và sao chép bài viết của sinh viên kèm với đánh giá của tôi trong 7 tuần.

Tôi hiểu rằng:

- Tôi có thế rút khỏi nghiên cứu này vào bất kỷ thời điểm nào trước ngày 20 tháng 01 và bất kỳ thông tin nào tôi cung cấp sẽ được trả lại cho tôi hoặc hủy bỏ.

- Thông tin nhận dạng mà tôi đã cung cấp sẽ bị hủy vào ngày 30 tháng 7 năm 2023.

- Mọi thông tin tôi cung cấp sẽ được giữ bí mật cho nghiên cứu viên và người hướng dẫn Rachael Ruegg.

- Tôi hiểu rằng các kết quả có thể được sử dụng cho luận văn thạc sĩ và các ấn phẩm học thuật và được trình bày trước các hội nghị.

- Tôi hiểu rằng các bản ghi âm sẽ được giữ bí mật cho nghiên cứu viên và người hướng dẫn Rachael Ruegg.

- Tôi muốn nhận một bản sao bản ghi âm phỏng vấn của tôi:

Yes No

- Tổi muốn nhận một bản sao bản ghi chép phỏng vấn của tôi:

Yes No

- Tôi muốn nhận một bản sao báo cáo cuối cùng và tôi đã thêm địa chỉ email Yes của mình bên dưới.

Chữ ký của người tham gia:

Họ tên người tham gia:

Ngày tháng năm:

Thông tin liên lạc: 
Appendix D: Teacher Interviews

\section{Teacher Interview Pre-treatment}

1. What is your name?

2. How long have you been teaching in the university?

3. How many years have you been teaching English writing course?

4. Have often do you give feedback on your students' writing essays?

5. What types of feedback for L2 learners that you prefer to use?

6. Have you ever used peer feedback for your class?

7. In your opinion, What types of corrective error feedback do your students expect to receive in your English writing class ?

8. What are your expections in providing comments on your students' writing?

9. How do you feel about giving corrective feedback ?

10. How many types of feedback that you usually use in your writing class?

11. In your opinion, what can be the advantages and disadvantages of feedback in writing class?

12. How would you explain your vision of feedback provision on your students' writing?

13. Could you please describe your feedback practice?

14. What aspects of your students' writing do you focus on? Why?

15. How do you determine the content of your feedback?

16. Please explain strategies that you use in providing feedback on errors in your students' writing?

17. Do you provide feedback on all errors or just some? If just some, how do you decide which errors to focus on?

18. What do you do to check students' understanding of your feedback?

19. What do you do to make students take your feedback into consideration? 
20. Do you students ever discuss your feedback with you?

21. Have you ever asked students to correct their own writing?

22. How do you feel about students correcting their own errors?

23. Have you ever asked students to correct their peers' writing?

24. What do you think about peer feedback?

25. Have you ever trained your students to give feedback and provide comments?

26. Which types of feedback do you think is beneficial to improve your students' writing?

27. Do you think that your students are able to remember the feedback given by you about their writing? 
Appendix E: Information for participants for surveys

\section{Written feedback in Second Language Writing:}

\section{Perceptions of Vietnamese Teachers and Students}

\section{INFORMATION FOR PARTICIPANTS FOR SURVEYS}

You are invited to take part in this research. Please read this information before deciding whether or not to take part. If you decide to participate, thank you. If you decide not to participate, thank you for considering this request.

Who am 1 ?

My name is Nguyen Phuong Anh and I am doing my Masters thesis in Applied Linguistics at Victoria University of Wellington. This research project is work towards my thesis.

What is the aim of the project?

In Vietnam, there are few studies about students' and teachers' perceptions of written feedback. This study aims to fill this gap by investigating the views of both students and teachers on different kinds of feedback. This research has been approved by the Victoria University of Wellington Human Ethics Committee 0000028136.

How can you help?

You have been invited to participate because you enrolled in this English writing course at the university in the second semester. If you agree to take part, I will collect your assignments, so I can provide five different types of feedback on them.

I will collect your assignments at the beginning of your class during the seven-week process to make copies and give feedback. Then, I will return these assignments with my feedback on them to you at the end of the class in the following week. You will be asked to check your assignments' feedback and answer a questionnaire form related to the type of feedback before you receive feedback from your teacher at the beginning of your class. Besides, you will not be required to submit another draft or revision of your work to me.

You will complete seven surveys (a pre-treatment questionnaire, five during-treatment questionnaires and a post-treatment questionnaire) in a period of seven weeks. The survey will ask your opinions about receiving feedback in writing. The survey will take you two to three minutes to complete. If you withdraw, the information you provided will be destroyed.

What will happen to the information you give?

This research is confidential. This means that everybody, including the researchers will be aware of your identity. By answering it, you are giving consent for us to use your responses in this research. Your answers will remain completely confidential and identifiable. Once you submit the survey, it will be impossible to retract your answer.

What will the project produce?

The information from my research will be used in my Masters thesis and academic publications. 


\section{Phản hồi dưới dạng viết trong bài viết ngôn ngữ thứ hai: Nhận thức của giáo viên và sinh viên Việt Nam}

\section{THÔNG TIN DÀNH CHO ĐÔI TƯợNG THAM GIA KHẢo SÁT}

Bạn được mời tham gia vào nghiên cứu này. Vui lòng đọc thông tin này trước khi quyết định có tham gia hay không. Nếu bạn quyết định tham gia, cảm on bạn. Nếu bạn quyết định không tham gia, cảm ơn bạn đã xem xét yêu cầu này.

Tôi là ai?

Tôi tên là Nguyễn Phương Anh và tôi là sinh viên thạc sĩ ngành Ngôn ngữ học ứng dụng tại Đại học Victoria tọa lạc tại Wellington. Dự án nghiên cứu này là hướng tới luận án của tôi.

Mục đích của nghiên cứu này là gi??

Ở Việt Nam, có rất ít nghiên cứu về nhận thức của giáo viên và sinh viên về phản hồi dưới dạng viết. Nghiên cứu này nhằm lấp đầy khoảng trống này bằng cách khảo sát quan điểm của cả sinh viên và giáo viên về các dạng phản hồi khác nhau. Nghiên cứu này đã được phê duyệt bởi Ửy ban đạo đức con người của Đại học Victoria tại Wellington 0000028136.

\section{Bạn có thể giúp gì?}

Bạn được mời tham gia vì bạn đã đăng ký lớp kỹ năng viết tiếng Anh vào học kỳ hai ở trường đại học. Nếu bạn đồng ý tham gia, tồi sẽ thu thập bài luận của bạn để cho đánh giá. Tối sẽ thu bài luận của bạn vào đầu giờ học trong thời gian 7 tuần để sao chép chúng và cho đánh giá. Sau đó, tồi sễ trả các bài luận cùng đánh giá của minh lại cho bạn vào cuối giờ học của tuần tiếp theo. Bạn sẽ được yêu cầu kiểm tra các đánh giá này và trả lời câu hởi có liên quan đến loại đánh giả đó, trước khi bạn nhận bài và đánh giá từ giáo viển của minh. Bền cạnh đó, bạn sễ không phải viết lại bài đã được chinh sứa cho tôi. Bạn sẽ hoàn thành bảy bài khảo sát ( 1 bảng hỏi trước thực nghiệm, 5 bảng hỏi trong quá trình thực nghiệm và 1 bảng hỏi sau thực nghiệm) trong thời gian 7 tuần. Bài khảo sát sẽ yêu cầu bạn nêu ý kiến của mình về việc tiếp nhận phản hồi (đánh giá) trong kỹ năng viết. Bạn sẽ mất 2 đến 3 phút để hoàn thành bài khảo sát. Nếu bạn rút khỏi nghiên cứu, thông tin bạn cung cấp sẽ bị hưy.

Điều gì sẽ xảy đến với các thông tin mà bạn cung cấp?

Nghiên cứu này được bảo mật. Mọi người, kể cả nhà nghiên cứu sẽ biết về danh tính của bạn Qua việc trả lời các câu hỏi, bạn đã đồng ý cho chúng tôi sử đụng câu trả lời của bạn trong nghiên cứu. Điều này có nghĩa là chỉ nghiên cứu viên có tên dưới đây sẽ biết về danh tính của bạn nhưng số liệu nghiên cứu sẽ được tổng hợp và danh tính của bạn sẽ được bảo mật trong bất kỷ báo cáo, bài thuyết trình hoặc tài liệu công khai. Một khi bạn nộp bải khảo sát, bạn sẽ không thể rút lại câu trả lời.

Sản phẩm của dự án nghiên cứu là gì?

Thông tin từ nghiên cứu của tôi sẽ được sử dụng trong văn bằng thạc sĩ và các ấn phẩm học thuật và hội thảo.. 
Appendix F: Consent to complete surveys 


\section{Written feedback in Second Language Writing: Perceptions of Vietnamese Teachers and Students}

\section{CONSENT TO COMPLETE SURVEYS}

This consent form will be held for one year.

Researcher: Nguyen Phuong Anh, Master Thesis of Applied Linguistics, Victoria University of Wellington.

- I have read the Information Sheet and the project has been explained to me. My questions have been answered to my satisfaction. I understand that I can ask further questions at any time.

- I agree to give my writing to the researcher to make copies and give feedback on my writing during the seven-week process.

- I agree to take part in the surveys during the seven-week process.

I understand that:

- I may withdraw from this study at any point before $20^{\text {th }}$ of January and any information that I have provided will be returned to me or destroyed.

- The identifiable information I have provided will be destroyed on $30^{\text {th }}$ of July, 2023.

- Any information I provide will be kept confidential to the researcher and the supervisor Rachael Ruegg.

- I understand that the findings may be used for a Masters thesis and academic publications.

- I understand that the recordings will be kept confidential to the researcher and the supervisor Rachael Ruegg.

Signature of participant:

Name of participant:

Date:

Contact details: 


\section{Phản hồi dưới dạng viết trong bài viết ngôn ngữ thứ hai: \\ Nhận thức của giáo viên và sinh viên Việt Nam}

\section{CHẢP THUẬN THAM GIA KHẢo SÁT}

Mẫu chấp thuận này sẽ được giữ trong một năm.

Nghiên cứu viên: Nguyễn Phương Anh, Luận văn thạc sĩ ngành Ngôn ngữ học ứng dụng, Đại học Victoria tại Wellington.

- Tôi đã đọc Bảng thông tin và được giải thích về dự án. Các câu trá lời thắc mắc cũng đáp ứng sự hài lòng của tôi. Tôi hiểu rằng tôi có thể hỏi thêm bất cứ lúc nào.

- Tôi đồng ý đưa bài luận của mình cho nghiên cứu sinh để sao chép và cho các bản hồi đánh giá trên bài luận của mình

- Tôi đồng ý tham gia vào khảo sát.

Tôi hiểu rằng:

- Tôi có thể rút khỏi nghiên cứu này vào bất kỳ thời điểm nào trước ngày 20 tháng 01 và bất kỳ thông tin nào tôi cung cấp sẽ được trả lại cho tôi hoặc hủy bỏ.

- Thông tin nhận dạng mà tôi đã cung cấp sẽ bị hủy vào ngày 30 tháng 7 năm 2023.

- Mọi thông tin tôi cung cấp sẽ được giữ bí mật cho nghiên cứu viên và người hướng dẫn Rachael Ruegg.

- Tôi hiểu rằng các kết quả có thể được sử dụng cho luận văn thạc sĩ và các ấn phẩm học thuật.

- Tôi hiểu rằng các bản ghi âm sẽ được giữ bí mật cho nghiên cứu viên và người hướng dẫn Rachael Ruegg.

Chữ ký của người tham gia:

Họ tên người tham gia:

Ngày tháng năm:

Thông tin liên lạc:

Appendix G: Pre-treatment background questionnaire 


\section{Pre-treatment background questionnaire}

Name:

Your student number:

1. How much of each essay will you read over again when your teacher returns it to you?
A. All of it
B. Most of it
C. Some of it
D. Non of it

2. None of it How many of your teacher's comments and corrections on your writing do you think about carefully?
A. All of it
B. Most of it
C. Some of it
D. None of it

3. How often would you like to give and receive peer feedback in English writing course?
A. Never
B. Once or twice
C. More than twice
D. Always

4. How often would you like to receive teacher feedback in English writing course?
A. Never
B. Once or twice
C. More than twice
D. Always

5. How often would you like to give and receive self feedback in English writing course?
A. Never
B. Once or twice
C. More than twice
D. Always

6. What do you usually do when you receive feedback on your writing? You should select only one response.
A. I only read the grade and discarded the paper.
B. I read the grade and the comments, and I discarded the paper
C. I read the grade and the comments, and I asked for clarification
D. I correct the mistakes that were easy to correct
E. I revised my writing taking into account the teacher's suggestions
F. I improved my writing with help of my home tutor or my peers

7. How would you like your teacher to repond to your composition? You should select only one response.
A. By giving the mark only
B. By suggesting error correction only
C. By providing comments on the content only 
D. By giving a mark and suggesting error correction

E. By giving a mark and providing comments on the content

F. By suggesting error correction and providing comments on the content

G. By giving a mark, suggesting error correction, and providing comments on the content

8. Would you like your teacher to react to:
A. All the errors
B. Most of the errors
C. A few of the errors
D. None of the errors

9. What type(s) of errors would you like your teacher to focus on in her/his feedback?
A. Grammar
B. Vocabulary
C. Spelling
D. Punctuation
E. Others :

10. What would you like your teachers' comments to focus on? You should select only one response?
A. Only Negative aspects
B. Mainly Negative aspects
C. Both Negative and Positive aspects
D. Only Positive aspects
E. Mainly Positive aspects

Please tick on the box that presents your answer on the following staments:

5-Strongly Agree; 4-Agree ; 3-Neither agree nor disagree; 2 -Disagree; 1 -Strongly disagree

\begin{tabular}{|c|c|c|c|c|c|}
\hline & $\mathbf{5}$ & 4 & 3 & $\mathbf{2}$ & 1 \\
\hline \multicolumn{6}{|c|}{ 11. What do you think about teacher's feedback in English writing? } \\
\hline 11.1 It is clear & & & & & \\
\hline \multicolumn{6}{|l|}{11.2 It is useful } \\
\hline \multicolumn{6}{|l|}{11.3 It is encouraging } \\
\hline \multicolumn{6}{|c|}{ 12. How do you feel about feedback on your writing? } \\
\hline \multicolumn{6}{|l|}{12.1 I am interested in reading it } \\
\hline \multicolumn{6}{|l|}{12.2 I feel Satified } \\
\hline 12.3 I am eager to improve my writing & & & & & \\
\hline
\end{tabular}




\section{Bảng hỏi trước thực nghiệm}

Họ tên sinh viên:

Mã số sinh viên:

1. Bao nhiêu bài viết mà bạn đã đọc lại khi giáo viên trả bài?
a. Tất cả
b. Đa số
c. Một vài
d. Không có

2. Bao nhiêu nhận xét và sửa lỗi của giáo viên trên bài viết mà bạn suy nghĩ cắn thận?
A. Tất cả
B. Đa số
C.Một vài
D. Không có

3. Số lần bạn muốn đưa ra và nhận phản hồi từ bạn bè trong lớp kỹ năng viết tiếng Anh?
a. Không bao giờ
b. Một hoặc hai lần
c. Nhiều hơn hai lần
d. Luôn luôn

4. Số lần bạn muốn tiếp nhận phản hồi từ giáo viên trong lớp kỹ năng viết tiếng Anh?
A. Không bao giờ
B. Một hoặc hai lần
C. Nhiều hơn hai lần
D. Luôn luôn

5. Số lần bạn muốn đưa ra và tiếp nhận phản hồi của bản thân trong lớp kỹ năng viết tiếng Anh?
a. Không bao giờ
b. Một hoặc hai lần
c. Nhiều hơn hai lần
d. Luôn luôn

6. Bạn thường làm gì khi nhận được phản hồi về bài viết của mình? Chỉ chọn một câu trả lời.
a. Tôi chỉ đọc điểm và bỏ bài làm.
b. Tôi đọc điểm và nhận xét, và bỏ bài làm.
c. Tôi đọc điểm và nhận xét, và tôi yêu cằu giải thích rõ
d. Tôi sửa các lỗi dễ
e. Tôi sửa lại bài viết của mình theo các gợi ý của giáo viên.
f. Tôi nhờ gia sư hoặc bạn bè cải thiện bài viết của mình

7. Bạn muốn giáo viên phản hồi về bài luận của bạn như thế nào? Chỉ chọn một câu trả lời.
a. Chỉ cho điếm
b. Chỉ đề xuất sửa lỗi
c. Chỉ nhận xét về nội dung 
d. Chỉ cho điếm và đề xuất sửa lỗi

e. Chỉ cho điếm và nhận xét về nội dung

f. Chỉ đề xuất sửa lỗi và nhận xét về nội dung

g. Cho điểm, đề xuất sửa lỗi, và nhận xét về mặt nội dung

8. Bạn muốn giáo viên phản hồi đối với:

a. Tất cả lỗi

b. Hầu hết các lỗi

c. Một vài lỗi

d. Không lỗi nào

9. Bạn muốn giáo viên tập trung vào dạng lỗi nào khi cho phản hồi?
a. Ngữ pháp
b. Từ vựng
c. Chính tả
d. Dắ câu
e. Khác:

10. Bạn muốn giáo viên nhận xét tập trung vào khía cạnh nào? Chỉ chọn một câu trả lời
a. Chi những khía cạnh tiêu cực
b. Chủ yếu là những khía cạnh tiêu cực
c. Cả khía cạnh tiêu cực và tích cực
d. Chi những khía cạnh tích cực
e. Chủ yếu là những khía cạnh tích cực

Đánh dấu vào ô thế hiện câu trả lời của bạn theo các mức độ sau:

5 - Hoàn toàn đồng ý ; 4 - Đồng ý ; 3 - Không ý kiến; 2 - Không đồng ý ; 1 - Hoàn toàn không đồng ý

\begin{tabular}{|c|c|c|c|c|c|}
\hline & $\mathbf{5}$ & 4 & 3 & 2 & 1 \\
\hline \multicolumn{6}{|c|}{ 11.Bạn nghĩ sao về phản hò̀ của giáo viên trong bài viết tiếng Anh? } \\
\hline \multicolumn{6}{|l|}{11.1 Rõ ràng } \\
\hline \multicolumn{6}{|l|}{ 11.2 Hữu ích } \\
\hline \multicolumn{6}{|l|}{11.3 Khích lę̣ } \\
\hline \multicolumn{6}{|c|}{ 12. Bạn cảm thấy như thế nào đới với phản hồi về bài viết của mình? } \\
\hline \multicolumn{6}{|l|}{ 12.1 Tôi thích đọc chúng } \\
\hline \multicolumn{6}{|l|}{ 12.2 Tôi cảm thấy hài lòng } \\
\hline 12.3 Tôi mong muốn cải thię̂n bài viết của mình & & & & & \\
\hline
\end{tabular}

Appendix H: During-treatment questionnaire: Peer feedback 
Name:

Your student number:

Please look at your essay that is included your peer's feedback. Then tick on the box that presents your answer on the following statements:

5-Strongly Agree ; 4-Agree ; 3 - Neither agree nor disagree; 2 -Disagree ; 1 -Strongly Disagree

\begin{tabular}{|c|c|c|c|c|c|}
\hline & 5 & 4 & 3 & 2 & 1 \\
\hline $\begin{array}{l}\text { 1. Peer feedback is easy to give and receive } \\
\text { in the classroom }\end{array}$ & & & & & \\
\hline 2. Peer feedback is understandable & & & & & \\
\hline 3. Peer feedback should be used frequently & & & & & \\
\hline $\begin{array}{l}\text { 4. Peer feedback helps me to understand my } \\
\text { errors deeply }\end{array}$ & & & & & \\
\hline $\begin{array}{l}\text { 5. I feel comfortable when my friends correct } \\
\text { and give feedback on my writing }\end{array}$ & & & & & \\
\hline $\begin{array}{l}\text { 6. I like to give and receive peer feedback in } \\
\text { my writing class }\end{array}$ & & & & & \\
\hline
\end{tabular}

7. In your opinion, what are the advantages and disadvantages of peer feedback on your English writing?

Advantages:

Disadvantages:

THANK YOU 
Họ tên sinh viên:

Mã̃ số sinh viên:

Vui lòng xem bài viết của bạn kèm theo phần phản hồi sửa lỗi từ bạn học. Sau đó đánh dấu vào ô thể hiện câu trả lời của bạn theo các mức độ sau:

5 - Hoàn toàn đổng ý ; 4 - Đồng ý ; 3 - Không ý kiến; 2 - Không đồng ý ; 1 - Hoàn toàn không đồng ý

\begin{tabular}{|c|c|c|c|c|}
\hline & 5 & 3 & 2 & 1 \\
\hline $\begin{array}{l}\text { 1. Dễ đưa ra và tiếp nhận phản hồi từ bạn } \\
\text { học trong lớp. }\end{array}$ & & & & \\
\hline 2. Phản hồi từ bạn học thì dễ hiếu & & & & \\
\hline $\begin{array}{l}\text { 3. Nên áp dụng phản hồi từ bạn học } \\
\text { thường xuyên }\end{array}$ & & & & \\
\hline $\begin{array}{l}\text { 4. Phản hồi từ bạn học giúp tôi hiểu rõ các } \\
\text { Iỗi mà mình đã mắc phải }\end{array}$ & & & & \\
\hline $\begin{array}{l}\text { 5. Tôi cảm thấy thoải mái khi bạn bè sửa } \\
\text { Iổi và đưa ra phản hồi đối với bài viết } \\
\text { của mình. }\end{array}$ & & & & \\
\hline $\begin{array}{l}\text { 6. Tôi thích đưa ra và tiếp nhận phản hồi } \\
\text { cho bạn trong lớp học viết. }\end{array}$ & & & & \\
\hline
\end{tabular}

7. Theo ý kiến của bạn, thuận lợi và bất lợi của việc đánh giá theo đôi (phản hồi từ bạn học) đới với kỹ năng Viết tiếng Anh của bản thân là gì?

Thuận lợi:

Bất lợi: 
Appendix I: During-treatment questionnaire: Direct feedback

Name:

Your student number:

Please look at your essay that is included the researcher's feedback. Then tick on the box that presents your answer on the following statements:

5-Strongly Agree ; 4-Agree ; 3 - Neither agree nor disagree; 2 - Disagree ; 1 -Strongly

Disagree

\begin{tabular}{|c|c|c|c|c|}
\hline & 4 & 3 & 2 & 1 \\
\hline $\begin{array}{l}\text { 1. Direct feedback is easy to use in the } \\
\text { classroom }\end{array}$ & & & & \\
\hline 2. Direct feedback is understandable & & & & \\
\hline 3. Direct feedback should be used frequently & & & & \\
\hline $\begin{array}{l}\text { 4. Direct feedback helps me to understand } \\
\text { my errors deeply }\end{array}$ & & & & \\
\hline $\begin{array}{l}\text { 5. I feel comfortable when my teacher } \\
\text { provides all of the correct forms for my } \\
\text { errors }\end{array}$ & & & & \\
\hline $\begin{array}{l}\text { 6. I like to receive direct feedback in my } \\
\text { writing }\end{array}$ & & & & \\
\hline
\end{tabular}

7. In your opinion, what are the advantages and disadvantages of direct feedback on your English writing?

Advantages:

Disadvantages: 
Họ tên sinh viên:

Mã số sinh viên:

Vui lòng xem bài viết của bạn kèm theo phần phản hồi của Nghiên cứu viên. Sau đó đánh dấu vào ô thể hiện câu trả lời của bạn theo các mức độ sau:

5 - Hoàn toàn đồng ý ; 4 - Đồng ý ; 3 - Không ý kiến; 2 - Không đồng ý ; 1 - Hoàn toàn không đồng ý

\begin{tabular}{|c|c|c|c|c|c|}
\hline & 5 & 4 & 3 & 2 & 1 \\
\hline $\begin{array}{l}\text { 1. Dề đưa ra và tiếp nhận phản hồi trực } \\
\text { tiếp trong lớp học. }\end{array}$ & & & & & \\
\hline 2. Phản hối trực tiếp thì dễ hiểu & & & & & \\
\hline $\begin{array}{l}\text { 3. Nên áp dụng phản hồi trực tiếp thường } \\
\text { xuyên }\end{array}$ & & & & & \\
\hline $\begin{array}{l}\text { 4. Phản hồi trực tiếp giúp tôi hiếu rõ các lỗi } \\
\text { mà minhn đă mắc phải }\end{array}$ & & & & & \\
\hline $\begin{array}{l}\text { 5. Tôi cảm thấy thoải mái khi giáo viên sửa } \\
\text { Iổi của minhn bẳng nhiểu cách }\end{array}$ & & & & & \\
\hline $\begin{array}{l}\text { 6. Tôi thích nhận phản hồi trực tiếp trong } \\
\text { bài viết của minh }\end{array}$ & & & & & \\
\hline
\end{tabular}

7. Theo ý kiến của bạn, thuận lợi và bất lợi của việc phản hồi trực tiếp đối với kỹ năng viết tiếng Anh của bản thân là gì?

Thuận lợi:

Bất lợi: 
Appendix J: During-treatment questionnaire: Indirect coded feedback

Name:

Your student number:

Please look at your essay that is included the researcher's feedback. Then tick on the box that presents your answer on the following statements:

5-Strongly Agree ; 4-Agree ; 3 - Neither agree nor disagree; 2 - Disagree ; 1 -Strongly Disagree

\begin{tabular}{|c|c|c|c|c|c|}
\hline & 5 & 4 & 3 & 2 & 1 \\
\hline $\begin{array}{l}\text { 1. Indirect coded feedback is easy to use in } \\
\text { the classroom }\end{array}$ & & & & & \\
\hline 2. Indirect coded feedback is understandable & & & & & \\
\hline $\begin{array}{l}\text { 3. Indirect codedfeedback should be used } \\
\text { frequently }\end{array}$ & & & & & \\
\hline $\begin{array}{l}\text { 4. Indirect coded feedback helps me to } \\
\text { understand my errors deeply }\end{array}$ & & & & & \\
\hline $\begin{array}{l}\text { 5. I feel comfortable when my teacher } \\
\text { locates my errors and uses codes. }\end{array}$ & & & & & \\
\hline $\begin{array}{l}\text { 6. I like to receive indirect coded feedback in } \\
\text { my writing }\end{array}$ & & & & & \\
\hline
\end{tabular}

7. In your opinion, what are the advantages and disadvantages of indirect feedback on your English writing?

Advantages:

Disadvantages: 
Vui lòng xem bài viết của bạn kèm theo phần phản hồi của Nghiên cứu viên. Sau đó đánh dấu vào ô thể hiện câu trả lời của bạn theo các mức độ sau:

5 - Hoàn toàn đổng ý ; 4 - Đồng ý ; 3 - Không ý kiến; 2 - Không đồng ý ; 1 - Hoàn toàn không đồng ý

\begin{tabular}{|c|c|c|c|c|c|}
\hline & 5 & 4 & 3 & 2 & 1 \\
\hline $\begin{array}{l}\text { 1. Dề sử dụng phản hồi dạng mã gián } \\
\text { tiếp trong lớp. }\end{array}$ & & & & & \\
\hline 2. Phản hồi dạng mã gián tiếp thì dê̌ hiểu & & & & & \\
\hline $\begin{array}{l}\text { 3. Nên áp dưng phản hồi dạng mã gián } \\
\text { tiếp thường xuyênn }\end{array}$ & & & & & \\
\hline $\begin{array}{l}\text { 4. Phản hồi dâng mã gián tiếp giúp tôi } \\
\text { hiểu rố các lỡi mà minh măc phải }\end{array}$ & & & & & \\
\hline $\begin{array}{l}\text { 5. Tôi cảm thấy thoải mái khi giáo viên chỉ } \\
\text { ra lỗi và sử dụng mã lỡi. }\end{array}$ & & & & & \\
\hline $\begin{array}{l}\text { 6. Tôi thich đưa ra và tiếp nhâan phản hồi } \\
\text { dạng mă gián tiếp đối với bải viết của } \\
\text { minh }\end{array}$ & & & & & \\
\hline
\end{tabular}

7. Theo ý kiến của bạn, thuận lợi và bất lợi của việc đánh giá dạng mã gián tiếp đới với kỹ năng Viết tiếng Anh của bản thân là gì?

Thuận lợi:

Bất lợi: 
Appendix K: During-treatment questionnaire: Indirect uncoded feedback

Name:

Your student number:

Please look at your essay that is included the researcher's feedback. Then tick on the box that presents your answer on the following statements:

5-Strongly Agree ; 4-Agree ; 3 - Neither agree nor disagree; 2 -Disagree ; 1 -Strongly Disagree

\begin{tabular}{|c|c|c|c|c|c|}
\hline & 5 & 4 & 3 & 2 & 1 \\
\hline $\begin{array}{l}\text { 1. Indirect uncoded feedback is easy to use in } \\
\text { the classroom }\end{array}$ & & & & & \\
\hline $\begin{array}{l}\text { 2. Indirect uncoded feedback is } \\
\text { understandable }\end{array}$ & & & & & \\
\hline $\begin{array}{l}\text { 3. Indirect uncoded feedback should be used } \\
\text { frequently }\end{array}$ & & & & & \\
\hline $\begin{array}{l}\text { 4. Indirect uncoded feedback helps me to } \\
\text { understand my errors deeply }\end{array}$ & & & & & \\
\hline $\begin{array}{l}\text { 5. I feel comfortable when my teacher } \\
\text { locates my errors without using error } \\
\text { codes. }\end{array}$ & & & & & \\
\hline $\begin{array}{l}\text { 6. I like to receive Indirect uncoded feedback } \\
\text { in my writing }\end{array}$ & & & & & \\
\hline
\end{tabular}

7. In your opinion, what are the advantages and disadvantages of indirect uncoded feedback on your English writing?

Advantages:

Disadvantages: 
Họ tên sinh viên:

Mã số sinh viên:

Vui lòng xem bài viết của bạn kèm theo phần phản hồi của Nghiên cứu viên. Sau đó đánh dấu vào ô thể hiện câu trả lời của bạn theo các mức độ sau:

5 - Hoàn toàn đồng ý ; 4 - Đồng ý ; 3 - Không ý kiến; 2 - Không đồng ý ; 1 - Hoàn toàn không đồng ý

\begin{tabular}{|c|c|c|c|c|c|}
\hline & 5 & 4 & 3 & 2 & 1 \\
\hline $\begin{array}{l}\text { 1. Dề áp dụng phản hồi không mã hóa } \\
\text { gián tiếp trong lớp học }\end{array}$ & & & & & \\
\hline $\begin{array}{l}\text { 2. Phản hối không mã hóa gián tiếp thì dễ } \\
\text { hiểu }\end{array}$ & & & & & \\
\hline $\begin{array}{l}\text { 3. Nên áp dunng phản hồi không mã hóa } \\
\text { gián tiếp thường xuyên }\end{array}$ & & & & & \\
\hline $\begin{array}{l}\text { 4. Phản hồi không mã hóa gián tiếp giúp } \\
\text { tôi hiểu rố các Iỗi mà mình đã mắc phải }\end{array}$ & & & & & \\
\hline $\begin{array}{l}\text { 5. Tôi cảm thấy thoải mái khi giáo viên chỉ } \\
\text { ra các Iới mà không sử dưng mă }\end{array}$ & & & & & \\
\hline $\begin{array}{l}\text { 6. Tôi thích nhận phản hồi không mã hóa } \\
\text { gián tiếp trong bài viết. }\end{array}$ & & & & & \\
\hline
\end{tabular}

7. Theo ý kiến của bạn, thuận lợi và bất lợi của việc phản hồi không mã hóa gián tiếp đới với kỹ năng viết tiếng Anh của bản thân là gì?

Thuận lợi:

Bất lợi: 
Appendix L: During-treatment questionnaire: Self-feedback

Name:

Your student number:

Please look at your essay that have been corrected and included your own feedback. Then tick on the box that presents your answer on the following statements:

5-Strongly Agree ; 4-Agree ; 3 - Neither agree nor disagree; 2 -Disagree ; 1 -Strongly

Disagree

\begin{tabular}{|c|c|c|c|c|}
\hline & 5 & 4 & 3 & 2 \\
\hline 1. Self feedback is easy to give and receive & & & & \\
\hline 2. Self feedback is understandable & & & & \\
\hline 3. Self feedback should be used frequently & & & & \\
\hline $\begin{array}{l}\text { 4. Self feedback helps me to understand my } \\
\text { errors deeply }\end{array}$ & & & & \\
\hline $\begin{array}{l}\text { 5. I feel comfortable when I correct errors by } \\
\text { myself }\end{array}$ & & & & \\
\hline $\begin{array}{l}\text { 6. I like to give and receive self feedback in } \\
\text { my writing }\end{array}$ & & & & \\
\hline
\end{tabular}

7. In your opinion, what are the advantages and disadvantages of self feedback on your English writing?

Advantages:

Disadvantages: 
Vui lòng xem bài viết mà bạn đã sửa lỡi kèm theo phần tự đánh giá (phản hồi) của mình. Sau đó đánh dấu vào ô thể hiện câu trả lời của bạn theo các mức độ sau:

5 - Hoàn toàn đồng ý ; 4 - Đồng ý ; 3 - Không ý kiến; 2 - Không đồng ý ; 1 - Hoàn toàn không đồng ý

\begin{tabular}{|c|c|c|c|c|c|}
\hline & 5 & 4 & 3 & 2 & 1 \\
\hline $\begin{array}{l}\text { 1. Dễ đưa ra và tiếp nhận phần tự đánh } \\
\text { giá của bản thân }\end{array}$ & & & & & \\
\hline 2. Tự đánh giá thì dễ hiễu & & & & & \\
\hline 3. Nên áp dụng tự đánh giá thường xuyên & & & & & \\
\hline $\begin{array}{l}\text { 4. Tự đánh giá giúp tôi hiếu rõ các lỗi mà } \\
\text { minh đã mắc phải }\end{array}$ & & & & & \\
\hline $\begin{array}{l}\text { 5. Tôi cảm thấy thoải mái khi tôi tự sửa lỗi } \\
\text { cho mình }\end{array}$ & & & & & \\
\hline $\begin{array}{l}\text { 6. Tôi thich tự đưa ra và tiếp nhận phần tự } \\
\text { đánh giá đối với bài viết của mình }\end{array}$ & & & & & \\
\hline
\end{tabular}

7. Theo ý kiến của bạn, thuận lợi và bất lợi của việc tự đánh giá đới với kỹ năng viết tiếng Anh của bản thân là gì?

Thuận lợi:

Bát lợi: 